\title{
Essays on remote monitoring as an emerging tool for centralized management of decentralized wastewater systems
}

\author{
Clement Solomon \\ West Virginia University
}

Follow this and additional works at: https://researchrepository.wvu.edu/etd

\footnotetext{
Recommended Citation

Solomon, Clement, "Essays on remote monitoring as an emerging tool for centralized management of decentralized wastewater systems" (2008). Graduate Theses, Dissertations, and Problem Reports. 4422. https://researchrepository.wvu.edu/etd/4422
}

This Dissertation is protected by copyright and/or related rights. It has been brought to you by the The Research Repository @ WVU with permission from the rights-holder(s). You are free to use this Dissertation in any way that is permitted by the copyright and related rights legislation that applies to your use. For other uses you must obtain permission from the rights-holder(s) directly, unless additional rights are indicated by a Creative Commons license in the record and/ or on the work itself. This Dissertation has been accepted for inclusion in WVU Graduate Theses, Dissertations, and Problem Reports collection by an authorized administrator of The Research Repository @ WVU. For more information, please contact researchrepository@mail.wvu.edu. 


\title{
Clement Solomon
}

\author{
Dissertation submitted to the \\ Davis College of Agriculture, Forestry and Consumer Sciences \\ at West Virginia University \\ in partial fulfillment of the requirements \\ for the degree of \\ Doctor of Philosophy \\ in \\ Resource Management and Sustainable Development
}

\section{Department of Resource Management}

Dr. Tim Phipps, PhD, Chair

Dr. Jerald J. Fletcher, PhD

Dr. Gerard D'Souza, PhD

Dr. Lianshin Lin, PhD

Dr. Michael Dougherty, PhD

\section{Morgantown, West Virginia.}

2008

Keywords: Remote Monitoring; Centralized Management; Decentralized Systems; Wastewater; Septic Systems; Sewage; Management Entity; Non Point Source Pollution 


\section{ABSTRACT \\ Essays on Remote Monitoring as an Emerging Tool for Centralized Management of Decentralized Wastewater Systems}

\section{Clement Solomon}

According to the United States Environmental Protections Agency (USEPA), nearly one in four households in the United States depends on an individual septic system (commonly referred as an onsite system or a decentralized wastewater system) to treat and disperse wastewater. More than half of these systems are over 30 years old, and surveys indicate at least 10 to $20 \%$ might not be functioning properly. The USEPA concluded in its 1997 report to Congress that adequately managed decentralized wastewater systems (DWS) are a cost-effective and long-term option for meeting public health and water quality goals, particularly in less densely populated areas.

The major challenge however is the absence of a guiding national regulatory framework based on consistent performance-based standards and lack of proper management of DWS. These inconsistencies pose a significant threat to our water resources, local economies, and public health. This dissertation addresses key policy and regulatory strategies needed in response to the new realities confronting decentralized wastewater management. The two core objectives of this research are to demonstrate the centralized management of DWS paradigm and to present a scientific methodology to develop performance-based standards (a regulatory shift from prescriptive methods) using remote monitoring.

The underlying remote monitoring architecture for centralized DWS management and the value of science-based policy making are presented. Traditionally, prescriptive standards using conventional grab sampling data are the norm by which most standards are set. Three case studies that support the potential of remote monitoring as a tool for standards development and system management are presented. The results revealed a vital role for remote monitoring in the development of standardized protocols, policies and procedures that are greatly lacking in this field.

This centralized management and remote monitoring paradigm fits well and complements current USEPA policy (13 elements of management); meets the growing need for qualitative data (objective and numerical); has better time efficiencies as real-time events are sampled and translated into machine-readable signals in a short period of time; allows cost saving rapid response to system recovery and operation; produces labor and economic efficiencies through targeted responses; and, improves the quality and operational costs of any management program.

This project was funded by the USEPA grant \# C-82878001 as part of the National Onsite Demonstration Project (NODP), West Virginia University. 


\section{ACKNOWLEDGEMENTS}

I would like to acknowledge many people for helping me during my doctoral work. I would especially like to thank my advisor, Dr. Tim Phipps, for his guidance and motivation, and being instrumental in me pursing this degree. I am also very grateful for having an exceptional doctoral committee and wish to thank Dr. Jerry Fletcher, Dr. Mike Dougherty, Dr. LianShin Lin, and Dr. Gerard D'Souza for their continual support and encouragement.

I wish to thank many colleagues of mine at the National Environmental Services Center, especially, Graham Knowles for being an intellectual partner and friend; Sherry Summers for her program support; and John Mori and Rick Phalunus for their unwavering confidence in me. I'd like to thank my USEPA project officers Stephen Hogye and Bill Hasselkus for their support.

I am extremely grateful for the many members of the wastewater industry who over the years have been a source of knowledge and support. I owe a special note of gratitude to Joseph Kamalesh for assisting me with a number of projects and Tim Suhrer for his editorial review.

I'm especially grateful to my wife and best friend, Pauline, for her patience and helping me keep my life in proper perspective and balance. Of course, the two jewels my daughter Anika and my son David, who have been sources of joy and inspiration to keep going. Finally, I'd like to thank my father who has inspired me, and my mother who was a constant source of support. I'm grateful to my brother and several family members for their encouragement.

I dedicate this dissertation to Pauline, Anika, and David.

ISAIAH 41: 9-10. 


\section{TABLE OF CONTENTS}

Title Page $\quad$ i

$\begin{array}{ll}\text { Abstract } & \text { ii }\end{array}$

$\begin{array}{ll}\text { Acknowledgements } & \text { iii }\end{array}$

Table of Contents $\quad$ iv

List of Tables $\quad$ vii

List of Figures

\section{Chapter 1: $\quad$ Project Narrative and Background}

$1.1 \quad$ Background

1.2 Introduction

1.3 Need for Wastewater Management 5

1.3.1. Public Health Impacts

1.3.2. Environmental Impacts $\quad 6$

$\begin{array}{ll}\text { 1.3.3. Economic Impacts } & 6\end{array}$

$\begin{array}{lll}1.4 & \text { Costs and Benefits } & 10\end{array}$

$1.5 \quad$ Policy and Regulatory Framework 12

1.5.1. Clean Water Act 13

$\begin{array}{lll}1.6 & \text { Performance-Based Standards } & 15\end{array}$

1.7 Decentralized System and Remote Monitoring Costs 17

$\begin{array}{lll}1.8 & \text { Objectives and Goals } & 19\end{array}$

1.9 Dissertation Organization and Scope $\quad 21$

\section{Chapter 2: $\quad$ Remote Monitoring Architecture Enabling Centralized} Management of Decentralized Systems

$2.1 \quad$ Background 23

2.2 Introduction $\quad 24$

\begin{tabular}{ll}
2.3 & Wastewater Management \\
\hline
\end{tabular}

\begin{tabular}{ll}
2.4 & Scope of the Project \\
\hline
\end{tabular}

2.5 Benefits 28

2.6 Architecture and System Design 29

2.6.1 Remote/Decentralized Features $\quad 30$

2.6.1.1 Probes and Sensors $\quad 32$

2.7 Centralized Data Acquisition Center 33

2.7.1 Data Retrieval, Storage and Analysis

$2.8 \quad$ Conclusion and Recommendations 37 


\section{Chapter 3: Real-time Monitoring of Operational Characteristics in}

Septic tanks

3.1 Background 42

3.2 Introduction 43

3.3 Objectives and Scope $\quad 45$

$\begin{array}{lll}3.4 & \text { Data Compilation and Analysis } & 47\end{array}$

3.5 Results and Discussion $\quad 48$

3.5.1 Water Use Analysis $\quad 48$

3.5.2 Design and Actual Flow Analysis $\quad 49$

3.5.2.1 Actual Water Use Verses Bedrooms 50

3.5.2.2 Actual Water Use Verses Occupants 51

3.5.3 Parameter Variations $\quad 52$

3.5.3.1 Ambient Temperature 52

3.5.3.2 Wastewater Temperature 52

3.5.3.3 $\mathrm{pH} \quad 53$

3.6 Conclusions and Recommendations 54

Chapter 4: Analysis of Remote Monitored Water Use Trends and Patterns in a Commercial Facility

$\begin{array}{lll}4.1 & \text { Introduction } & 58\end{array}$

4.2 Estimating Wastewater Flow $\quad 59$

4.3 Scope of the Project 60

4.4 Facility and System Description 62

4.5 Remote Monitoring 64

4.6 Results and Discussion 66

4.6.1 Conventional Metered Data Analysis 67

4.6.2 Remote Monitored Data and Flow Analysis 69

4.6.3 Hypothetical Design Values $\quad 73$

$\begin{array}{lll}4.7 & \text { Conclusions } & 74\end{array}$

Chapter 5: Characterization of $\mathrm{pH}$ Variations in Septic Tanks using Remote Monitored Data

$\begin{array}{lll}5.1 & \text { Introduction } & 77\end{array}$

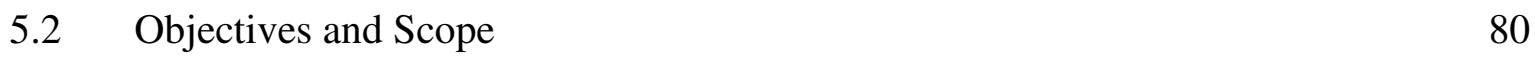

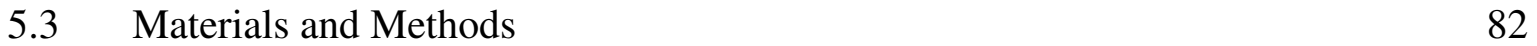

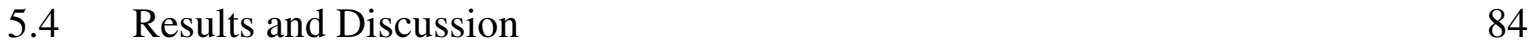

$\begin{array}{lll}5.4 .1 & \mathrm{pH} \text { Variations } & 84\end{array}$

$\begin{array}{lll}\text { 5.4.2 Frequency Distribution } & 85\end{array}$

5.5 Conclusions 86 


\section{Chapter 6: Summary of Results and Conclusions}

6.1 Summary of Results $\quad 90$

6.1.1 Remote Monitoring Architecture Enabling Centralized Management of Decentralized Systems 90

6.1.2 Real-time Monitoring of Operational Characteristics in Septic tanks
6.1.2.1
Water Use
6.1 .2 .2
Ambient Temperature
91
6.1 .2 .3
Wastewater Temperature
93
6.1.2.4
$\mathrm{pH}$
93

91

6.1.3 Analysis of Remote Monitored Water Use Trends and Patterns in a Commercial Facility

6.1.3.1

Conventional Metered Water Use

95

6.1.3.2

Remote Monitored Data and Actual Flow

95

6.1.2.2

Hypothetical Wetland Design

96

6.1.4 Characterization of $\mathrm{pH}$ Variations in Septic Tanks

Using Remote Monitored Data

97

6.1.4.1

$\mathrm{pH}$ Variations

97

6.1.2.2

pH Frequency Distribution

98

98

6.2 Conclusions

99

6.2.1 Decentralized Wastewater Management: The Key

100

6.2.2 Centralized Management of DWS - The Paradigm

102

6.2.3 Remote Monitoring - A Viable Tool

104

6.2.4.1

Water Use

104

6.2.4.2

$\mathrm{pH}$

105

6.2.5 Policy and Cost Efficiency Analysis 107

6.3 Recommendations for the Future

109

\section{Appendices}

1. Bibliography

2. Co-Author Biography 


\section{LIST OF TABLES}

$\begin{array}{lll}\text { Table } 1 & \text { Panel and Probe Costs } & 18\end{array}$

Table $2 \quad$ List of Parameters and Types of Probes 32

Table 3 Overview of the Systems Monitored 46

Table $4 \quad$ Summary of Water Use Data (Site 2) 49

$\begin{array}{lll}\text { Table } 5 & \text { Summary of Water Usage } & 50\end{array}$

Table 6 Original Design Characteristics of the Wetland System 63

$\begin{array}{lll}\text { Table } 7 & \text { Estimated Total Water Use Based on Fixtures Installed } & 67 \\ & \text { in the Facility }\end{array}$

Table $8 \quad$ Water Use Based on Conventional Water Meter Reading 68

Table $9 \quad$ Overview of the Systems Monitored 80

Table $10 \quad$ Data Points and Period of Study $\quad 82$

Table $11 \quad$ Minimum and Maximum pH values Recorded in the Septic Tank 84

Table 12 Wastewater $\mathrm{pH}$ in the Acidic, Neutral and Alkaline Range 86 


\section{LIST OF FIGURES}

Figure 1 Onsite Treatment System Distribution in the United States 3

Figure 2 Economic costs of an HAB event in a Commercial Fishery 8

Figure 3 Economic costs of an HAB event in a Recreational Fishery 9

$\begin{array}{lll}\text { Figure } 4 & \text { Hierarchy of Policy/Regulatory Structure } & 13\end{array}$

Figure 5 Model of the Centralized Monitoring System 30

Figure 6 Layout of the Decentralized Components 31

Figure $7 \quad$ Layout of the Centralized Data Acquisition Center 34

Figure 8 Data Pathway Flowchart from the Remote Location to the Desktop 36

Figure $9 \quad$ Cross-Sectional Views of Conventional Septic Tanks 44

Figure $10 \quad$ Parameter variations in AT, WT, and $\mathrm{pH}$

Figure 11 Schematic of the Constructed Wetland System 63

Figure 12 Model of the Centralized Monitoring System 65

Figure 13 Cumulative Annual Water Use and Cumulative Sunday Attendees 69

Figure 14 Daily Average Water Use during November, 2004

Figure 15 Average Water Usage Determined by Digital Water Meter 71

Figure 16 Actual Sunday Water Usage versus Projected Water Usage (2 gpd) 72

$\begin{array}{lll}\text { Figure } 17 & \text { Calculated Hypothetical Design Values }\end{array}$

$\begin{array}{lll}\text { Figure } 18 & \text { Cross-sectional View of a Septic Tank } & 78\end{array}$

$\begin{array}{lll}\text { Figure } 19 & \text { Box Plots of } \mathrm{pH} & 84\end{array}$

$\begin{array}{lll}\text { Figure } 20 & \text { Frequency Distribution of } \mathrm{pH} \text { Values } & 85\end{array}$ 


\section{CHAPTER I}

\section{INTRODUCTION AND SCOPE}

\subsection{Background}

A strong, nonpartisan, and consistently sound environmental policy is supported by most Americans. They recognize that the costs of ensuring a clean, safe, and healthy environment are also significant. In 1994, the United States spent more than $\$ 120$ billion on pollution abatement and control—nearly 2 percent of the nation's gross domestic product—and this amount is only a part of the total cost of ensuring a clean, healthy, and vibrant environment. On an annual basis, more than $\$ 600$ million is spent by the federal government alone on collecting environmental data. Regulatory requirements impose additional costs on the private sector, for monitoring of emissions and effluents (Office of the President, 1997). Other governmental agencies and organizations and the private sector devote considerable resources to environmental monitoring, above and beyond what is required for simple compliance.

Given the importance and cost of environmental protection, considerable efforts have been directed to evaluate the condition of the nation's environment to chart changes in its quality and trace their causes. Attempts have been made through comprehensive studies of national environmental protection to develop more coherent and comprehensive information on the state of our environment. Despite some excellent syntheses of data on specific problems and places, there is no periodic, comprehensive, and reliable compilation of essential information about the overall state of the nation's environment (The Heinz Center, 2002).

\subsection{Introduction}

The USEPA 2004 needs survey report estimates that nationwide capital investment needs for wastewater pollution control is $\$ 202.5$ billion: $\$ 134.4$ billion for wastewater treatment and 
collection systems; $\$ 54.8$ billion for combined sewer overflow corrections; and $\$ 9.0$ billion for stormwater management. Small communities with populations of 10,000 or less have documented needs of approximately $\$ 17.0$ billion.

A major environmental issue that confronts all Americans today is the safe and proper treatment and disposal of wastewater generated from domestic sources. Wastewater is typically processed by either a conventional sewer or individual/cluster onsite (septic) systems. A conventional sewer is a channel or conduit that carries wastewater and storm-water runoff from the source to a treatment plant or receiving stream. Sanitary sewers carry household, industrial, and commercial waste. An on-site system, referred to as a decentralized wastewater system, is designed to treat and dispose of domestic sewage in close proximity to a home or a cluster of homes.

The high cost of sewers and centralized wastewater treatment plants has greatly limited communities in their efforts to address their wastewater treatment needs. DWS are becoming a widely-accepted, viable and cost-effective option for domestic wastewater treatment and dispersal from single-family dwellings, clusters of homes, and commercial facilities when conventional sewers are not feasible. USEPA concluded in its 1997 Report to Congress that adequately managed DWS are a cost-effective and long-term option for meeting public health and water quality goals, particularly in less densely populated areas.

Also, according to the USEPA, nearly one in four households in the United States depends on an individual septic system also referred to as an onsite system or decentralized wastewater system to treat wastewater (Figure 1). Populations served by septic systems nearly doubled from 7.7 million in 2000 to 15.6 million in 2004 representing only approximately onefifth of the current U.S. population being served by onsite systems. Observing land use patterns 
and development trends, it is clear that there was considerable underreporting that seems to point in a direction that would significantly increase in the use of DWS.

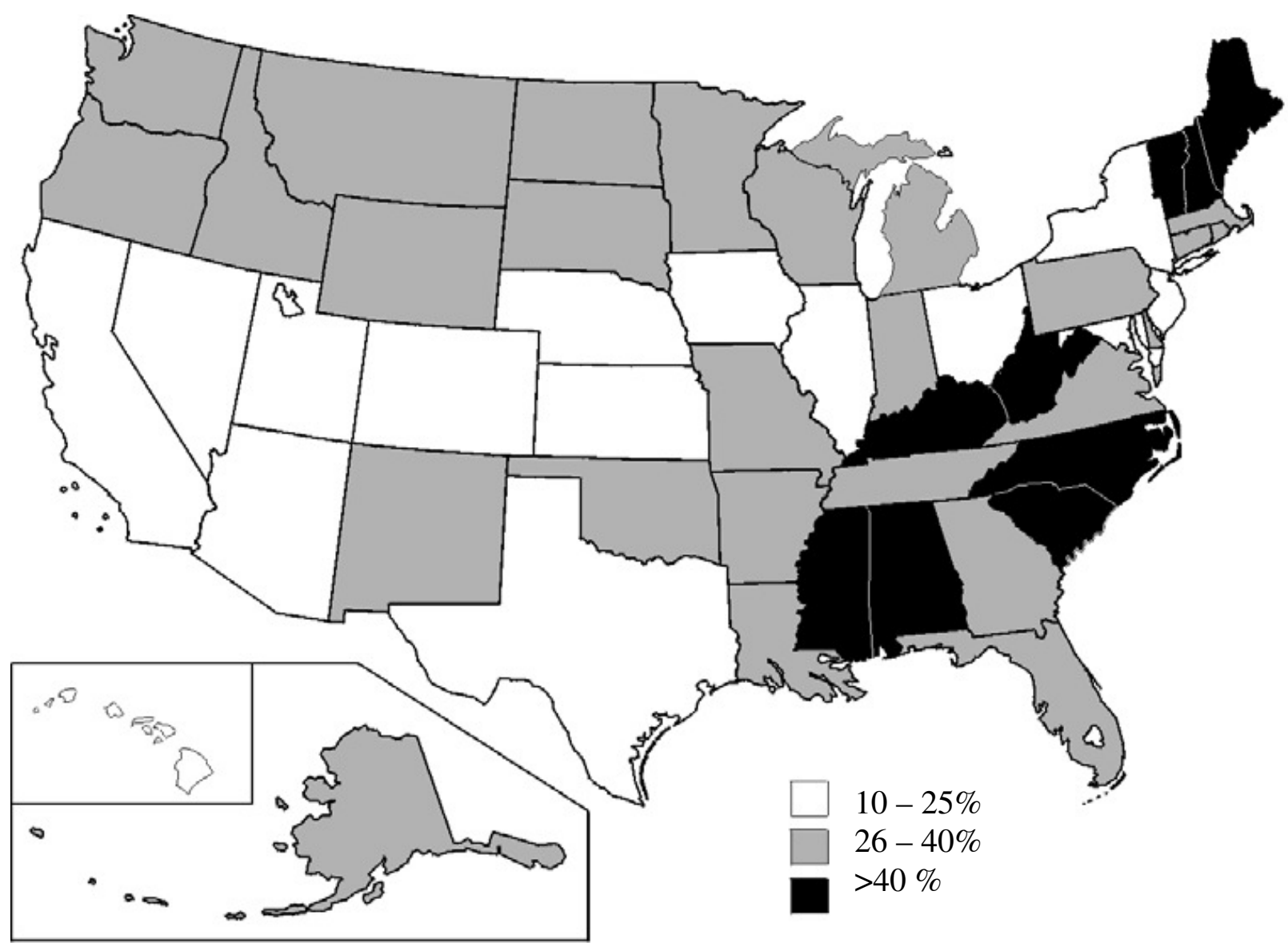

Figure 1. Onsite Treatment System Distribution in the United States

DWS, commonly called septic systems, treat sewage from homes and businesses that are not connected to a centralized wastewater treatment plant. They consist of a tank that receives waste from a residence or business and a system of tile lines or a pit for disposal of the liquid effluent (sludge) that remains after decomposition of the solids by bacteria in the tank and must be pumped out periodically (USEPA, 1997 and USEPA, 2002). The different types of DWS include individual onsite septic systems, cluster systems, and alternative wastewater treatment 
technologies like home aeration units, constructed wetlands, recirculating sand filters, peat filters, textile filters, mound systems, and ozone disinfection systems.

Most systems discharge treated septic tank wastewater to the soil, but some discharge to ditches, streams, lakes, and other waterbodies and need special federal or state permits. State and local governments are now looking to innovative treatment systems and management options to help reduce or eliminate problem DWS. Some communities have built advanced sewage treatment systems and created management entities as a long-term, reliable solution for unsewered areas. Others are focusing on enhancing existing programs to help homeowners better manage their septic systems.

With rapid development in suburban and outer fringes of cities and towns, it is anticipated that these systems will play an even greater role in the future. They are often more affordable and can be designed to perform under a greater variety of site-specific conditions than conventional centralized sewage treatment plants. They provide flexible wastewater solutions and help achieve land-use objectives when planned, designed, and installed properly. However, more than half of these systems are over 30 years old, and surveys indicate at least 10 to $20 \%$ might not be functioning properly.

In far too many cases, DWS are installed and largely forgotten until problems arise. The difference between failure and success is the implementation of an effective wastewater management program. Such a program, if properly executed, can protect public health, preserve valuable water resources, and maintain economic vitality in a community. 


\subsection{Need for Wastewater Management}

According to the U.S. Bureau of the Census at least 10 percent of onsite systems have failed, with some communities reporting failure rates as high as 70 percent (U.S. Department of Commerce, 1997). The proper operation and performance of DWS is a national issue of great concern. Unfortunately, many of the systems in use are improperly managed and do not provide the level of treatment necessary to adequately protect public health and surface and groundwater quality. This section presents an overview of environmental and economic impacts as a result of improperly managed DWS affecting our water resources, public health and economy.

\subsubsection{Public Health Impacts}

Human sickness and death result in lost wages and work days. The economic impact caused by such events is measured by people's willingness-to-pay (WTP) to avoid health issues due to DWS failures or willingness-to-accept (WTA) compensation for such illnesses. This economic cost is often approximated by the costs of medical treatment and lost wages. The approximations do not include the social costs of pain and suffering which are included in the broader WTP and WTA measures. The information most readily available is on cases of sickness and death due to DWS failures.

According to the National Water Quality Inventory: 1996 Report to Congress, state agencies designated septic systems as the second most frequently cited contamination source that threatens their ground water resources (USEPA, 1998). It states that "improperly constructed and poorly maintained septic systems are believed to cause for a substantial and widespread nutrient and microbial contamination to ground water." Consumption of improperly treated groundwater as per USEPA estimates results in 168,000 viral and 34,000 bacterial illnesses each year. The 
contaminants of primary concern in USEPA study of ground water-based drinking water systems are waterborne pathogens from fecal contamination (USEPA, 2000).

\subsubsection{Environmental Impacts}

States across the nation have reported in their 1998 lists of polluted waters that designated uses are not being met for 5,281 waterbodies because of pathogens and that 4,773 waterbodies are impaired by nutrients (USEPA, 1998). DWS are often significant contributors of pathogens and nutrients contaminating both ground and surface drinking water sources. The 1995 National Shellfish Register reported that septic systems were a major source of groundwater contamination at 32 percent of problem sites (US Department of Commerce, 1995). Other contributors were urban runoff (principal or contributing factor in 40 percent of all harvest-limited growing areas), followed by unidentified upstream sources (39 percent), and wildlife (38 percent).

DWS may also be contributing to an overabundance of nutrients in ponds, lakes, and coastal estuaries, leading to overgrowth of algae and other nuisance aquatic plants. For example, the 45,000 septic systems in Sarasota County, Florida, contribute four times more nitrogen to Sarasota Bay than the City of Sarasota's advanced wastewater treatment plant (Sarasota.Bay, 1992).

\subsubsection{Economic Impacts}

The adverse impacts of pollutants on water quality threaten the ecology and use of the lake, river or marine environment as well as groundwater. All these effects have very serious economic consequences affecting a wide range of industries, ecosystems, and public health. The 
types of economic impacts from contaminated water resources include public health, commercial fishery, recreation and tourism, and monitoring and management.

There are a few studies that have examined true economic costs but many have estimated economic impacts. A study conducted by the Woods Hole Oceanographic Institution and Nanzun University is presented as an example to demonstrate the economic impacts due to nutrient contamination. Although there is little mention of sewage in this particular study, other studies have established the link between improperly treated wastewater and algal blooms.

Highlighted in this example is a theoretical cost analysis of a commercial and recreational fishery as a result of nutrient contamination (Anderson, 2000). "Economic impact" is defined broadly to mean either lost gross revenues in the relevant product or factor markets, expenditures for environmental monitoring and management, or other costs that would not have been incurred in the absence of Harmful Algal Blooms (HAB).

Nutrients come from a variety of sources such as fertilizers, sewage treatment plants, detergents, septic systems, combined sewer overflows, sediment mobilization, animal manure, atmospheric deposition and internal nutrient recycling from sediments (Paerl, 1997). Excessive nutrient loadings result in excessive growth of macrophytes or phytoplankton and potentially HABs, leading to oxygen declines, imbalance of prey and predator species, public health concerns, and a general decline of the aquatic resource.

Although there is not enough data to execute a detailed analysis as part of this study, economic theory can be used to measure the environmental costs of water pollutants due to improperly functioning DWS. The main concern is the excess nutrients that reach water bodies as a result of human activities. As an example, the changes in supply and demand for the products generated by a commercial fishery, recreational activities and tourism due to water 
pollution from DWS may be used to measure the economic costs of water pollution. Under ideal circumstances, the shifts in supply and demand would be used to measure the lost consumer and producer surpluses in the relevant markets due to shifts in demand or supply curves because of the pollution.

\section{Example 1: Commercial Fishery}

Figure 2 shows the supply and demand in a commercial fishery during one season. In this case the cost associated with the closure of a fishery due to an $\mathrm{HAB}$ event is examined. The closure causes a shift in the supply curve for individual firms, from $S_{0}$ to $S_{1}$. The supply of fish reduces from $F_{0}$ to $F_{1}$ and the price of fish increases from $P_{0}$ to $P_{1}$.

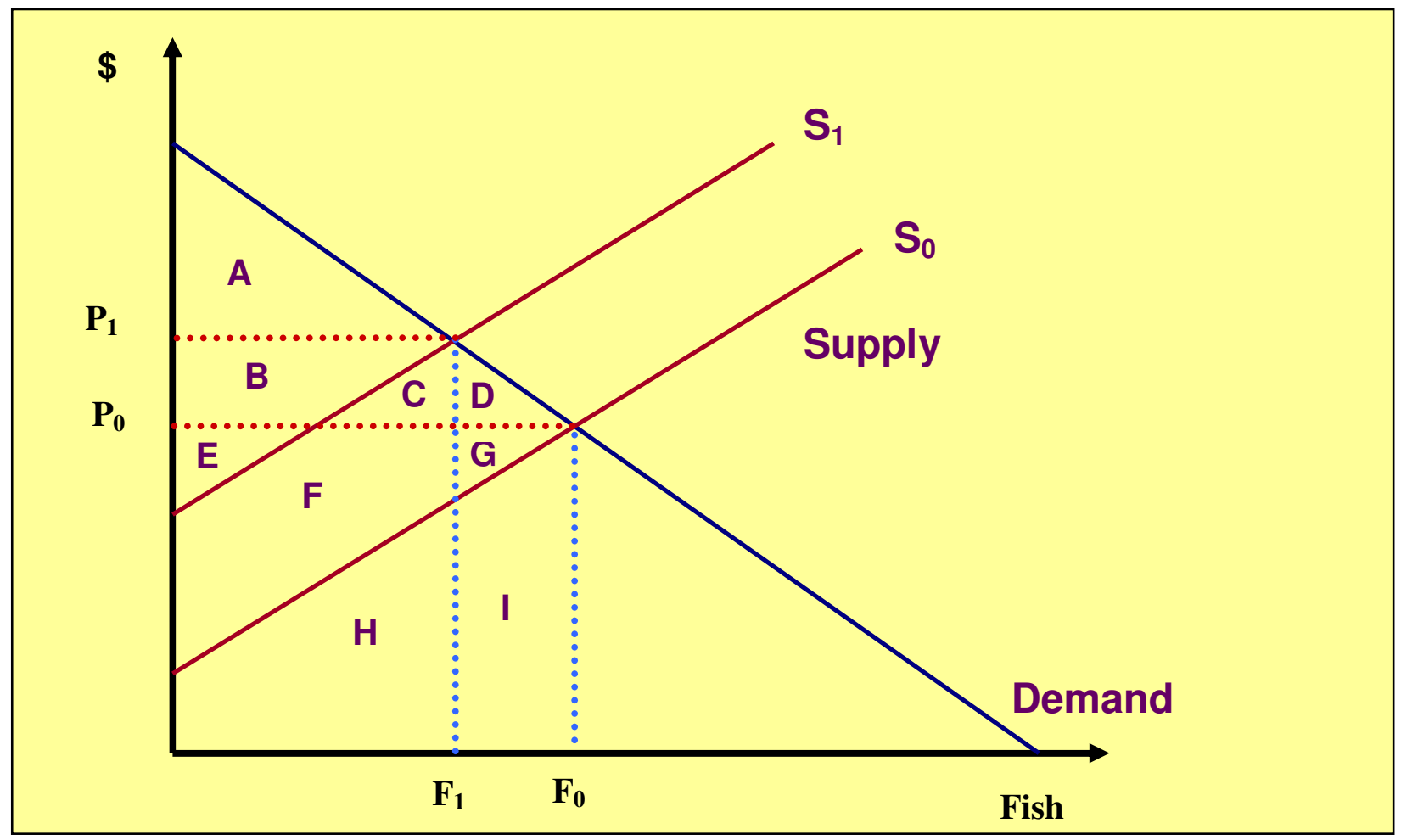

Figure 2: Economic Costs of an HAB Event in a Commercial Fishery 
The net benefits flowing from the fishery are shown below:

\begin{tabular}{|c|c|c|}
\hline \multirow[t]{2}{*}{ Prior to the closure: } & Consumer Surplus & $=A+B+C+D$ \\
\hline & Producer Surplus & $=E+F+G$ \\
\hline \multirow[t]{3}{*}{ After closure: } & Consumer Surplus & $=\mathrm{A}$ \\
\hline & Producer Surplus & $=B+E$ \\
\hline & Net economic loss & $=\mathrm{C}+\mathrm{D}+\mathrm{F}+\mathrm{G}$ \\
\hline
\end{tabular}

\section{Example 2: Recreational Fishery}

The economic impact of recreational fishery is approximated from the loss in consumers' surplus due to water pollution. The closure causes a shift in the market demand (MD) curve from $\mathrm{MD}_{0}$ to $\mathrm{MD}_{1}$ and the days lost from $\mathrm{DF}_{0}$ to $\mathrm{DF}_{1}$ (Figure 3). The consequent loss in consumer surplus may be used to approximate the true economic losses to recreational fishermen.

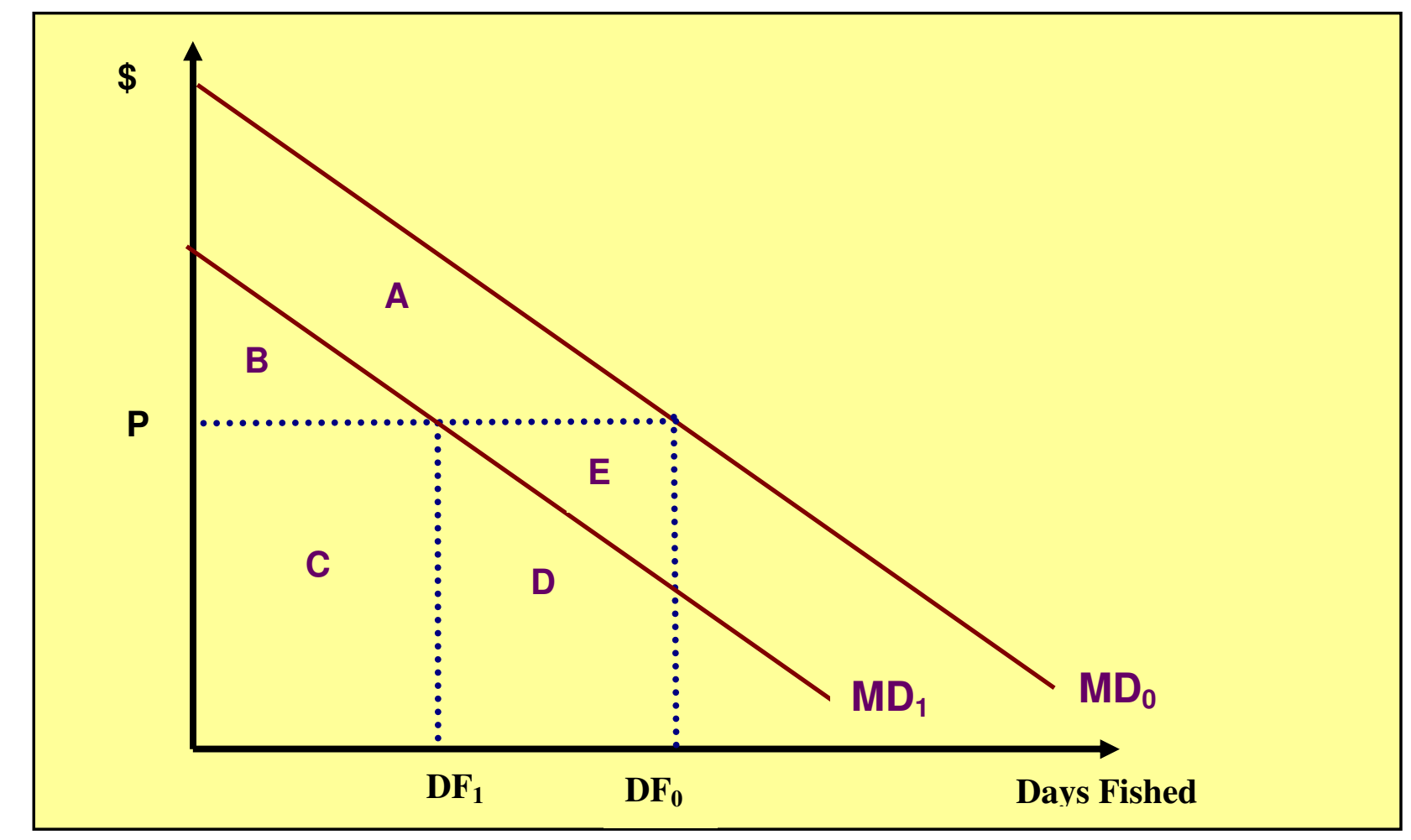

Figure 3: Economic Costs of an HAB Event in a Recreational Fishery 
Prior to the closure:

$$
\begin{array}{ll}
\text { Gross benefits } & =\mathrm{A}+\mathrm{B}+\mathrm{C}+\mathrm{D}+\mathrm{E} \\
\text { Expenditures } & =\mathrm{C}+\mathrm{D}+\mathrm{E} \\
\text { Net benefits } & =\mathrm{A}+\mathrm{B}
\end{array}
$$

In the case of an $\mathrm{HAB}$ event where some fishing areas are closed, reduced fishing opportunities and reduced fishing quality all serve to decrease the demand for recreational fishing. This decline in fishing demand results in the contraction of recreational market demand for each level of aggregate days fished (shift from $\mathrm{MD}_{0}$ to $\mathrm{MD}_{1}$ ). A new level of days fished is established at the new level of expenditures.

Following the logic described above, after closure, net benefits at new level of days fished is equal to area B and loss in consumer surplus is equal to area $\mathrm{A}$. It should be noted that there is no explicit market for days fished. The demand days for days fished is a non-market demand and needs to be estimated using specialized environmental-economic methods.

\subsection{Costs and benefits}

USEPA continues to support the most environmentally sound and cost-effective approach to implementing protective water pollution control solutions whether it be centralized or decentralized. Implementing a DWS management system can help communities meet water quality and public health goals, provide a greater range of options for cost-effectively meeting wastewater needs, and protect consumers' investments in home and business ownership.

The four direct benefits from a properly functioning DWS system are listed below.

1. Protect property values: There are many documented instances over the past few decades of property values increasing in areas formerly served by failing onsite systems after the area has been connected to a centralized sewer system. Management 
programs offer an opportunity to obtain the same level of service and aesthetics as sewered communities at a fraction of the cost, thus providing property appreciation and cost savings.

2. Preservation of tax base: A well-managed onsite system prevents small communities from having to finance the high cost of centralized sewers. Many small communities have exhausted their tax base, at the expense of other public safety and education programs, to pay for those sewers. Many of these communities then entice growth in an effort to pay for the systems, thus destroying the community structure that originally attracted residents.

3. Life-cycle cost savings: There is a clear indication that in many cases management may pay for itself in terms of lower failure rates and alleviation of the need for premature system replacement; however, this will depend on the types of systems employed and the management program chosen. Documentation of that savings is only now being initiated.

4. Recreation and Commercial Interests: Several millions of dollars have been lost due to closure of recreational and commercial fishing areas. When systems are designed, installed and maintained properly pollution risk is greatly reduced in these areas.

Other indirect benefits include protection of public health and local water resources, groundwater protection and other ecosystems. The benefits generated by a DWS management system need to be compared with the additional costs needed to upgrade existing systems. These costs are discussed in section 1.7 below. 


\subsection{Policy and Regulatory Framework}

As mentioned in the previous section, decentralized wastewater management remains a reality for a large percentage of the U.S. population. Public health and environmental protection officials now acknowledge that onsite systems are not just temporary installations that will be replaced eventually by centralized sewage treatment services but permanent approaches to treating wastewater for release and reuse in the environment. DWS will continue to be a part of sustainable water policy far into the future due to suburban and exurban/rural sprawl trends as well as infrastructure funding challenges.

The major challenge confronting the DWS pollution issue is the absence of a guiding national regulatory framework and consistent performance-based standards. These inconsistencies have posed a significant threat to our water resources, local economies and public health. Complicated state and local bureaucracies coupled with the lack of proper oversight has yielded solutions that are not technically sound or viable long-term.

The industry as a whole, with a few exceptions, functions as a cottage industry with locally suppliers adapting to local regulations. As a result, it has been difficult to establish a consistent and efficient market for DWS systems. Also, due to such variations it is extremely difficult to compare the economic efficiency of the different regional markets or to perform economic engineering studies to calculate the cost and efficiency of each type of system. Cash strapped communities and homeowners have largely been driven by a first cost response rather than applying an integrated strategy of minimizing cost and maximizing value.

Although the USEPA and the 50 states have been partnering on finding solutions to the NPS related issues for the past two decades, much work is still needed to deal comprehensively with this issue, both from a policy and regulatory standards perspective. At best, it is loosely tied 
to the Clean Water Act (CWA) of 1972. It should be noted that the CWA provides a national framework primarily for surface water quality restoration and protection through state agencies. No such national standards or framework exist for DWS.

As seen in Figure 4, there are no federal policies or standards that specifically guide or address DWS issues and standards. States have being charged with the responsibility to make the changes themselves or through the political process. Without a guiding framework to standardize standards based on science these efforts largely magnify the problems of the existing regulatory patchwork.

\subsubsection{Clean Water Act}

The principal statute governing water quality is the 1972 CWA that establishes the basic structure for regulating discharges of pollutants into the waters of the United States and regulating quality standards for surface waters. The statute's goal is to restore, maintain and preserve the integrity of the nation's waters, with an interim goal of providing water that is both fishable and swimmable (U.S. Congress, 1972). The CWA was enacted in 1972 as a series of amendments to the Federal Water Pollution Control Act of 1948. It was the first comprehensive 
national clean water legislation, drafted in response to growing public concern about serious and widespread water pollution. This is the primary federal law that protects the nation's waters, including lakes, rivers, aquifers and coastal areas.

The CWA made it unlawful to discharge any pollutant from a point source into surface waters unless a permit was obtained USEPA National Pollutant Discharge Elimination System (NPDES) permit program controls discharges. Point sources are discrete conveyances such as pipes or man-made ditches. Individual homes that are connected to a municipal system, use a DWS or do not have a surface discharge do not need an NPDES permit. Industrial, municipal, and other facilities must obtain permits if their discharges go directly to surface waters.

The CWA regulates both the direct and indirect discharge of pollutants into the nation's waters. It mandates permits for wastewater and storm water discharges, regulates publicly owned treatment works that treat municipal and industrial wastewater, requires states to establish sitespecific water quality standards for navigable bodies of water, and regulates other activities that affect water quality, such as dredging and the filling of wetlands. The major elements of the CWA are listed below.

- Requires major industries to meet performance standards to ensure pollution control

- Charges states and tribes with setting specific water quality criteria appropriate for their waters and developing pollution control programs to meet them

- Provides funding to states and communities to help them meet their clean water infrastructure needs

- Protects valuable wetlands and other aquatic habitats through a permitting process that ensures that development and other activities are conducted in an environmentally sound manner. 
The past century has witnessed an explosion in sewage treatment technology and widespread adoption of centralized wastewater collection and treatment services in the United States and throughout the world. Although broad uses of these systems have vastly improved public health and water quality in urban areas, homes and businesses without centralized collection and treatment systems often continue to depend on technologies developed more than 100 years ago. Septic tanks for primary treatment of wastewater appeared in the late 1800s, and discharge of tank effluent into gravel-lined subsurface drains became common practice during the middle of the 20th century (Kreissl, 2000).

In January 2005, USEPA, Office of Wastewater Management (OWM), presented a program strategy with a clear vision, mission, and actions to improve the performance of DWS to better protect public health and water resources. Their vision was, "DWS are appropriately managed, perform effectively, protect human health and the environment." They are a key component of our nation's wastewater infrastructure (USEPA 2005).

\subsection{Performance-Based Standards}

In the United States, most regulated activities unlike the decentralized wastewater industry have adopted performance-based standards. During the last decade, several new technologies capable of producing a very high quality of effluent have emerged in the market. The key to operating these systems within optimum control points requires a clear understanding of operational and performance characteristics at each level of treatment. Today, there is still a lack of understanding and consensus among practitioners about some of the basic wastewater characteristics in a septic tank. 
The current system is inefficient and ineffective with each state developing a general or baseline policy and some design standards. It should be noted that performance expectations considered adequate at the time of initial permitting and start-up may not be acceptable under today's water quality standards and goals. They are installed with a shortsighted view of lowest initial cost rather than lowest life-cycle costs. Compare this with the case of public sewers, which are often at least partially planned, funded, and managed by utilities that are ultimately accountable to rate-payers, with an accompanying driver to minimize life cycle costs (WERF, 2008).

States that are progressive have been moving toward comprehensive performance-based standards while others are still lagging. At best it is erratic, with some proactive regulators and local communities joining together to set standards driven only as a response to deteriorating water quality issues or a public health problem. Furthermore, as shown in Figure 4, this approach adds another level of variation and complication with local jurisdictions developing their own set of policies and standards. The result of such a fragmented system of policy and standards creates a serious set of inconsistent policies, protocols and procedures.

Information about human health and the environment-environmental characteristics; physical, chemical, and biological processes; and chemical and other pollutants-underlies all environmental management and health protection decisions. The availability of, and access to, information and the appropriate analytical tools to understand it are essential for assessing environmental and human health risks, designing appropriate and cost-effective policies and response strategies, and measuring environmental improvements.

According to a GAO report, without this information, it is difficult to set priorities, evaluate the success of programs and activities, and report on accomplishments in a credible and 
informed way. Inconsistencies across state and local jurisdictions have created a myriad of practices, protocols, and procedures making it extremely difficult to establish baselines for an objective frame of reference. Standards that are developed have not been examined carefully and structured properly with the ultimate desired future state in mind. Many local jurisdictions have focused on methods rather than principles in their decision-making process.

The focus of this research is not to attempt to fill in all data gaps needed for the preferred alternative of performance-based standards. Instead, the primary focus is to present a new paradigm where knowledge gained through the use of remote data acquisition methodologies can greatly enhance regulators with performance-based standard setting. It is also prudent to invest in these technologies to counter the "out of sight, out of mind" problem that is rampant. They serve as a tool to monitor performance and make operation/maintenance visits only as needed and deemed appropriate. The other advantage is that when these upfront investments are made either by the homeowner or a management entity, problems are detected early, thus, enhancing the life of a system.

\subsection{Decentralized System and Remote Monitoring Costs}

The construction and maintenance costs of onsite/decentralized systems can be significantly lower than centralized systems, especially in low-density residential areas, making them an attractive alternative for small towns, suburban developments, remote school and institutional facilities, and rural regions. Onsite/decentralized wastewater treatment systems also avoid potentially large transfers of water from one watershed to another via centralized collection and treatment (USEPA, 1997). A typical conventional sewer project splits about 65 to 75 percent of the total project cost on the collection system and the rest on the treatment system. 
The purpose of the collection system is to move wastewater from one point to another. This escalates the project cost by running miles and miles of sewer lines, building lift stations and huge pumps that need to be operated and maintained. By distributing the infrastructure, sewer lines that transport sewage can be eliminated and public infrastructure can be downsized.

Thus, choosing a decentralized option would brings about considerable cost savings in upfront capital costs as well operation and maintenance costs. These cost savings could be used to develop remote monitoring as a tool to study, monitor, and perform maintenance on DWS systems. This tool can greatly reduce the number of site visits (operation and maintenance) that are currently prescriptive in nature to a more performance-based response. It is anticipated that such a targeted response strategy (TRS) would greatly reduce costs.

From the simplest wastewater applications to the most complicated, remote monitoring provides an excellent solution for monitoring and controlling systems from a central location. Table 1 presents a summary of costs for panels, probes, sensors and other accessories used in this research study.

Table 1: Panel and probe costs

\begin{tabular}{|l|l|r|}
\hline \multicolumn{1}{|c|}{ Parameter/Equipment } & \multicolumn{1}{|c|}{ Type: Panel, Probe or Sensor } & Cost (\$) \\
\hline Data Collection & Sensaphone Panel & $2,000.00$ \\
\hline Dissolved Oxygen & Transmitter and probe & $1,400.00$ \\
\hline Temperature & Probe & 300.00 \\
\hline Water Use & Pulsating Disc Meter & 480.00 \\
\hline Drainfield Ponding & On/Off Float & 65.00 \\
\hline pH & Transmitter and probe & $1,400.00$ \\
\hline Cables & Entire project & $3,200.00$ \\
\hline Other Accessories & Junction boxes and other electrical supplies & 500.00 \\
\hline
\end{tabular}


Remote monitoring using telemetry systems is becoming a more feasible option for onsite wastewater applications. It can be used in multiple wastewater treatment sites and could be an invaluable tool in optimizing the treatment process and regulatory compliance. Another key advantage is that costly damages, severe financial losses and possible penalties due to unanticipated environmental changes and process divergences can be avoided. With the advent of new technologies and the implementation of the cluster concept for wastewater management, this monitoring approach can be applied by any Responsible Management Entity (RME). It allows for rapid detection of problems off-site, and is easier and faster than conventional on-site troubleshooting.

It should be noted that this study focuses on the remote monitoring instrumentation and methodology of DWS. RME's that chose to use this tool may need only one or two of these probes or sensors to monitor and evaluate system performance. However, the particular type of probe depends on the type of system, the parameter of interest, regulatory standards, and other requirements.

\subsection{Objectives and Goals}

Today, many wastewater treatment technologies and wastewater management systems are available and provide a low-cost alternative to conventional sewers. Unfortunately, many of these systems are improperly managed and thus do not meet public health and water quality goals. It is paramount that key policy and regulatory issues that confront DWS need to be addressed without delay as they can be costly and irreversible.

The availability of, and access to, information and the analytical tools to understand system performance and operations are essential for assessing environmental and human health 
risks; designing appropriate and cost-effective policies, and response strategies; and, measuring environmental improvements. Without information, it is difficult to set priorities, evaluate the success of programs and activities, and report on accomplishments in a credible and informed way.

The underpinnings of this research are as follows:

- Environmental regulatory policy states a goal of "sound science."

- Knowledge gaps compromise our ability to make accurate predictions and set appropriate policies, standards, and guidelines.

- Accurate data is a critical decision-making tool for policy-makers and regulators to develop performance-based standards.

- Conventional methods of data collection compromise performance variations and continue to support prescriptive standards.

- Repetitive collection of data to evaluate changes and trends is needed.

- The potential net benefits of this approach are sizable and present a great market opportunity.

The two core objectives of this research study are based on the paradigm of centralized management of decentralized systems using remote monitoring technology. They include:

1. Develop an architecture that is scientifically sound to support the Centralized Management concept

2. Demonstrate the applicability of remote monitoring in Performance Based Standards Development, a regulatory shift from conventional methodologies.

Using remote monitoring as a tool, wastewater systems in remote locations can be monitored from a central location. With the advent of new communication and data monitoring 
devices, this concept is becoming a feasible oversight option. It saves time and helps monitor performance at short time intervals on a real-time ongoing basis. The overall goals of this research are summarized below.

1. Develop sound scientific data collection and analysis methods to support development of performance-based standards.

2. Use remote sensing as a tool to evaluate system performance and economics.

3. Aid policy development (paradigm shift) by putting data into a meaningful context and increase our knowledge base.

4. Study/evaluate wastewater trends and characteristics (operational thresholds).

5. Perform a comparative data analysis to observe correlations.

6. Isolate parameters of interest and equipment for further evaluation.

\subsection{Dissertation Organization and Scope}

Using the abovementioned framework, this research focuses on two critically lacking or deficient issues that stem from nonpoint source pollution (NPS) caused by inadequately or improperly managed DWS. The summary goal of this research is to demonstrate the means to formulate policy and regulatory standards that protect the nations water resources. It is important that there be a shift in thinking to adopt the centralized management of DWS paradigm and develop performance-based design standards using remote monitoring. Addressing these issues and gaps from a policy and a regulatory standard perspective is of paramount importance as it directly relates to protecting public health and preventing further deterioration of the environment. It calls for major actions at the federal level aligning its vision to the overall goals 
of the Clean Water Act (CWA). To further elaborate on this paradigm-shift, this dissertation is organized in two major parts.

- Part 1 (Chapter 2): The first part focuses on the underlying architecture needed for DWS management. It will present the Environmental Management Systems (EMS) framework for action and architecture for wastewater management.

- Part 2 (Chapters 3, 4, and 5): The second part will presents case studies that reveal the value of science-based policy making and regulatory standards development, using remote monitoring technology. Three case studies supporting the value of technology-based decision making to standards development, and greater understanding of operational characteristics are presented in detail.

Chapters 2, 3, 4, and 5 clearly demonstrate the vital role of remote monitoring in the development of standardized protocols, policies and procedures that are currently lacking in this arena of wastewater management. Chapter 6 summarizes the benefits of using the right combination of machine and manpower (instrumentation, data collection, analysis and policy/decision-making) as well as making recommendations for future research. 


\section{CHAPTER 2}

\section{A REMOTE MONITORING ARCHITECTURE ENABLING CENTRALIZED MANAGEMENT OF DECENTRALIZED WASTEWATER SYSTEMS ${ }^{1}$}

\subsection{Background}

All Americans, regardless of their geographic location or income level, are entitled to basic water sanitation services. Adequate treatment and disposal of wastewater is fundamental to protecting and ensuring public and environmental health. The USEPA estimates that about \$16 billion is needed for wastewater treatment and collection systems in small communities (population of fewer than 10,000 people and an average daily wastewater flow of less than 1 million gallons) alone (USEPA, 2003).

According to the U.S. Census Bureau, onsite and clustered wastewater systems (commonly called septic systems) serve nearly $25 \%$ of U.S. households and up to $33 \%$ of new development (U.S. Department of Commerce, 1990). More than half of these systems are over 30 years old, and surveys indicate at least 10 to $20 \%$ might not be functioning properly (U.S. Department of Commerce, 1997; Nelson et al., 1998).

In 1997, the USEPA acknowledged in a report to Congress that "adequately managed decentralized wastewater systems are a cost-effective and long-term option for meeting public health and water quality goals, particularly in less densely populated areas" (USEPA, 1997). In January 2005, USEPA presented a program strategy with a clear vision, mission, and actions to improve the performance of decentralized wastewater treatment systems, thereby providing

\footnotetext{
${ }^{1}$ Solomon, C., Kamalesh, and L. S. Lin. A Remote Monitoring Architecture Enabling Centralized Management of Decentralized Wastewater Systems. ASABE Annual International Meeting, Portland, Oregon. July 2006 (Paper Number: 063068). Reprinted with permission from the American Society of Agriculture and Biological Engineers (ASABE). Note: Minor formatting changes were made to meet the electronic thesis and dissertation submission requirements of West Virginia University.
} 
better protection of public health and water resources. Their vision was, "Decentralized wastewater treatment systems are appropriately managed, perform effectively, protect human health and the environment, and are a key component of our nation's wastewater infrastructure" (USEPA, 2005).

Today, many wastewater treatment technologies and management approaches are available for providing low-cost alternatives to conventional sewers. These systems are especially appropriate for small and rural communities, particularly those in isolated or environmentally sensitive areas. In addition to protecting the public health, safeguarding the environment, and reducing costs, appropriate wastewater treatment infrastructure helps small communities to remain economically viable and provide jobs for their citizens.

To protect the public and environmental health of citizens, small communities must have access to these proven technologies that collect and treat wastewater, usually at a substantial cost savings when compared to conventional sewers. However, there currently exists a limited amount of information to document health and water quality problems resulting from poorly designed, operated, and maintained systems, partly due to their widely distributed nature. Currently, the impacts of nonpoint source pollution to groundwater and surface water from subsurface dispersal or surface-discharging decentralized systems are generally unknown and are being investigated.

\subsection{Introduction}

An estimated 60 million people in the U.S. rely on decentralized systems to treat their domestic wastewater. It is anticipated that these systems will play an even greater role in the future, as they are often more affordable and can be designed to perform under a greater variety 
of site-specific conditions than conventional centralized sewage treatment plants. Decentralized systems do provide flexible wastewater solutions and help achieve land-use objectives when planned, designed, and installed properly. Other benefits to this approach include: protection of property values, water conservation, preservation of the tax base, life-cycle cost savings, and efficient/effective planning.

Information about human health and the environment--environmental characteristics; physical, chemical, and biological processes; and chemical and other pollutants--underlies all environmental management and health protection decisions. The availability of, and access to, information and the analytical tools to understand it are essential for assessing environmental and human health risks, designing appropriate and cost-effective policies and response strategies, and measuring environmental improvements (USEPA, 2002). Without this information, it is difficult to set priorities, evaluate the success of programs and activities, and report on accomplishments in a credible and informed way (U.S. GAO, 2000).

According to the Advisory Commission on Intergovernmental Relations, research and development (R\&D) efforts offer the most rapidly growing potential for improving public works performance. R\&D efforts, coupled with technology demonstrations, help to remove or minimize the barriers and risks confronted when implementing new technologies and practices. This allows for testing and application of innovative wastewater management approaches in a flexible and controlled environment furthering product and process refinement.

While engineers, designers, planners, and regulators are familiar with these systems to varying degrees, comparatively little attention has typically been given to the factors that ultimately affect system performance: community involvement, system performance goals, selection criteria, site suitability, operation and maintenance, and overall system management. 


\subsection{Wastewater Management}

It's important to understand why wastewater management programs have not been effective in the past. A review of current state and local onsite regulatory and management approaches reveals that many programs rely on homeowners to assume full responsibility for the operation and maintenance (O\&M) of onsite systems. Many of these programs, however, do not provide the information and trained service providers that homeowners need to accomplish this job. Local regulators often lack the legal authority to hold homeowners accountable for not properly maintaining their systems. This is compounded by the fact that few homeowners are trained to check their systems. Without proper training, they can actually risk injury or death from exposure to hydrogen sulfide and other gases generated in the tank (USEPA, 2002).

As communities grow, many new rural and suburban residents move to unsewered areas unaware of their system location and the need for periodic maintenance. In this "unmanaged" condition, septic systems will not perform adequately, and many will have problems ultimately resulting in failure. The key to achieving effective performance of decentralized sewage treatment systems--from the simplest "box and rocks" septic tank and drainfield system to the most complex treatment and dispersal unit--is an effective management strategy (Tchobanoglous et al., 1998; Rubin et al., 1999; USEPA, 2005).

In order to properly manage an onsite system effectively and efficiently, the capability to monitor the operational status and performance from a central location is needed. This can be accomplished by installing probes and sensors at various points within a system to provide realtime, operational information using telemetry or telemonitoring (Ryan George and Schillinger, 1997). Telemetry is the science and technology of automatic measurement and transmission of 
data by wire, radio, or other means from remote sources to receiving stations for recording and analysis.

Remote monitoring using telemetry systems is becoming a more feasible option for onsite wastewater applications. With the advent of new technologies and the implementation of the cluster concept for wastewater management, this monitoring approach is well suited for RME's. It allows for immediate detection of problems off-site and is easier and faster than on-site troubleshooting.

\subsection{Scope of the Project}

This demonstration project was funded by the USEPA as part of the National Onsite Demonstration Program of West Virginia University. The overall goal was to provide a unique learning experience for state and local officials, community members, and other stakeholders by assisting them in their decision-making process. This was achieved by integrating innovative, appropriate and affordable technologies and implementing strategic management systems.

Based on the process paradigm of "Centralized Management of Decentralized Wastewater Systems," this project explored the possibility of monitoring multiple systems from a central location (Nawathe, 2000; Tchobanoglous and Crites, 1998). As technology innovations occur, the complexity of systems increases, resulting in a greater need for automated monitoring and control systems that have become a key component to process management. The primary objective of this project is to test and evaluate the applicability of the need for this "centralized paradigm" in the context of managing onsite systems distributed and located in different sites.

A number of probes and sensors were installed to study wastewater characteristics at various points within the system. In addition, efforts are being directed to study the performance 
of the probes/sensors and potential causes of failure, as well as the maintenance requirements during routine operation. The two major goals of the project are to:

- Demonstrate the potential of remote monitoring equipment as a tool for a responsible management entity

- Perform a comparative analysis of telemetry data with typical wastewater lab results (Solomon et al., 2006).

However, the single focus of this paper is to illustrate the framework and architecture of this design and its implementation. Information regarding the software and hardware requirements for real-time monitoring of data is presented in the following sections. Included in this paper is a complete architecture from data collection to analysis. Also discussed are the various steps involved in the collection, retrieval, storage, and analysis of data.

\subsection{Benefits}

Onsite/decentralized systems are a permanent component of our wastewater infrastructure. Although the human element is an important piece of the puzzle in data collection and analysis, the sheer number of systems, their distribution, and underground location makes it difficult to study their performance characteristics or impact on the environment. It is anticipated that one of the primary benefits of this project will be a data-driven decision-making process to assist in the development of standards and criteria related to the process performance of a system.

As mentioned earlier, as complexity of the system increases, practices and procedures are necessary for controlling pumps, alarms, and other process equipment (Leverenz et al., 2002). The monitoring process provides basic control and alarm systems to alert the system owner of a 
malfunction. It also provides more insight into wastewater characteristics and other properties that may impact the performance of the system. Other benefits of the monitoring process include:

- Meeting the growing need for qualitative data (objective and numerical)

- Sampling and translating real-time events into machine-readable signals in a short period of time, thus predicting and preventing failures

- Providing a rapid response to system recovery and operation

- Reducing system downtime by performing maintenance only when it is needed

- Correcting small problems before they escalate

- Maintaining the established quality and performance standards

- Streamlining labor and other economic efficiencies through a targeted response approach (Horton et al., 1995)

- Cost-effectively protecting the owner's investment in the system

In addition to these benefits, real-time automation can improve the quality of any management system by complementing the various elements of decentralized wastewater management, such as education and training, planning, performance, site evaluation, design, construction, operation and maintenance, residuals management, and corrective actions. It can serve as a useful tool for RME's that cover a large geographical area. The element of distance is greatly marginalized by this approach.

\subsection{Architecture and System Design}

The basic architecture of the "Centralized Monitoring System" (CMS) has two distinct components: offsite and onsite. Figure 5 shows a generic model of the complete monitoring system. The onsite component includes the remote and decentralized features that contain all the 
probes and hardware units. The offsite component includes the Centralized Data Acquisition Center (CDAC), where all data are collected, stored and processed.

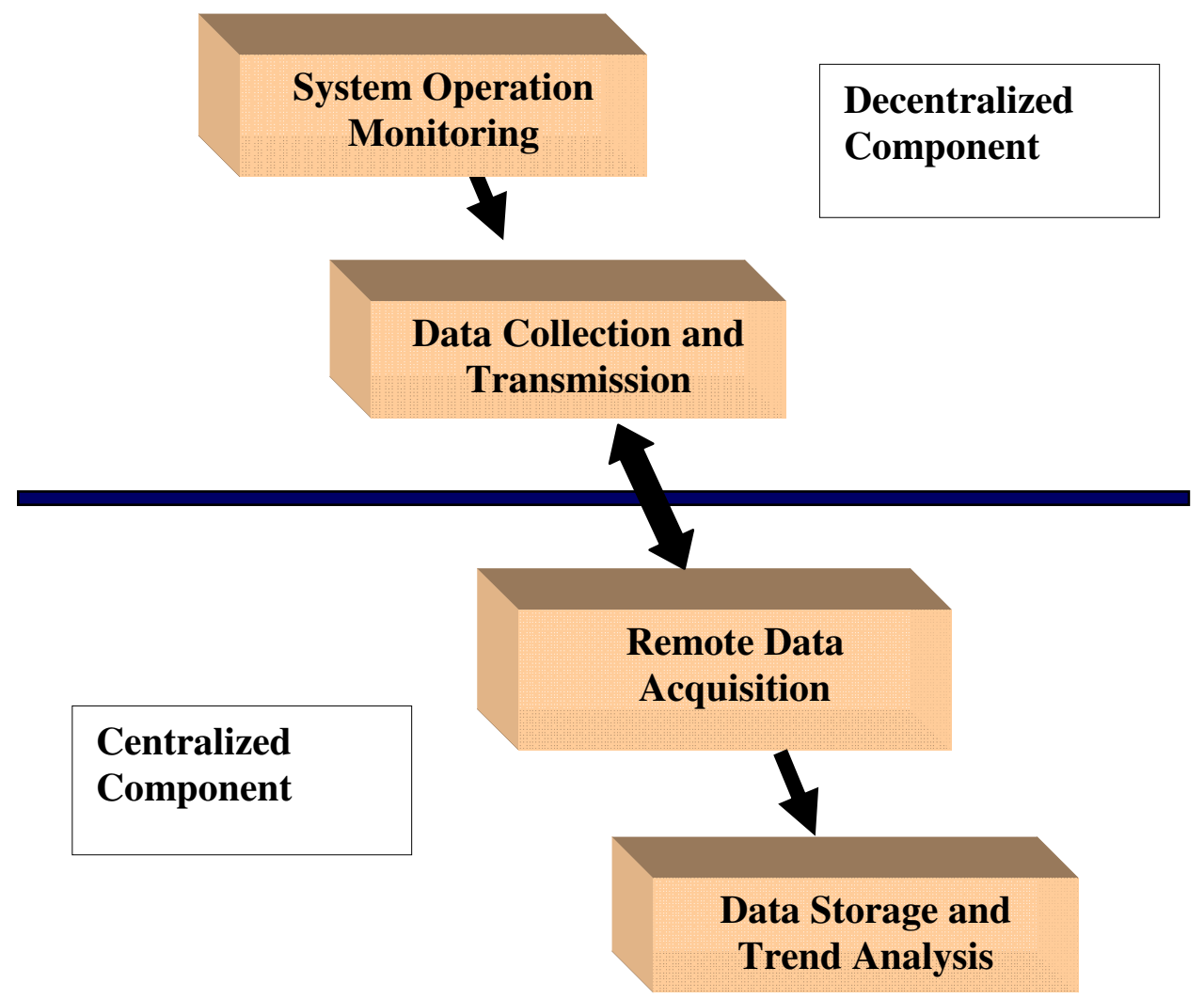

Figure 5: Model of the Centralized Monitoring System

\subsubsection{Remote/Decentralized Features}

This component is mainly composed of hardware units that measure and transmit data collected by probes located at various points in the wastewater system. They include the wastewater system fitted with probes and sensors, and the Remote Data Acquisition Panel (RDAP) with all the transmitters and the data logger. Figure 6 shows a schematic of this decentralized component. The probes or sensors are installed either in the treatment units or 
within close proximity to the system. The probes and sensors in the units measure wastewater characteristics while the others measure weather-related conditions.

A total of six to eight parameters are monitored and data are collected for each system. They include water use, ambient and wastewater temperature, $\mathrm{pH}$, dissolved oxygen (DO), pump run time, and trench liquid level (wherever applicable). Data were collected at regular intervals of three minutes and transmitted to the RDAP.

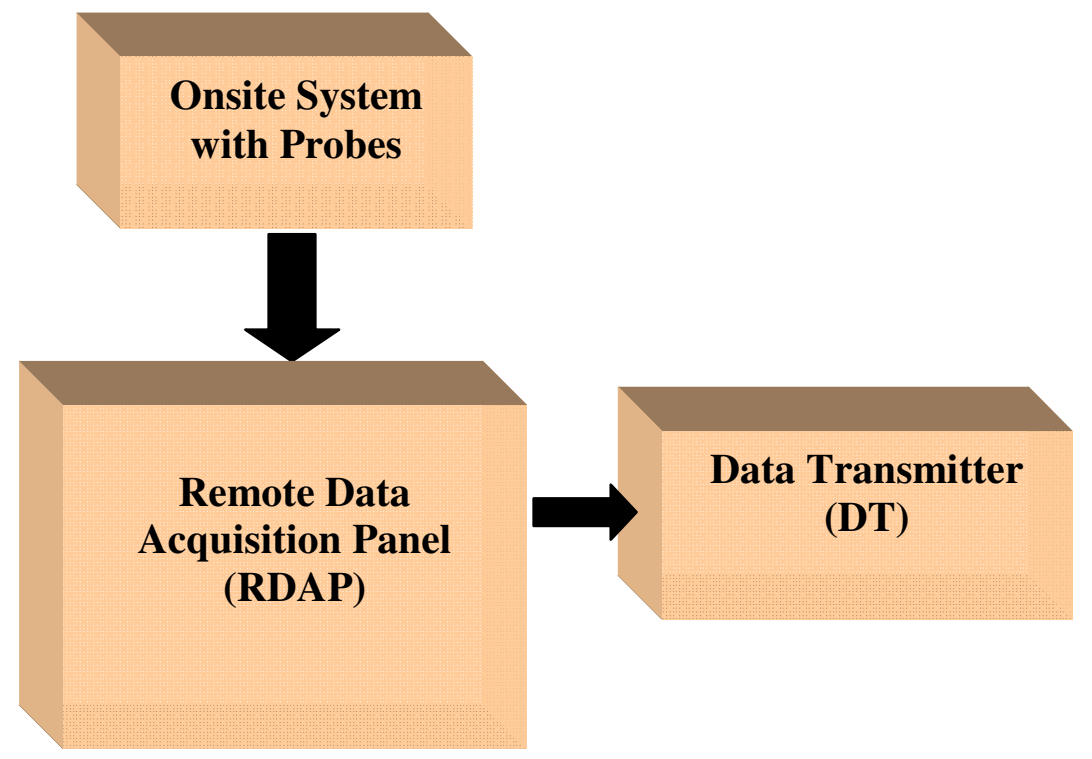

Figure 6: Layout of the Decentralized Components

The RDAP is the heart of the monitoring system and can be accessed for programming or monitoring both onsite and offsite (remote). It is a custom-built panel that houses the transmitters, relays, and other accessories, serving as a temporary data storage device. All probes and sensors are wired to this panel. Data can be accessed from the RDAP using an onsite or a remote mode of data acquisition.

The onsite mode is mainly used for calibration, initial programming, and setup of the RDAP. While using the onsite mode, a direct connection is established by connecting a laptop through a data transfer cable. When using the remote mode, a modem connection is used. This 
mode is primarily used to observe the need for routine maintenance and data downloads. Data transfer from RDAP to CDAC is done through a transmission line, which in this case is a regular telephone line.

\subsubsection{Probes and Sensors}

One of the main features of this closed-loop system is the ability to control data collection and transmission from a central and/or remote location. Table 2 shows a list of parameters and the types of probes used in this research study. The $\mathrm{pH}, \mathrm{DO}$, and temperature probes are analog sensors while the relays, floats, and water meter are digital sensors.

Table 2: List of Parameters and Types of Probes

\begin{tabular}{|l|l|}
\hline Parameter & Probe/Sensor Type \\
\hline DO & Quantum DO Sensor and Transmitter \\
\hline pH & Quantum pH Sensor and Transmitter \\
\hline Pump Run & Allen Bradley Relays \\
\hline Air Temperature & FGD 0104 Temperature Sensor \\
\hline Water Temperature & Oxyguard Temperature Sensor \\
\hline Float & W.E Anderson Liquid Level Switches \\
\hline Water Meter & Badger Recordall Electronic Transmitter \\
\hline
\end{tabular}

A total of six sites spread across Georgia, Maryland, and West Virginia were chosen for this study. The types of systems monitored include constructed wetland, home aeration systems, and recirculating media filter. The actual location of the probes varied according to the 
parameters being monitored and type of wastewater system. General locations of the probes and sensors are listed below.

1. DO: either in the primary or secondary treatment unit

2. $\mathrm{pH}$ : near the inlet tee of the primary treatment device

3. Pump run time: pump tank (pressure distribution system) or aeration device

4. Ambient air temperature: within 50 to 150 feet of the system

5. Water Temperature: either in the primary or secondary treatment unit

6. Floats: trench or dispersal area

7. Water Meter: where main water supply enters the building

The temperature sensors and drainfield float were connected using a $3 / 8$ " diameter, direct-burial telecomm cable while the $\mathrm{DO}, \mathrm{pH}$, and water meter were connected using Quantum cable in a conduit for maximum protection. The cables were buried in a hand-dug trench about 6 to12 inches deep. In general, sensors were attached to PVC pipe and anchored from a riser close to the ground surface. Probes were connected to a waterproof junction box (NEMA specified) mounted in the access port or riser.

\subsection{Centralized Data Acquisition Center}

The CDAC is mainly constituted of software applications required for data retrieval and storage for further analysis. This component actually has two hardware units: a designated Data Reception Line (DRL) and a Data Acquisition Computer (DAC). The DAC is used to connect with the RDAP and download data on a periodic basis in order to monitor the performance of the wastewater system. The DAC is a personal computer (PC) using a Sensaphone 2000 (S2000) Manager software application. The S2000 Manager is the data management software associated 
with the RDAP, providing the ability to program and operate the unit from a remote location. The connection to the remote site is established using the modem line on the DAC and a DRL. Figure 7 shows a layout of the CDAC.

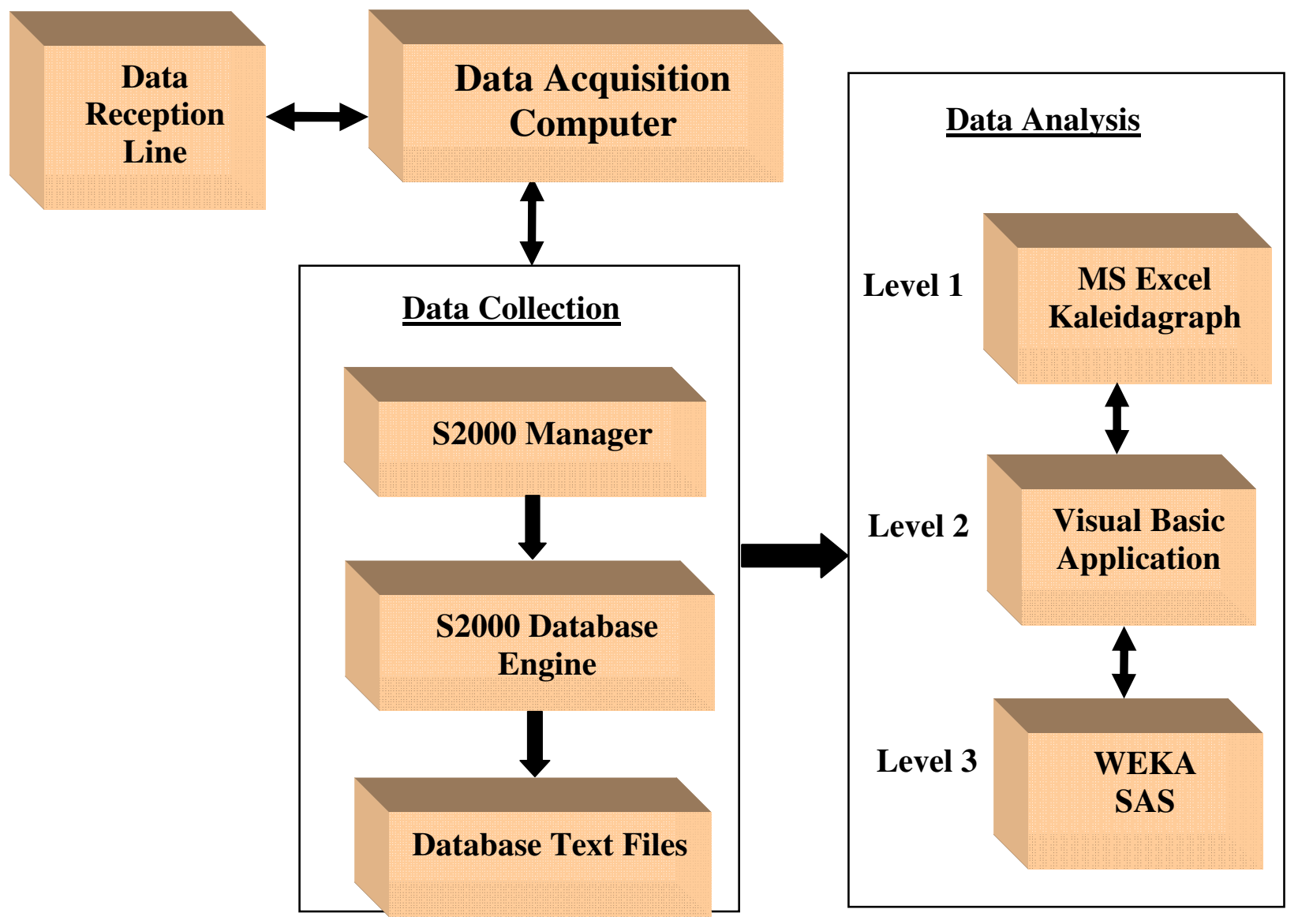

Figure 7: Layout of the Centralized Data Acquisition Center

\subsubsection{Data Retrieval, Storage, and Analysis}

It is important that the integrity of the data be protected and maintained throughout the entire process. Wastewater data from the remote sites are automatically downloaded according to a preset polling schedule on a periodic basis and stored on the DAC. 
Two steps of polling are involved in the data-collection process. First, the data from the probes are collected and stored by the data logger. The data logger has eight slots to receive eight inputs (parameters), which are programmed to call on each sensor at a specified polling interval. In this study, the polling interval is set to three minutes, resulting in a total of 480 data points recorded per parameter per day. This setup is user-defined and is typically programmed prior to installation of the unit.

The data logger at each site is also set to be polled by the S2000 manager to retrieve the stored data. The S2000 manager is programmed to automatically poll the data logger in these remote sites using a phone-modem connection on a regular (daily) basis. The polling time by the S2000 is made unique for each site to avoid any clash between various units. As soon as the connection is established, the data are downloaded into the database engine of the S2000 (Sensaphone, Inc. 2003).

In order to manage a large volume of data, it must be stored properly in a format that is readable and understandable. In order to accomplish this, the retrieved data are stored as text files. The parameters for these queries are user-specified, and the querying is done in the data logging section of the S2000 Manager. These text files can now be directly imported to any data analysis application, such as Microsoft Excel or Access (Microsoft, 2002), a Visual Basic (VB) application, or KaleidaGraph 2005 (Synergy software, 2005), to observe trends and correlations.

Figure 8 shows a flowchart of the pathway of information transfer (data collection, transmission, and retrieval) from the remote location to the CDAC. The two main elements of data queried are the parameter values along with their corresponding times. Data stored in the database engine of S2000 Manager are retrieved manually and then stored offsite for further analysis. 
The first step in the analysis of the data involves checking for irregularities and removing erroneous data points. Erroneous data points from power and probe failure, calibration issues, fouling of membranes, or other such factors, were identified and removed. Since the raw data have time stamps, it is easy to identify and remove such points to obtain a consistent data set for further analysis. From this data set, averages are calculated for $\mathrm{pH}$, ambient temperature (AT), water temperature (WT), and total water usage per day. Daily and monthly averages of each parameter are calculated for statistical analyses to address research questions related to system

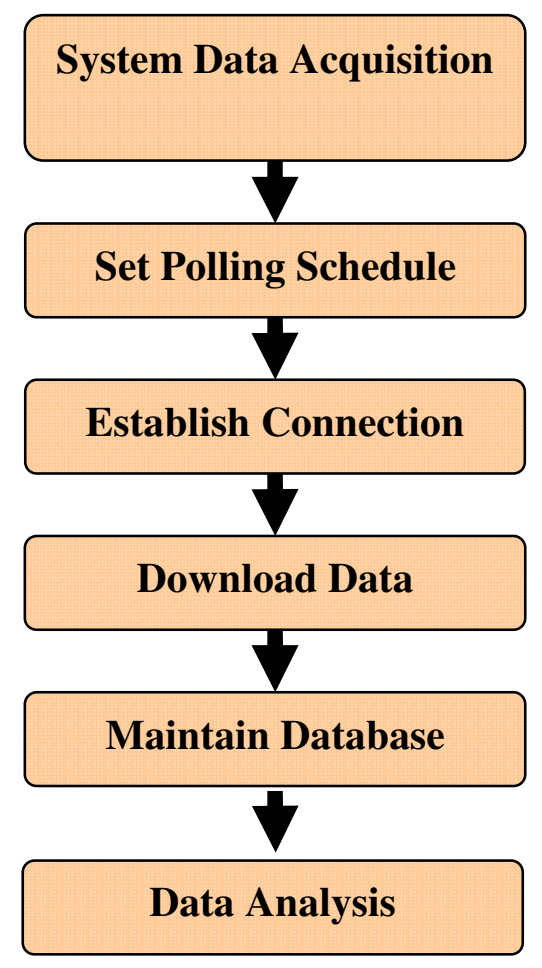

Figure 8: Data Pathway Flowchart from the Remote Location to the Desktop performance, robustness, and design.

Correlation and regression analyses between the parameters are conducted to explore causal relationships (Kottegoda and Renzo, 1997). These correlation and regression analyses are done using the Analysis Toolpak in MS Excel, and the confidence level for these regression analyses is set at $95 \%$. Overall trends and behavior patterns of the system are also studied.

More detailed analysis of the data will be performed with an advanced version of SAS packages and data mining techniques using a tool called WEKA. WEKA is a collection of machine learning algorithms for data mining tasks. The algorithms can either be applied directly to a dataset or called from a user-created Java code. WEKA contains tools for data pre-processing, classification, regression, clustering, association rules, and visualization (Gene, 1991). 


\subsection{Conclusion and Recommendations}

Federal, state, and local agencies need comprehensive information on environmental conditions and changes. Real-time information will help set levels of protection in water quality standards and identify problem areas that are emerging or that need additional regulatory and non-regulatory actions. This directly supports water quality management decisions such as determining the total maximum daily loads (TMDLs) of pollutants allowed, issues surrounding National Pollutant Discharge Elimination System (NPDES) permits, enforcement, and non-point source management.

This project initiates a new direction and comprehensive approach in the development of a monitoring strategy that reflects a full range of water quality management objectives including, but not limited to, the Clean Water Act goals. System-specific data gathered from this project can be used to develop, set, and adapt management protocols, practices and procedures. The information collected will enable RME's to identify core indicators and set acceptable performance criteria and threshold levels (both low and high).

The case for federal, state, and local funding to meet the growing needs of the wastewater infrastructure is compelling, especially in small, rural, and low-income communities. Creative and new ways to finance and manage these projects effectively and efficiently over their lifecycle should be pursued. It is recommended that demonstration projects, such as this be used to demonstrate the range of innovative and cost-effective options available to integrate technological and managerial solutions at a low risk. An economic analysis comparing efficiency improvements in just using human labor (versus a combination of human labor and technology) should be explored. It is anticipated that a significant reduction in labor costs can be achieved by using a targeted response approach. 


\section{Acknowledgements}

The authors would like to thank the USEPA for their support and funding of this project. Special thanks to the homeowners who were early adopters of this concept and their willingness to participate in this project. Our thanks to Michael Aiton, Eric Menear, and Mike Fogel for their

contribution to this project. Special thanks to David Collins, Margaret Caigan McKenzie, and Tim Suhrer for their editorial support. 


\section{References}

\section{Journal}

Horton, D., and M. Cross. 1995. Combined Maintenance, Management Cuts Labor Costs. Water Environment and Technology. 7(8): 28-30.

Ryan, G., and G. Schillinger. 1997. Illinois Facility Upgrade Monitoring Ability with Spread Spectrum Radio for SCADA Systems. Water Environment and Technology. 6(2): 59-62.

Tchobanoglous, G. 1998. Decentralized Wastewater Management. Trans ASCE - Water Resources and the Urban Environment, 559-564. Chicago, IL.

\section{Book}

Gene, M.Y. 1991. Environmental Data Bases: Design, Implementation and Maintenance. Lewis Publishers, Inc. ISBN, 0-87371-422-9.

Kottegoda, T., and R. Renzo. 1997. Statistics, Probability, and Reliability for Civil and Environmental Engineers. McGraw-Hill Companies, Inc. ISBN. 0-07-035965-2.

Tchobanoglous, G., and R. Crites. 1998. Small and Decentralized Wastewater Management Systems. McGraw-Hill Companies, Inc. ISBN 0-07-289087-8.

\section{Bulletin or Report}

General Accounting Office. 2000. Water Quality-Key EPA Limited by Inconsistent and Incomplete Data. GAO/RCED-00-54. Washington, D.C.

Leverenz, H., G. Tchobanoglous, and J. Darby. 2002. Review of Technologies for Onsite Treatment of Wastewater in California. Center for Environmental and Water Resources 
Engineering, Department of Civil and Environmental Engineering, University of California, Davis. Davis, California.

Rubin, A.R., and R. Otis. 1999. Wastewater Management Options for Individual Homes and Small Communities - Development of Voluntary Management Standards. Sixth EPA Technology Transfer Workshop, Kansas City, MO.

U.S. Department of Commerce 1997. American Housing Survey for the United States -1995. U.S. Census Bureau, Washington, D.C.

U.S. Department of Commerce 1990. Historical Census of Housing Tables: Sewage Disposal. U.S. Census Bureau, Washington, D.C.

USEPA 2003. Clean Watersheds Needs Survey - Report to Congress. EPA 832-R-03-001. U.S. Environmental Protection Agency, Washington, D.C.

USEPA 2005. Decentralized Wastewater Treatment Systems: A Program Strategy. EPA 832-R05-002. Office of Water, U.S. Environmental Protection Agency, Washington, D.C.

USEPA 2002. Guidelines for Ensuring and Maximizing the Quality, Objectivity, Utility, and Integrity of Information Disseminated by the Environmental Protection Agency. EPA 260R-02-008. U.S. Environmental Protection Agency, Office of Environmental Information, Washington, D.C.

USEPA 2005. Handbook for Managing Onsite and Clustered (Decentralized) Wastewater Treatment systems - An Introduction to Management Tools and Information for Implementing EPA’s Management Guidelines. EPA 832-B-05-001. Office of Water, U.S. Environmental Protection Agency, Washington, D.C.

USEPA 1997. Response to Congress on Use of Decentralized Wastewater Treatment Systems. EPA 832-R-97-001b. U.S. Environmental Protection Agency, Washington, DC. 
USEPA 2003. Voluntary National Guidelines for Management of Onsite and Clustered (Decentralized) Wastewater Treatment Systems. EPA 832-B-03-001. U.S. Environmental Protection Agency, Washington, D.C.

\section{Published Paper}

Nawathe, Dilip. 2000. Using Smart Controllers with Remote Monitoring Capability to Meet the New Market Needs. Conf Proc. of National Onsite Wastewater Recycling Association (NOWRA).

Nelson, V.I., S.P. Dix, and F. Shephard. 1998. Advanced Onsite Wastewater Treatment and Management Scoping Study- Assessment of Short-Term Opportunities and Long-Run Potential, Conf Proc. NOWRA.

Solomon, C., J. Kamalesh, and L. S. Lin. 2006. Real-time Monitoring of Operational Characteristics in Septic Tanks, ASABE Annual International Meeting, Portland, OR.

\section{Software}

Microsoft. 2002. Microsoft Excel 2002: Data Analysis Toolpak.

Synergy Software. 2005. KaleidaGraph 2005: Tools for Discovery Version 4.0.

Sensaphone, Inc. 2003. Sensaphone 2000 Manager. Version 3.4. 


\section{CHAPTER 3}

\section{REAL-TIME MONITORING OF OPERATIONAL CHARACTERISTICS IN SEPTIC TANKS ${ }^{2}$}

\subsection{Background}

Households not served by public sewers in small and rural communities usually depend on individual onsite or decentralized systems (also referred to as septic systems) to treat and disperse wastewater. In 2003, the USEPA reported in their Clean Watershed Needs Survey (CWNS) that small communities have an estimated need of approximately $\$ 16$ billion. This represents about $10 \%$ of the $\$ 161.9$ billion in documented wastewater treatment and collection needs for the country. A small community is defined as communities with a population of fewer than 10,000 people and an average daily wastewater flow of less than 1 million gallons (USEPA, 2003).

According to the U.S. Census Bureau, decentralized wastewater treatment systems serve nearly $25 \%$ of U.S. households and almost $33 \%$ of new developments (U.S. Census Bureau, 1997). Decentralized wastewater treatment systems collect, treat, and release about 4 billion gallons of treated effluent per day from an estimated 26 million homes, businesses, and recreational facilities nationwide. About half of the existing systems in the U.S. are more than 30 years old (USEPA, 2002; USEPA, 2005).

In the past, states and tribal agencies have reported that septic systems constitute the third most common source of groundwater contamination and have failed because of inappropriate

\footnotetext{
${ }^{2}$ Solomon, C., Kamalesh, and L. S. Lin. Real-Time Monitoring of Operational Characteristics in Septic Tanks, ASABE Annual International Meeting, Portland, Oregon. July 2006 (Paper Number: 062157). Reprinted with permission from the American Society of Agriculture and Biological Engineers (ASABE). Note: Minor formatting changes were made to meet the electronic thesis and dissertation submission requirements of West Virginia University.
} 
siting, design, or inadequate long-term maintenance (USEPA, 1996). The discharge of partially treated sewage from these malfunctioning systems has been identified as a principal or contributing source in the degradation of shellfish-growing areas. Also, they have contributed to an overabundance of nutrients in ponds, lakes, and coastal estuaries, leading to the excessive growth of algae and other nuisance aquatic plants (USEPA, 1996).

In addition, onsite systems contribute to contamination of drinking water sources. The USEPA estimates that 168,000 viral illnesses and 34,000 bacterial illnesses occur each year as a result of consumption of drinking water from systems that rely on improperly treated groundwater. Malfunctioning septic systems have also been identified as one potential source of groundwater contamination (USEPA, 2000 and 2003). However, when properly designed, constructed, and operated, individual onsite and decentralized systems are an appropriate and permanent solution, rather than an interim solution, to water pollution and public health problems (USEPA, 2000).

\subsection{Introduction}

Recognition of the impacts of onsite systems on groundwater and surface water quality (e.g., nitrate and bacterial contamination and nutrient inputs to surface waters) has increased interest in optimizing the systems' performance. Public health and environmental protection officials now acknowledge that onsite systems are not just temporary installations that will be replaced eventually by centralized sewage treatment services, but are a permanent approach to treating wastewater for release and reuse in the environment. Onsite systems are recognized as a viable, low-cost, long-term, decentralized approach to wastewater treatment when they are planned, designed, installed, operated, and maintained properly (USEPA, 1997). 
One of the critical components of most onsite or decentralized systems is a septic tank which provides primary treatment. Septic tanks attenuate peak flows and enable passive anaerobic biological digestion. Figure 9 shows a cross-sectional view of a conventional septic tank (single- and two-compartment). A septic tank is a large, underground, watertight tank consisting of one or two compartments made of concrete, plastic, fiberglass, or other materials. They are typically about nine feet long, four to five feet wide, five feet tall, and are connected to the home's sewer line.

Raw wastewater from the bathroom, kitchen, and laundry room flows into the tank where the solids separate from the liquid. Light solids, such as soap suds and fat, float to the top and form a scum layer. This layer remains on top and gradually thickens while the heavier solids settle to the bottom of the tank where they are decomposed by bacteria. The middle layer consists of liquid waste (clarified effluent) that is sent for further treatment or dispersed into a drainfield. Baffles installed at the inlet and outlet of the tank help prevent scum and solids from escaping. Some non-decomposed solids remain in the tank, forming a sludge layer that is eventually pumped out. An important factor to achieving proper sedimentation is maintaining quiescent conditions (Tchobanoglous et al., 1998). Typically, the volume or capacity of a septic tank is determined by the number of bedrooms in the home.
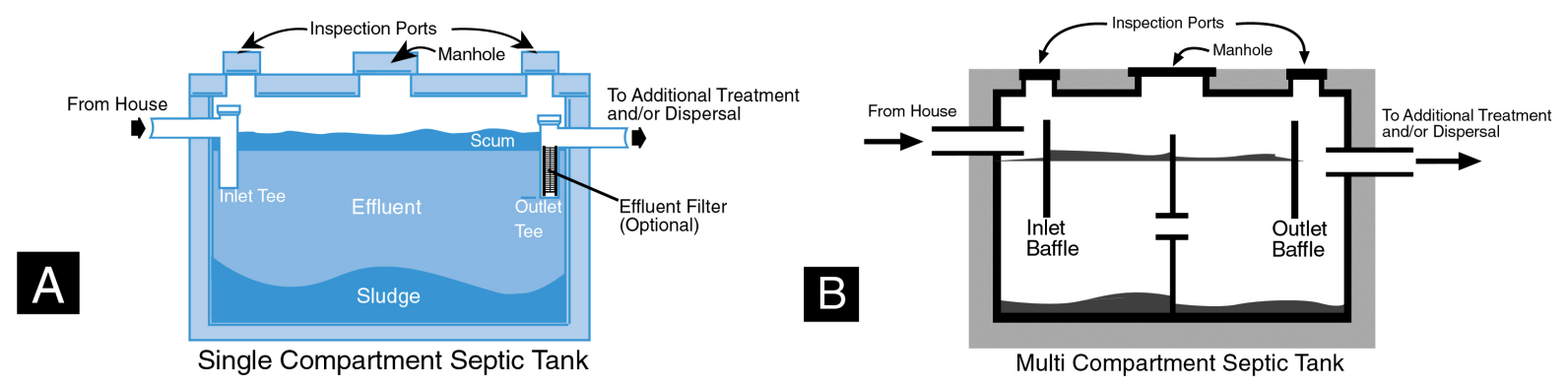

Figure 9: Cross-Sectional Views of Conventional Septic Tanks 
Historically, the selection and siting of onsite systems has been an inconsistent process. Conventional septic tank and drainfield systems were installed based on economic factors, the availability of adequate land area, and simple health-based measures aimed only at preventing direct public contact with untreated wastewater (USEPA 2002). Little analysis was devoted to understanding the dynamics of these systems and the potential impacts on groundwater and surface waters.

Today, there is still greater need for understanding the design, construction materials, installation, operation and maintenance, and performance of septic tanks. This problem is further compounded by prescriptive procedures and practices used by different states and local agencies. A paucity of published data still exists to describe the operational characteristics of septic tanks and the factors that affect their performance. Traditional data collection methods in septic tanks involve grab or composite sampling (not very common) procedures, but rarely on a continuous, real-time basis. Also, most monitoring schemes revolve around secondary treatment, with little attention given to establishing the necessary baseline characteristics within the septic tank. However, it is important that the operational characteristics of a septic tank be clearly understood for effective and efficient performance of secondary treatment devices in achieving high effluent quality goals.

\subsection{Objectives and Scope}

The overall objective of this project was to assess and evaluate the characteristics and performance of onsite systems. In addition to ambient temperature, key parameters relevant to system performance such as $\mathrm{pH}$, wastewater temperature, and water use were monitored in three onsite systems. Funded by the USEPA, this part of the research study was conducted to collect 
and analyze operational data that characterize the performance of septic tanks using remote sensing probes on a real-time basis.

This paper presents a comparative analysis of real-time data collected on $\mathrm{pH}$, wastewater temperature, ambient air temperature, and water use from three onsite systems located in Georgia, Maryland, and West Virginia. Real-time data were analyzed to observe variations and trends among the monitored parameters. The systems that were monitored include an anaerobic up-flow filter, a recirculating media filter, and a constructed wetland. All three systems used a septic tank as their primary treatment device prior to receiving partially treated wastewater.

Site 1 was a residential system with three bedrooms and two occupants. Site 2 was also a residential system with three bedrooms but five occupants. Site 3 was a non-residential system designed for a total occupancy of 350 seats. The residential systems were designed based on the number of bedrooms at 150 gallons per day (gpd) per bedroom while the non-residential system was designed at two gallons per person per day (with no kitchen facilities). Table 3 presents an overview of the systems that were monitored.

Table 3: Overview of the Systems Monitored

\begin{tabular}{|l|l|l|l|}
\hline Site ID & System Description & Design Flow (gpd) & Occupants \\
\hline 1 & $\begin{array}{l}\text { Septic tank => Up-flow filters => Pump } \\
\text { tank => Shallow trenches }\end{array}$ & 450 & 2 \\
\hline 2 & $\begin{array}{l}\text { Septic tank => Recirculating Media filters } \\
=>\text { Pump tank => Chamber System }\end{array}$ & 450 & 5 \\
\hline 3 & $\begin{array}{l}\text { Septic tank => Constructed wetland => } \\
\text { Pump tank => Gravelless Pipe }\end{array}$ & 700 & 350 \\
\hline
\end{tabular}


The actual location of the probes inside the septic tank varied according to the type of system and parameters of interest. General locations of the probes and sensors are listed below.

- $\mathrm{pH}$ : near the inlet tee of the primary treatment device

- Ambient air temperature: usually within 50 to 150 feet of the system

- Wastewater Temperature: septic tank (sites 1 and 2) and wetland (site 3)

- Water Meter: main water supply entering the building

\subsection{Data Compilation and Analysis}

The main feature of this remote monitoring project is continuous data logging. Data collected by the probes from these remote sites were downloaded and viewed on a periodic basis. The polling interval or frequency for each parameter is three minutes, which results in a total of 480 data points recorded in a 24-hour period. Details on the architecture of the data acquisition system can be found in a publication by Solomon et al., 2006.

The raw data were first checked for irregularities, and erroneous data points were removed. The raw data contained some erroneous data points that were caused by power and probe failure, calibration issues, fouling of membranes, and other such factors. Since the raw data has time stamps, these erroneous data points were easy to identify and remove in order to obtain a consistent data set for analysis. From this data set, daily averages were calculated for $\mathrm{pH}$, ambient temperature (AT), wastewater temperature (WT), and total water usage. Daily and monthly averages for each parameter were calculated and used in our analyses. 


\subsection{Results and Discussion}

In this section, an analysis of variations in the $\mathrm{pH}, \mathrm{AT}, \mathrm{WT}$, and water use for the three systems is presented. The observed ranges for each of the parameters and their averages are discussed below.

\subsubsection{Water Use Analysis}

Water use patterns in all three of the sites were different and varied according to the number of occupants, type of indoor and outdoor uses, and, to some extent, the weather and climatic conditions. Water use data were recorded near the main water supply line (actual water meter reading). It should be noted that this data is the total water consumed that includes both the

indoor and outdoor uses. All three sites had some form of outdoor water use, such as watering plants, washing driveways, filling swimming pool, and using sprinklers.

The onsite systems receive wastewater only from indoor applications (bathroom, kitchen, and laundry room). Therefore, outdoor water use had to be deducted from the total amount of water used since it is not related to the wastewater entering the onsite system. Indoor water use was approximated using the procedure described below. The calculation was based on an assumption that there was very negligible outdoor water use during winter in all three sites. Using the winter water use average as a baseline, any additional water used in summer over this volume was considered outdoor water use. This excess water use was then deducted from the summer months to obtain the total indoor water use for the entire period. 
Table 4: Summary of Water Use Data (Site 2)

\begin{tabular}{|l|l|l|l|l|}
\hline \multirow{2}{*}{ Water Use Period } & \multirow{2}{*}{$\begin{array}{l}\text { Actual } \\
\text { (gallons) }\end{array}$} & \multicolumn{2}{|l|}{ Average Water Use* } & Indoor Water Use \\
\cline { 3 - 4 } (gallons)
\end{tabular}

* Includes both indoor and outdoor water use

Table 4 presents an example of water use data for site 2 monitored for approximately nine months in 2005. In this analysis, a period with no outdoor water use is termed winter (6 months) and with outdoor water use is summer ( 3 months). The total water used during summer and winter periods were 54,421 and 26,719 gallons, respectively. Hence, total water used outdoors during summer is 27,702 gallons (i.e., 54,421-26,719 =27,702). For summer, the average daily outdoor water usage was calculated to be about $311 \mathrm{gpd}$. Using this value, the indoor water use during summer can be approximated as shown in the following example.

Example:

Date: June 6, 2005 (Site 2)

Total water used: 594 gallons

Water Use (summer, Indoor) $=$ Water Use (Total, in gpd) $^{-}$Water Use (summer avg)

Water Use ${ }_{(\text {summer, Indoor) }}=594-311=283$ gallons

\subsubsection{Design and Actual Flow Analysis}

In this section, an analysis of the design flows versus the actual water used is presented. It is assumed that all indoor water used is discharged into the septic tank. Comparisons were made 
to determine whether the actual flow was over or under the original design flow. An analysis based on two different design approaches was conducted to evaluate the performance of the systems.

1. Actual water use versus number of bedrooms

2. Actual water use versus number of occupants

The first approach involves the common design practice of sizing a septic tank based on the number of bedrooms. A typical design value of 150 gallons per bedroom per day is used. In the latter approach (that involves the number of occupants), two design flow values (with and without conservation) were calculated (Vickers, 2002). The design flow was calculated using standard design values of 50 gallons per capita per day (gpcd) with conservation and 70 gpcd without conservation. Table 5 shows a summary of indoor water use at all three sites.

\section{Table 5: Summary of Water Usage}

\begin{tabular}{|l|l|l|l|l|l|l|}
\hline Site & $\begin{array}{l}\text { Design Flow: No. of } \\
\text { Bedrooms (gpd) }\end{array}$ & \multicolumn{6}{|l|}{ Actual Usage (gpd) } & \multicolumn{2}{l|}{$\begin{array}{l}\text { Design Flow: No. of Occupants } \\
\text { (gpcd) }\end{array}$} \\
\hline & & Avg. & Min. & Max. & W/Conservation & W/O Conservation \\
\hline 1 & 450 & 111.4 & 14 & 334 & 100 & 140 \\
\hline 2 & 450 & 232 & 34 & 896 & 250 & 350 \\
\hline 3 & N/A & 203.5 & 4 & 1806 & 700 & \\
\hline
\end{tabular}

\subsubsection{Actual Water Use versus Bedrooms}

Sites 1 and 2, both residential, had three bedrooms with a total design flow of $450 \mathrm{gpd}$ each. It can be seen from Table 5 that the actual water use in site 1 did not exceed the design flow. The average and maximum daily water use was around $25 \%$ and $74 \%$ of the total design flow, respectively. However, in site 2 the actual water use exceeded the design value (450 gpd). 
The average and maximum daily water use was around $52 \%$ and $200 \%$ of the design value, respectively.

\subsubsection{Actual Water Use versus Occupants}

Site 1 had two occupants, with a design flow of 100 gpd (with conservation) and 140 (without conservation) based on occupancy. The average and maximum daily water use exceeded the design flow with conservation by $11 \%$ and $234 \%$, respectively. However, when calculated without conservation, the average water use was lower by $19 \%$, while the maximum water use was higher by $139 \%$ than the design flow.

Site 2 had five occupants, with a design flow of 250 gpd (with conservation) and 350 (without conservation). The average water use was lower by $7 \%$, while the maximum water use exceeded the design flow with conservation by $258 \%$. When designed without conservation, the average water use was lower by $34 \%$, while the maximum water use was $156 \%$ higher than the design flow.

Since site 3 is a non-residential system, it was designed based on 2 gpcd for 350 persons. The total design value was 700 gpd. The average water use was lower by $71 \%$, while the maximum water use exceeded the design flow by $158 \%$. It should be noted that site 3 was heavily used during the weekends, with minimal use during weekdays. This allows time during weekdays for the system to process the large volume of wastewater produced during weekends. 


\subsubsection{Parameter Variations (AT, WT, and $\mathrm{pH})$}

Figure 10 shows the variations in the monitored parameters for the three sites with boxwhisker plots (Nathabandu and Renzo, 1997; Synergy Software, 2005). The variability shows the conditions under which the systems were operated during the monitoring periods.
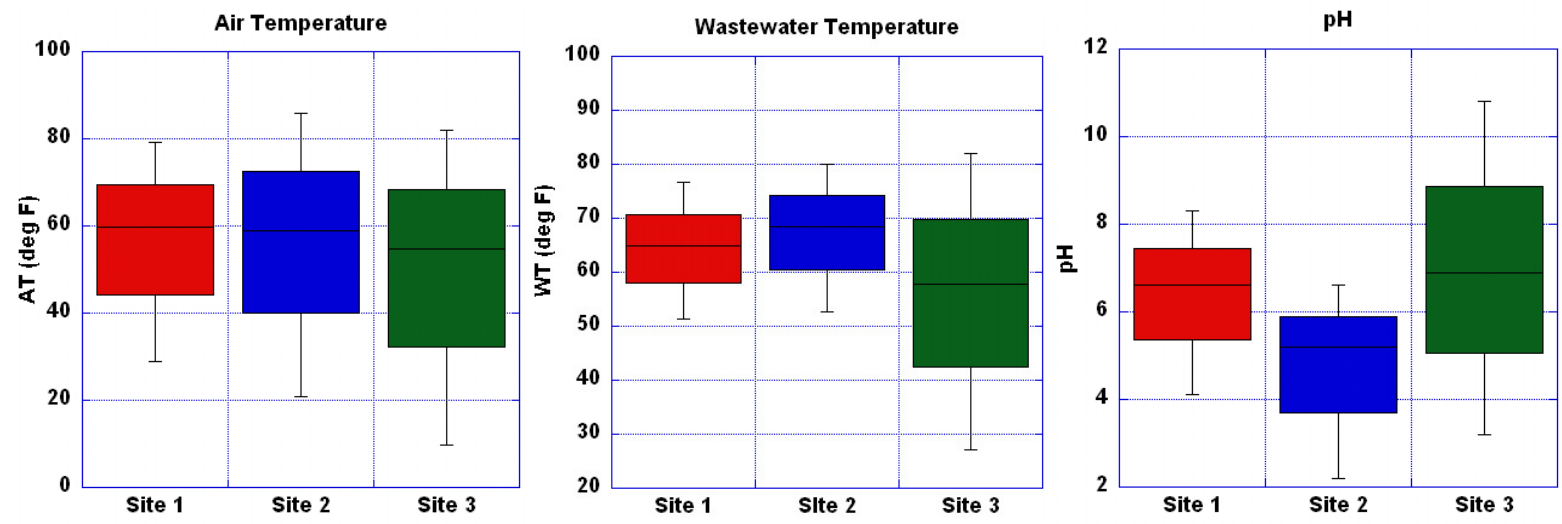

Figure 10: Parameter Variations in AT, WT, and pH

\subsubsection{Ambient Temperature}

The ambient air temperature may be having a significant influence on the wastewater temperature in the systems and have significant effects on the biological activity in them. The median ambient temperature at site 3 was lower than those measured at the other two sites. This can be primarily attributed to the geographical location of the system, which is at a higher elevation than the other two systems.

\subsubsection{Wastewater Temperature}

Wastewater temperature was measured in a closed environment: concrete structures for the residential systems and wetland soil in the wetland system. The wastewater temperature at all 
three sites was consistently within the ranges of ambient temperature, indicating the insulation effect of the confining structures (concrete and soil matrix). In general, wastewater temperature in the wetland system had a lower median temperature and a larger variability $\left(27.2\right.$ to $\left.81.9^{\circ} \mathrm{F}\right)$ than the other two sites. This can be attributed to the overall lower temperature at the site and likely better insulation by the concrete structure than the wetland soil. Wastewater temperature in the two septic tanks ranged from low 50 s to around $80^{\circ} \mathrm{F}$.

\subsubsection{3 $\mathrm{pH}$}

One of the important factors that influence the existence of microbial activity is $\mathrm{pH}$, which typically is between 5 and 9 (Tchobanoglous and Crites, 1998). The pH values at site 1 were mostly acidic except for a small portion of the time, when they were above neutral $\mathrm{pH}(4.1$ to 8.3 ). At site 2 , all $\mathrm{pH}$ values were below 7 (2.2 to 6.6). The $\mathrm{pH}$ in the wetland system showed a wider range, covering both acidic and alkaline conditions (3.2 to 10.8). During certain periods of operation, conditions existed in all three systems where the $\mathrm{pH}$ values dropped or rose above the typical range, indicating a possible reduction in biological activity in the system. This could be due to a number of factors, such as household chemical use, laundry, and other substances that enter the system affecting the $\mathrm{pH}$.

\subsection{Conclusion and Recommendations}

States all across America have taken very different approaches, within their resource limitations, to implement monitoring programs. It is clear that there is a need for accurate and comprehensive information which is the central element for protecting public health and the environment. Although some differences can be attributed to variations in standards and data 
collection, assessment methods, and the relative representativeness of the available data, a knowledge gap still exists that adversely affects the credibility of environmental management programs.

The real-time monitoring of septic tanks provides greater insight and valuable operational information never before available with this level of detail. This information is useful for decision makers, regulators, designers, manufacturers, installers, and other stakeholders in enhancing and adding to the existing knowledge base. This project presents opportunities for testing and evaluating commercially available monitoring systems and developing new products with a better understanding of primary treatment capabilities.

In summary, all systems monitored seem to operate within design limits when average actual water use is considered, but when comparing the maximum water use (peak flows) to design flows, the systems exceeded the design values. This may result in decreased retention times, inadequate treatment, and hydraulic overloading (affecting dispersal area performance). Preliminary analysis of the relationship between air and wastewater temperatures shows a good correlation between them. Although variations in $\mathrm{pH}$ were large, it seems that the septic tank does equalize flow and maintain the biological activities in the tank. Although no definite conclusions can be made at this time on performance, preliminary observations indicate no major operational failures due to fluctuations or variations.

More detailed analyses of the data will be performed for seasonal trends and spatial/temporal distributions of the monitored parameters. In particular, further analyses will be conducted to answer questions related to system robustness and acceptable performance thresholds. Also, correlations between the different parameters to identify relationships under different conditions in the system will be calculated. 


\section{Acknowledgements}

The authors would like to thank the USEPA for supporting and funding this project. Special thanks to the homeowners who were early adopters of this concept and their willingness to participate in this project. Our thanks to Michael Aiton, Eric Menear, and Mike Fogel for their

contribution to this project. Special thanks to David Collins, Margaret Caigan McKenzie and Tim Suhrer for their editorial support. 


\section{References}

\section{Book}

Kottegoda, T., and R. Renzo. 1997. Statistics, Probability, and Reliability for Civil and Environmental Engineers. McGraw-Hill Companies, Inc. ISBN. 0-07-035965-2.

Tchobanoglous, G., and R. Crites. 1998. Small and Decentralized Wastewater Management Systems. McGraw-Hill Companies, Inc. ISBN 0-07-289087-8.

Vickers A. 2002. Handbook of Water Use and Conservation. Waterplow Press. ISBN 19311579-07-5.

\section{Bulletin or Report}

USEPA. 2003. Clean Watersheds Needs Survey - Report to Congress. EPA 832-R-03-001. U.S. Environmental Protection Agency, Washington, D.C.

USEPA. 2000. 40 CFR Parts 141 and 142. National Primary Drinking Water Regulations: Ground Water Rule; Proposed Rules, Federal Register. U.S. Environmental Protection Agency, Washington, D.C.

USEPA. 2005. Handbook for Managing Onsite and Clustered (Decentralized) Wastewater Treatment systems - An Introduction to Management Tools and Information for Implementing EPA’s Management Guidelines. EPA 832-B-05-001. Office of Water, U.S. Environmental Protection Agency, Washington, D.C.

USEPA. 1996. National Water Quality Inventory Report to Congress [305b Report]. EPA 841R-97-008. U.S. Environmental Protection Agency, Washington, D.C. 
USEPA. 2002. Onsite Wastewater Treatment Systems Manual. EPA. 625-R-00-008. U.S. Environmental Protection Agency, Washington, D.C.

USEPA. 1997. Response to Congress on Use of Decentralized Wastewater Treatment Systems. EPA 832-R-97-001b. U.S. Environmental Protection Agency, Washington, D.C.

USEPA. 2003. Voluntary National Guidelines for Management of Onsite and Clustered (Decentralized) Wastewater Treatment Systems. EPA 832-B-03-001. U.S. Environmental Protection Agency, Washington, D.C.

\section{Published paper}

Solomon, C., J. Kamalesh, and L. S. Lin. 2006. A Remote Monitoring Architecture Enabling Centralized Management of Decentralized Wastewater Systems. ASABE Annual International Meeting, Portland, OR.

\section{Software}

Synergy Software. 2005. KaleidaGraph 2005: Tools for Discovery Version 4.0.

\section{Online Source}

USEPA. 1996. Clean Water Needs Survey Report to Congress. U.S. Environmental Protection Agency, Available at: http://www.epa.gov/owm. Accessed January 2006.

U.S. Census Bureau. 1999. 1997 National Data Chart for Total Occupied Housing Units. U.S. Census Bureau, Available at: http://www.census.gov. Accessed January 2006. 


\section{CHAPTER 4}

\section{ANALYSIS OF REMOTE MONITORED WATER USE TRENDS AND PATTERNS IN A COMMERCIAL FACILITY ${ }^{3}$}

\subsection{Introduction}

According to the U.S. Census Bureau, decentralized wastewater treatment systems serve nearly $25 \%$ of U.S. households and almost $33 \%$ of new developments (U.S. Census Bureau, 1997). Decentralized wastewater treatment systems collect, treat, and release about 4 billion gallons of treated effluent per day from an estimated 26 million homes, businesses, and recreational facilities nationwide. The discharge of partially treated sewage from these malfunctioning systems has been identified as a principal or contributing source in the degradation of water quality.

Today, there are several acceptable alternative and innovative options available to deal with decentralized wastewater treatment and disposal. When properly designed, constructed, and operated, individual onsite and decentralized systems are an appropriate and permanent solution, rather than an interim solution, to water pollution and public health problems (USEPA, 2000). Subsurface constructed wetlands have gained popularity as an alternative method for wastewater treatment. They can treat wastewater from a variety of sources and are commonly used to provide additional or advanced treatment of wastewater from homes, businesses, and communities.

\footnotetext{
3 Solomon, C., Kamalesh, and A. Sexstone. Analysis of remote monitored water use trends and patterns in a commercial facility, NOWRA 16th Annual Technical Education Conference \& Exposition, Baltimore, Maryland, March 2007 (Paper XX-SPE-0744). Reprinted with permission from the National Onsite Wastewater Recycling Association (NOWRA). Note: Minor formatting changes were made to meet the electronic thesis and dissertation submission requirements of West Virginia University.
} 
Subsurface constructed wetlands are artificial wastewater treatment systems consisting of a shallow bed (typical depth 20"-24") with aquatic plants relying upon natural microbial, biological, physical and chemical processes to treat wastewater. When used to treat domestic sewage, a septic tank or another type of primary treatment devices precedes a wetland. They are good at handling intermittent periods of both light and heavy flows, thus making them an appropriate wastewater treatment option suitable for churches, hotels, campsites, resorts, recreational areas and other nonresidential or commercial applications (USEPA 2002).

Constructed wetlands typically have impervious clay or synthetic liners, and engineered structures to control the flow direction, liquid retention time and water level. Depending on the type of system, they may or may not contain an inert porous medium such as rock, gravel or sand. They are passive biological systems that perform very well when provided with adequate retention time.

\subsection{Estimating Wastewater Flow}

Accurate characterization of raw wastewater, including daily volumes, rates of flow, and associated pollutant load, is critical for effective treatment system design. An accurate assessment of wastewater generated is needed to determine treatment system performance requirements, select appropriate treatment processes, design the treatment system, and operate the system. The most commonly reported failure of residential or commercial systems is hydraulic overloading. Hydraulic overloads can be caused by wastewater flow or pollutant loads that exceed system design capacity. When more water is processed than a system is designed to handle, retention time within the treatment train is reduced, which can decrease pollutant 
removal in the tank and overload. Reducing water use can decrease hydraulic loading to the treatment system and generally improve system performance.

Only a few types of nonresidential wastewater characterization criteria is available today that can bee easily applied to accurately predict flows and pollutant loadings. To account for variations in wastewater characteristics from a particular dwelling or nonresidential establishment conservative predictions or factors of safety are typically used. They attempt to ensure adequate treatment by the onsite system without requiring actual analysis of the variability in flow or wastewater quality (USEPA, 2002-1).

\subsection{Scope of the Project}

Current design standards focus on current water usage with little consideration given to future growth and expansion experienced by many commercial facilities after a wastewater system is operational. While most systems can be upgraded to accommodate the increase in wastewater generated, some may not able to do so due to limitations such as land area available, financial constraints, and lack of capacity to expand treatment. It is important that these issues be considered during the planning and design phase using a performance based multi-decision criteria system that would take into account future growth.

Funded by the USEPA as part of the National Onsite Demonstration Program, the research study was conducted to assess and evaluate the water use trend and characteristics on a real-time basis in a commercial facility. Incorporating increased usage is an important element that must be considered in onsite wastewater system design for commercial applications. A unique feature of the present study involved remote monitoring using telemetry systems to monitor the wastewater system on a continuous basis. A number of probes and sensors were 
installed to study wastewater characteristics at various points within the system. Parameters that were monitored as part of the overall project include ambient temperature, $\mathrm{pH}$, temperature, pump run time, and dissolved oxygen.

Here we report real-time water use during the period from May 2004 to October 2006. Our objective was to conduct an analysis on the amount of water used during the low and high use periods. Variations during these periods were evaluated to understand the relationships between the observed (actual) water use and expected (predicted or projected) wastewater to the system based on the design criteria established during initial design. Observed or actual water use is the amount of water use recorded by the water meter for a particular time period under consideration. E.g.: Water meter reading on October 12, 2006 was 700 gallons. Expected, predicted or projected water use is the amount of water use calculated on the actual number of users (persons) on a given weekend. Using the same example, on October 12, 2006 the number of persons were 800. As per design standards, the system capacity for peak loading in this case should be 1,600 gpd.

A comparative analysis was executed between the original and current design flow due to increased usage. Peaking loading estimates were calculated based on the actual number of attendees during high flow conditions. The major goals of the overall project were to:

- Observe any visible failure of the system due to use of the facility

- Put data into a meaningful context to increase our knowledge base

- Provide a greater insight in the estimating operational patterns necessary to predict design feature(s)

- Perform a comparative analysis of remote monitoring data to observe correlations 
- Demonstrate the potential of remote monitoring equipment as a tool for performancebased standards and decision making

The primary focus of the current paper is to present real-time monitoring data pertaining to the relationship between water use and wetland system design standards/specifications for a commercial facility. Ambiguities in regulatory design guidelines and flow variations due to increased usage are explored. Also included in this paper are a brief description of the treatment system and the computer architecture of the telemetry system.

With sufficient knowledge of water usage (such as daily, average and maximum flow), it would be possible to predict operational characteristics and design systems properly based on hydraulic inputs. Other broader objectives of the project include:

- Develop sound methods to support the centralized management concept

- Study/evaluate wastewater trends and characteristics (operational thresholds)

- Use remote sensing as a tool to evaluate system performance

\subsection{Facility and System Description}

The commercial facility is a church with no kitchen facilities and a 350 seat auditorium built to accommodate about the same number of people per meeting. A wastewater treatment system (constructed wetland) was originally designed for this facility which typically had 2 meetings per weekend (Figure 11). Based on the West Virginia State regulations (WVBPH, 2004), at 2 gallons per member (seat) the system was designed to handle a hydraulic load of 700 gallons per day (gpd).

The number of users at the facility varied throughout the week but was small minimal when compared to the number of users during the weekends (Sunday's being the maximum). 
However, in the course of the last five years the number of persons using this facility grew from about 700 to about 1,800 to 2,000 per weekend. This involved the addition of 3 more meetings that resulted in a total of 5 meetings per weekend. Table 6 presents a summary of the design specifications.

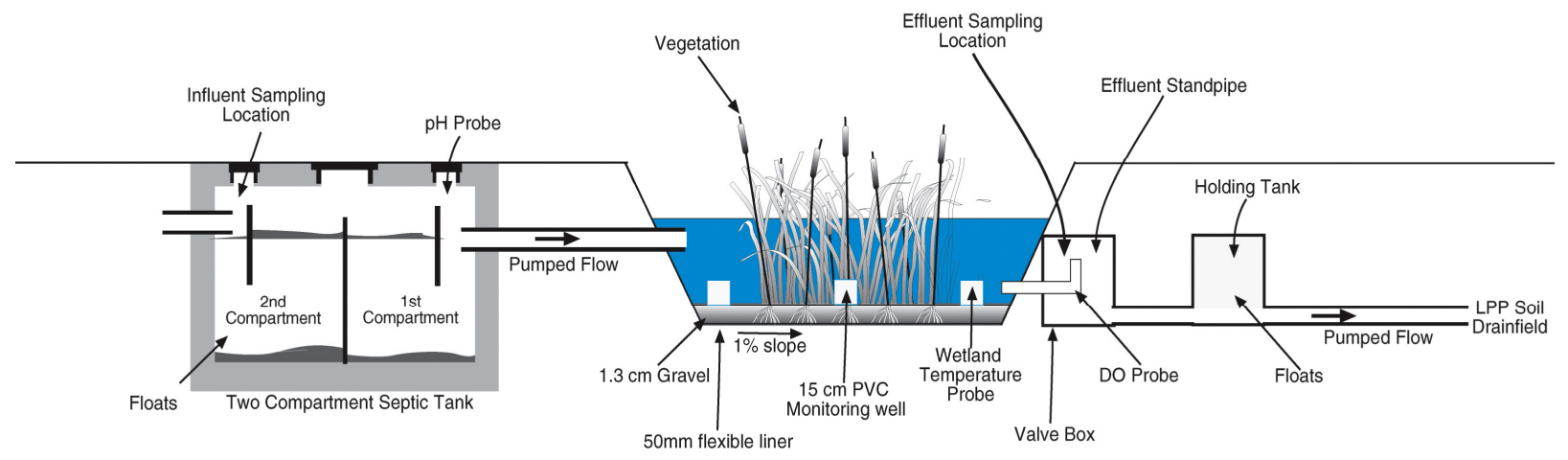

Figure 11: Schematic of the Constructed Wetland System (adapted, Friedland, J. 2004)

Wastewater from the facility flowed into a 1,500 gallon two-compartment septic tank fitted with an effluent filter and pumped to a $15^{\prime}$ X $60^{\prime}$ constructed wetland system that served as the secondary treatment unit. The second compartment of the septic tank acted as a dosing tank for the wetland. The secondary effluent was then pumped from a 1,000 gallon pump tank that dosed four sixty foot 10" gravelless pipe dosing trenches (Friedland, J. 2004)

Table 6: Original Design Characteristics of the Wetland System

\begin{tabular}{|l|l|}
\hline Criteria & Design Values \\
\hline Number of users & 350 \\
\hline Gallons per seat (no kitchen) & 2 \\
\hline Hydraulic Load & $700 \mathrm{gpd}$ \\
\hline Hydraulic Loading (Based on TVA Recommendations) & $1.3 \mathrm{ft}^{2} / \mathrm{g} / \mathrm{d}$ \\
\hline Minimum Surface Area Required & $910 \mathrm{ft}^{2}$ \\
\hline Total Lateral Length & $240{ }^{\prime}$ \\
\hline Dosing Volume & $175 \mathrm{gal}$ \\
\hline
\end{tabular}


The wetland was constructed with $1.3 \mathrm{~cm}$ gravel (approximately $44 \%$ porosity - based on field testing), lined with a $50 \mathrm{~mm}$ flexible liner. The slope of the wetland was approximately $1 \%$ from the inlet to discharge end. The wetland water level was maintained at a constant level of approximately $18 \mathrm{~cm}$. Approximately $40 \%$ of the wetland was planted with reed (Phragmites sp.) and iris (Iris sp.). One side of the wetland was nearly completely covered with reed and iris plants while the other side contained few plants.

Water use was measured using a digital magnetic water meter that was installed on the incoming water supply line. The water meter is a two-piece device: a metal alloy bottom and an electronic transmitter. The metal alloy bottom is equipped with magnetic sensors that determine the amount of water passing through the meter. The transmitter detects the movement of the magnetic sensors and sends out an electric signal to the data logger. The transmitter is mounted onto the metal alloy bottom. The transmitter is powered externally and the output is a scaled pulse which can be recorded on the data logger. These meters do not function if there is a back flow. Hence, to avoid this problem control valves were fitted on either ends of the metal alloy bottom.

\subsection{Remote Monitoring Methodology}

With the advent of new technology options, the "Centralized Management of Decentralized Systems" using remote sensing technology is gaining prominence. Although the human element is an important piece of the puzzle in data collection and analysis, the sheer number of systems, their distribution, and underground location makes it difficult to study their performance characteristics or impact on the environment. One of the primary benefits of this 
data-driven decision-making process is to assist in the development of standards and criteria related to the design and process performance of a system.

The computer architecture of the "Centralized Monitoring System" (CMS) has two distinct components: offsite (decentralized) and onsite (centralized). A generic model of the complete monitoring system is shown in Figure 12. The onsite component includes the remote and decentralized features that contain all the probes and hardware units. The offsite component includes the Centralized Data Acquisition Center (CDAC), where all data are collected, stored and processed. A detailed description on the architecture of the data acquisition system can be found in a publication by Solomon et al., 2006.

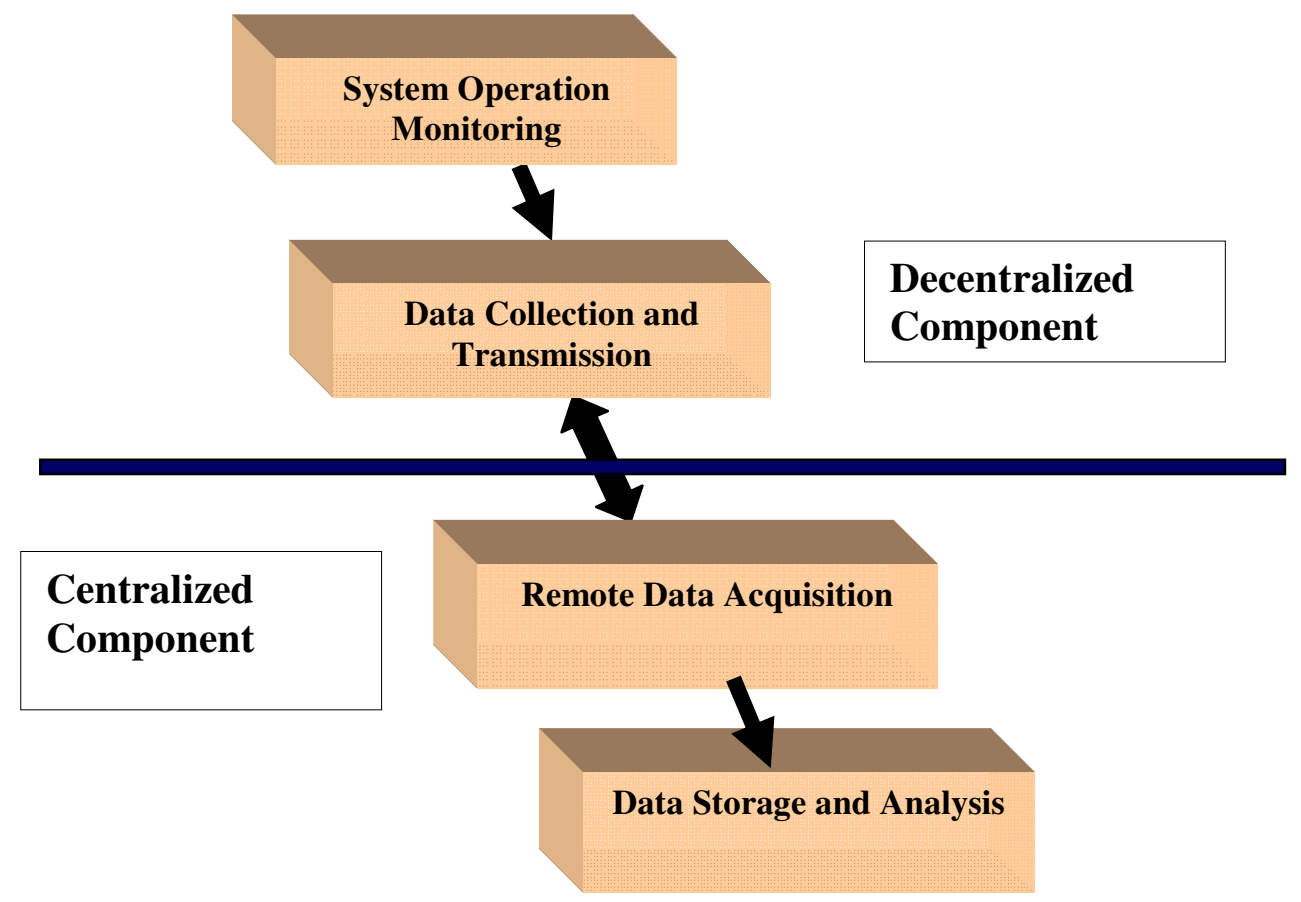

Figure 12: Model of the Centralized Monitoring System

The decentralized component comprises of hardware devices such as probes, sensors, data logger and telephone (transmission) line. The probes or sensors are installed either in the treatment units or within close proximity to the system. The computer at the CDAC has 
customized software which is used to operate the data logger. Using a telephone-modem connection data from the remote sites are downloaded automatically daily based on a pre-set poll. This data is later compiled and used for analysis.

The main feature of the remote monitoring project was continuous data logging. Water use was recorded every 3 minutes on the data logger resulting in a total of 480 data points during a 24-hour period. In this paper, the data has been averaged to a daily flow basis for ease of analysis.

Some data could not be logged during the study period due to operation issues or maintenance activities. Therefore, raw data was first checked for irregularities and missing points, and erroneous data points were removed. The erroneous data points were caused by power and probe failure, calibration issues, physical factors such as backflow. Raw data have time stamps so erroneous data points were easily identified and removed.

\subsection{Results and Discussion}

Water use followed a constant high and low pattern depending on the day of the week. On an average Sunday, the facility was used by approximately 1,350 people. During Monday through Friday the facility was used by no more than 50 persons. Water use data recorded includes the total water consumption by the facility, both indoor and outdoor. Wastewater generated from indoor applications was mainly from toilets and sinks in the restrooms. Since the water used for outdoor applications was negligible in this facility, it is assumed that all the water

used resulted in generating wastewater. Thus, in the following sections the terms water usage and wastewater generated will be used synonymously. Table 7 shows an estimate of total wastewater generated based on the actual number of fixtures used in this facility (Vickers, A., 2002). 
Table 7: Estimated Total Water Use Based on Fixtures Installed in the Facility

\begin{tabular}{|l|l|l|l|l|}
\hline Fixture & Number & Design Rating & Tsage (uses/day/person) & \\
\hline Toilets(gpf*) & 6 & 1.6 & 5.1 & 48.96 \\
\hline Urinals(gpf) & 2 & 1 & 2 & 4 \\
\hline Sink(gpm) & 6 & 1 & 8.1 & 48.6 \\
\hline Total & \multicolumn{3}{|l}{} & 101.56 \\
\hline
\end{tabular}

*gpf: Gallons per flush

Note: Fixture usage values adapted from Vickers, A., 2002.

An analysis of water use (same as wastewater generated) and its relationship to the original design values are presented for the two types of data recorded. The first part of the analysis will present a discussion on water use recorded by a conventional water meter for a time period of January 2000 to October 2006. This data was compiled using actual water bills as recorded by the local water utility. The second part of the analysis will present a discussion on water use using remote monitoring water meter that spanned from May 2004 to October 2006. Also, in this analysis a hypothetical estimate based on the observed values of actual water use and the number of persons using this facility is included.

\subsubsection{Conventional Metered Data Analysis}

Table 8 presents a summary of the water use recorded between 2000 and 2006 using a conventional water meter. The annual water use steadily increased (approximately 3-fold) in these 6 years of operation from 32,000 gallons in 2000 to about 106,000 gallons through October, 2006. If the system were to be designed today based on the current per person usage of 
the facility, it would be required to handle an annual hydraulic load of 255,000 gallons which is 5 times the original design.

Table 8: Water Use Based on a Conventional Water Meter Reading

\begin{tabular}{|c|c|c|c|c|c|}
\hline \multirow[b]{2}{*}{ Year } & \multirow[b]{2}{*}{ Users } & \multicolumn{4}{|c|}{ Water Used (gallons) } \\
\hline & & Annual & Monthly Ave. & Weekly Ave. & Daily Ave. \\
\hline 2006 & 67,144 & 106,000 & $8,833.33$ & $2,038.46$ & 290.41 \\
\hline 2005 & 66,673 & 149,000 & $12,416.67$ & $2,865.38$ & 408.22 \\
\hline 2004 & 63,332 & 102,000 & $8,500.00$ & $1,961.54$ & 279.45 \\
\hline 2003 & 54,117 & 71,000 & $5,916.67$ & $1,365.38$ & 194.52 \\
\hline 2002 & 45,430 & 71,000 & $5,916.67$ & $1,365.38$ & 194.52 \\
\hline 2001 & 36,937 & 50,000 & $4,166.67$ & 961.54 & 136.99 \\
\hline 2000 & NA & 32000 & $2,666.67$ & 615.38 & 87.67 \\
\hline
\end{tabular}

However, when comparing the average daily water use to the maximum daily loading (700 gpd), wastewater generated did not exceed the original design specifications. The average daily wastewater generated ranged from a 408 to $88 \mathrm{gpd}$. This clearly indicates there is very little correlation between the water use and number of users or the total number of seats in the facility

Daily average water use underestimates maximum daily system loading, which occurs on Saturday and Sunday rather than throughout the seven day week. Figure 13 shows a cumulative annual water usage derived from an analysis of water bills compared with cumulative Sunday attendance. The trend in increased water use over time and the increased number of Sunday attendees (users) of this facility is demonstrated, which accounts for the majority of water usage. 


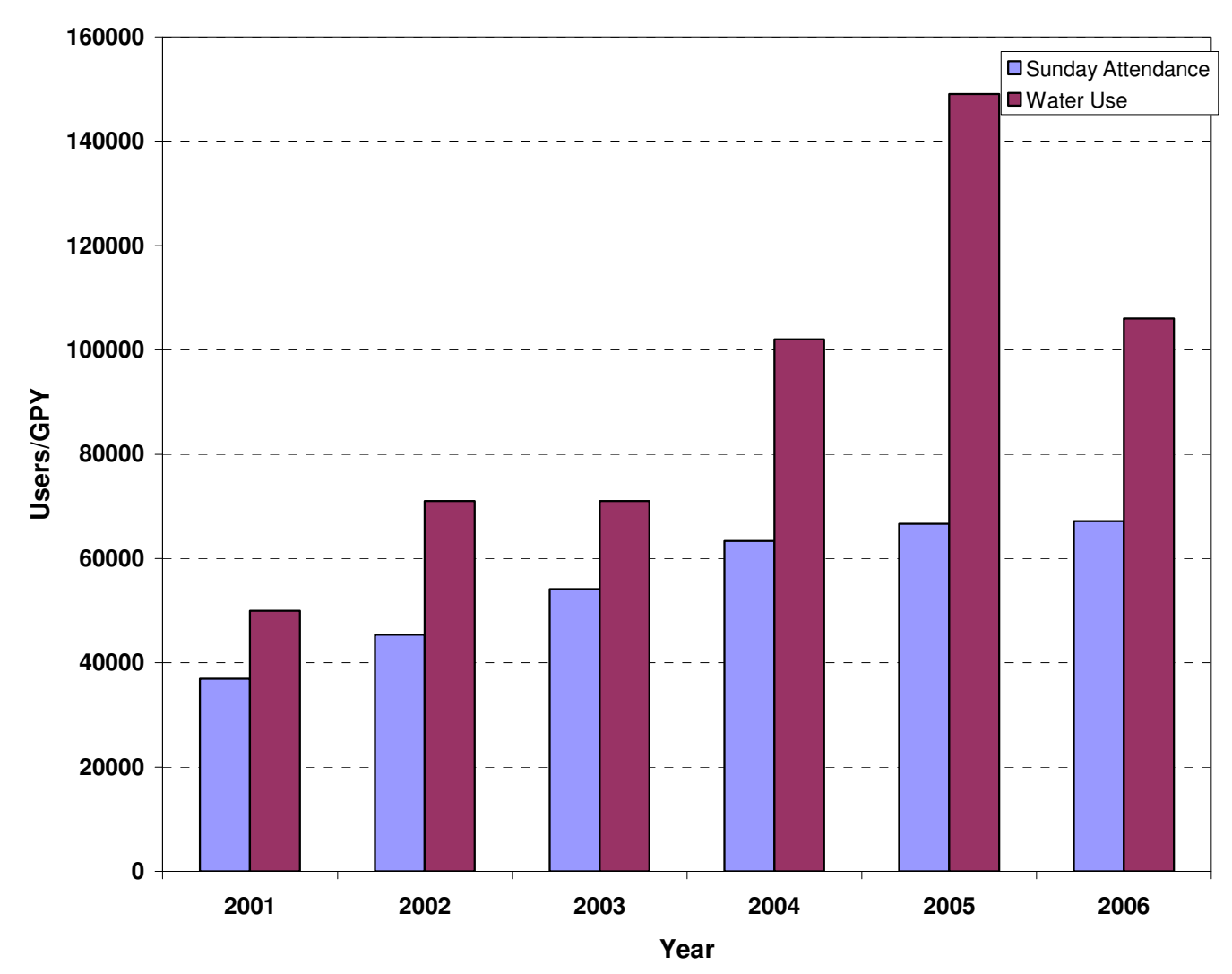

Figure 13: Cumulative Annual Water Use and Cumulative Sunday Attendees

\subsubsection{Remote Monitored Data and Actual Flow Analysis}

Assuming that all indoor water used was discharged into the septic tank, comparisons were made to determine whether the actual flow measured by the digital water meter and recorded via telemetry was over or under the original design standard of $700 \mathrm{gpd}$. Telemetric data were compressed and summarized as daily averages.

An example of monthly water use (November 2004) is presented in Figure 14, demonstrating the peak hydraulic loading that generally occurred once a week on Sundays. In general, water use on Saturdays exceeded the weekday consumption limits at all times. However, the water use on Saturdays stayed well within design standard of 700 gpd. It was usually in the range between 100 and 200 gpd with a few peaks. Some of variations could have been due 
cleaning or a seasonal activity in the facility. It is clear that these recorded values are about a third of the original design loading rate.

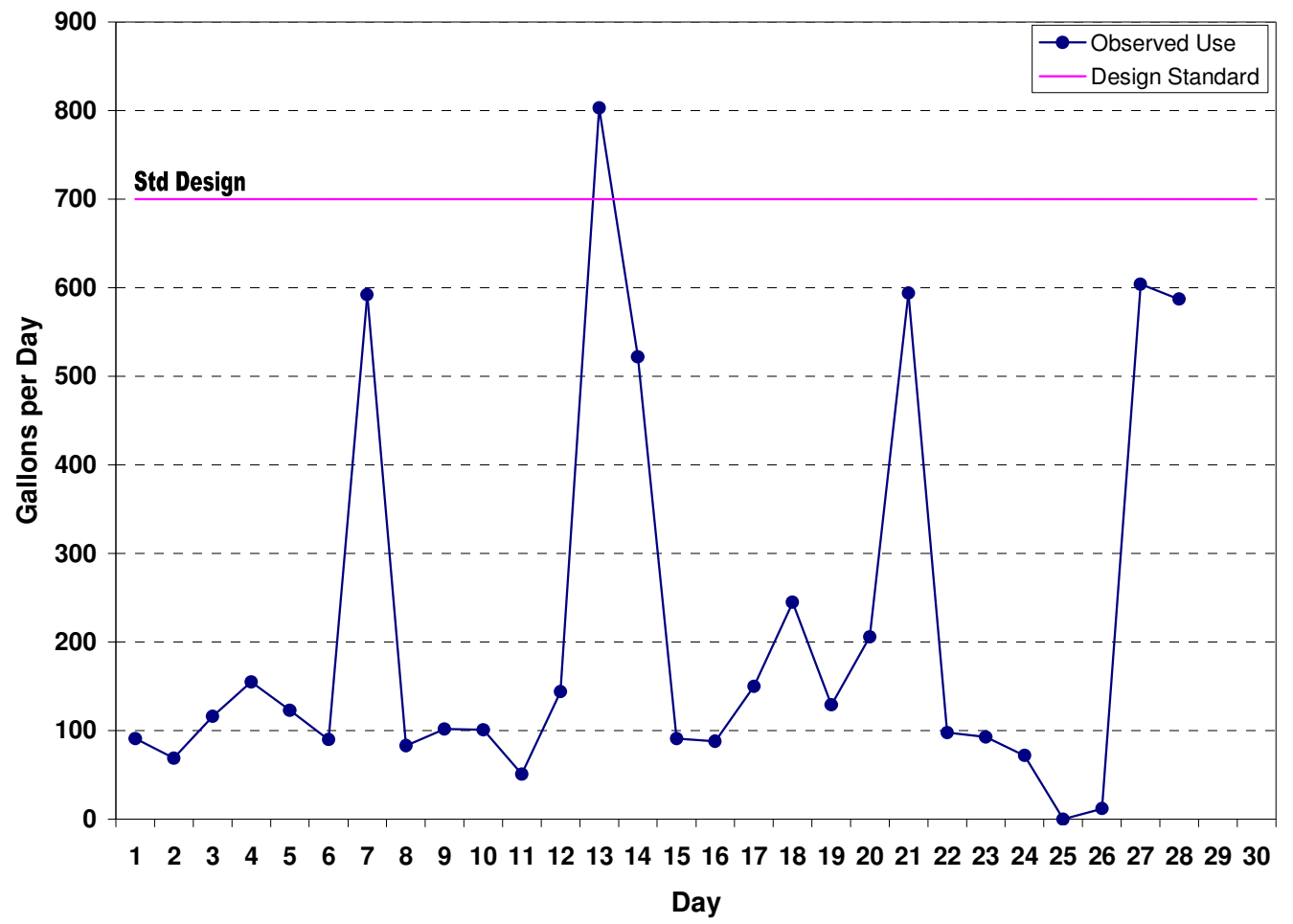

Figure 14: Daily Average Water Use during November, 2004.

Figure 15 shows four types of water usage patterns that were analyzed for this study. They are classified into four basic categories of usage: Saturdays, Sunday, weekends, and weekdays. Data presented in Figure 15 includes a total of 73 Saturdays, 79 Sundays, 146 weekends and 384 weekdays observed during this study. A comparative analysis of this data is presented below.

It was observed that the lowest water usage occurred during Monday through Friday (weekdays), followed by increased Saturday usage, and maximum usage on Sunday. Increased variability in mean estimates was observed with increasing water usage. Average water flow was always within the design standard regardless of weekly interval; however individual daily observations sometimes exceeded the design criterion. Individual daily maximum flow exceeded 
700 gpd on Saturday and Sundays by a factor of up to 1.5 , but weekday determinations never exceeded the design standard.

Excess loading on Saturdays was infrequent occurring in only $3 \%$ of the total observations, while the excess loading on Sundays was more common, occurring in about $25 \%$ of the total observations. However, since usage was minimal on weekdays, apparently the system had high enough Hydraulic Retention Time (HRT) to handle the higher weekend loads. This condition might

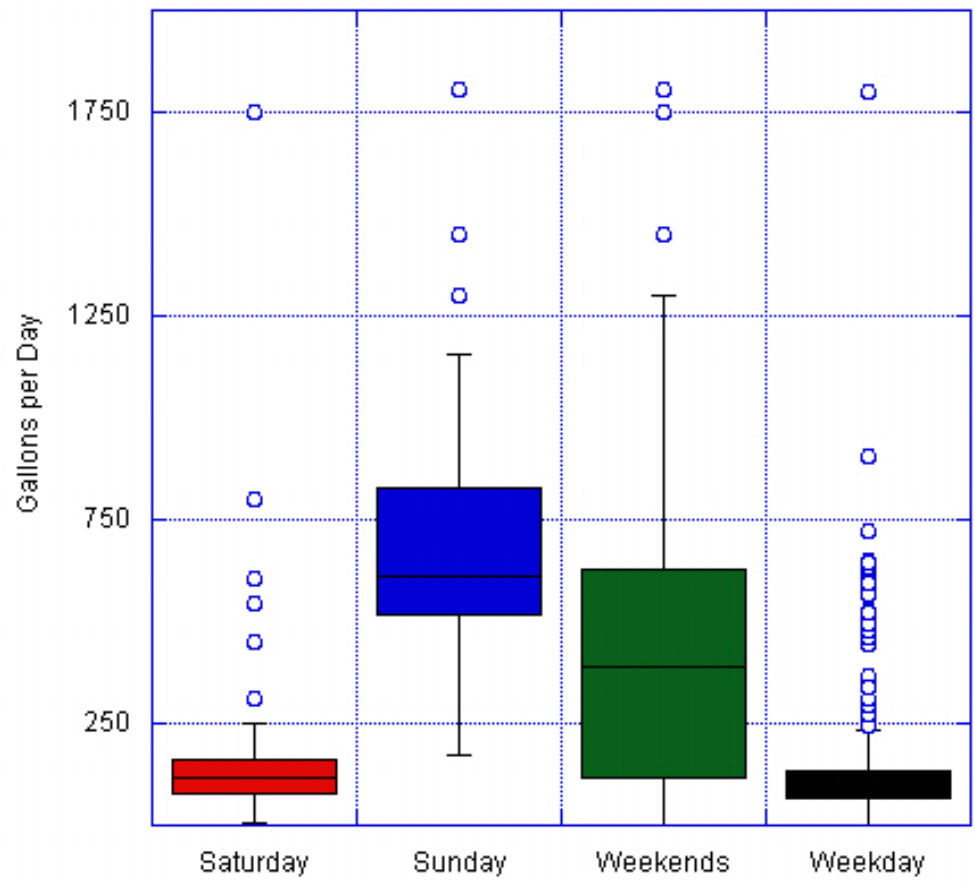

Figure 15: Average water usage determined by digital water meter.

have been useful for the system to rest and recover. Neither, surface ponding, unpleasant odors were noticed or any visible signs of failure occurred. It should also be noted that an acceptable reduction in TSS and $\mathrm{BOD}_{5}$ was generally observed (data not shown).

Figure 13 compares actual Sunday water usage (determined by the digital water meter) with cumulative per person projected water usage ( 2 gallons per person per day) used to size a wastewater treatment system for a Church with no kitchen facilities. Data was collected over a two-year period from August 2004 to October 2006, plotted chronologically. As mentioned earlier water use was monitored for a total of 79 Sundays. Maximum water use periods on Sundays occurred between $8: 30$ am to $1: 00 \mathrm{pm}$ and $6: 00 \mathrm{pm}$ to $8: 00 \mathrm{pm}$. During this data 
collection period the number of persons using this facility ranged from a low of 751 to a high of 1774.

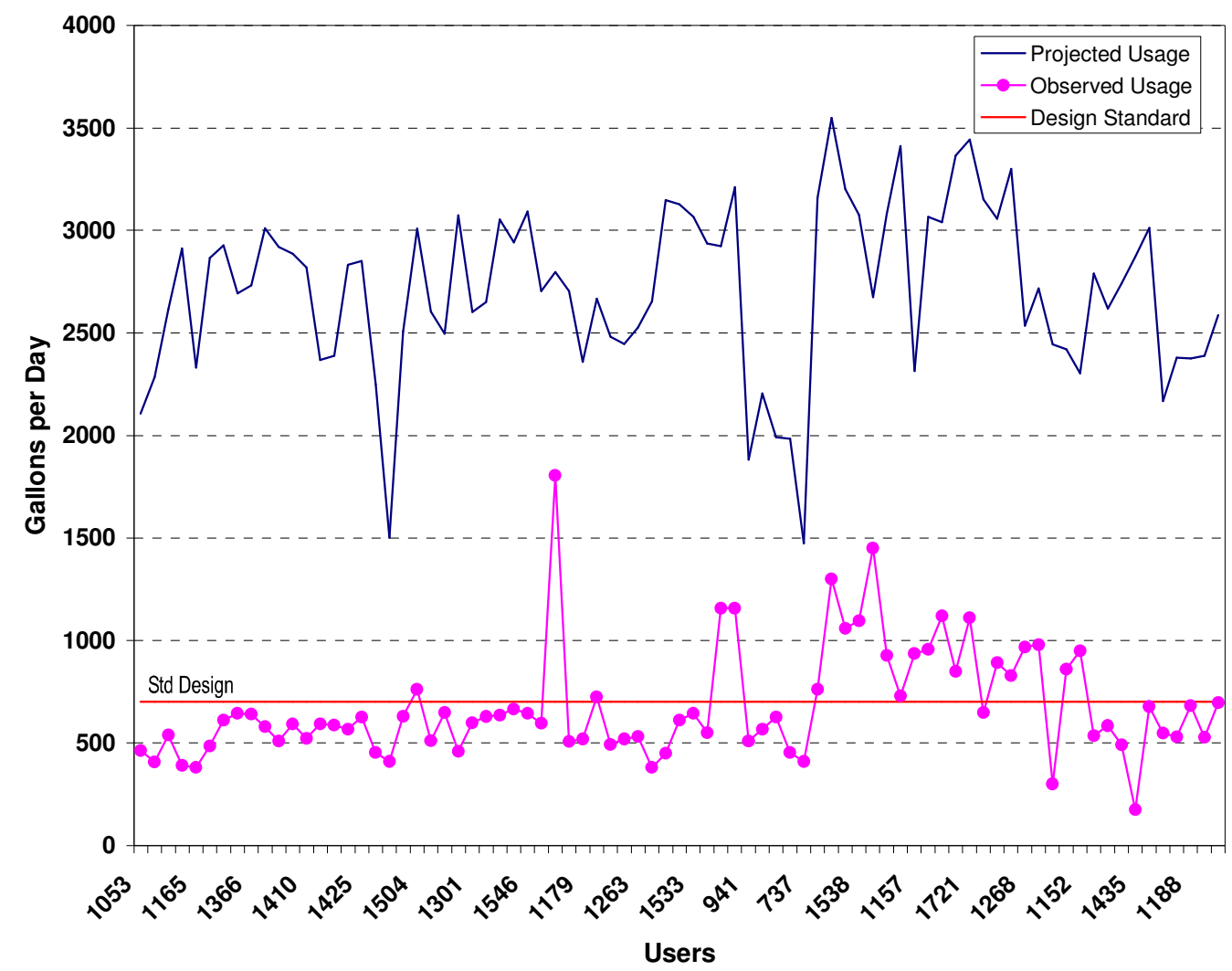

Figure 16: Actual Sunday Water Usage versus Projected Water Usage (2 gpd)

A comparative analysis of the data presented summarizes the major point of this paper. Although originally designed for significantly fewer users (350 persons), peak Sunday loads received by the wastewater wetland were within the 700 gpd standard $75 \%$ of the time even though the number of users had increased 5-fold by the year 2006. It is also interesting to note that the Sunday with highest water did not necessarily correspond with the highest number of users of the facility. For example, when the facility recorded its highest water use of 1,806 gpd, the corresponding actual number of users was 1,399 . On the contrary, when then facility had the highest number of users of 1774; the water use was only around $1300 \mathrm{gpd}$. This indicates that 
there is no direct correlation between the number of users or total number of seats and the water use.

If the system were to be designed and installed today, based on 2 gallons of wastewater per person per day as the regulation, the wetland would have to be sized to receive an average of 3,500 gpd. This would involve a significant increase in the size of the system. Also, a larger system would mean higher construction costs and a larger foot-print. This may result in perhaps precluding the use of this innovative and passive, yet effective technology as an option. The large difference between actual water usage and projected water usage illustrated by Figure 16 represents an opportunity to refine regulations governing construction of effective on-site systems.

\subsubsection{Hypothetical Design Values}

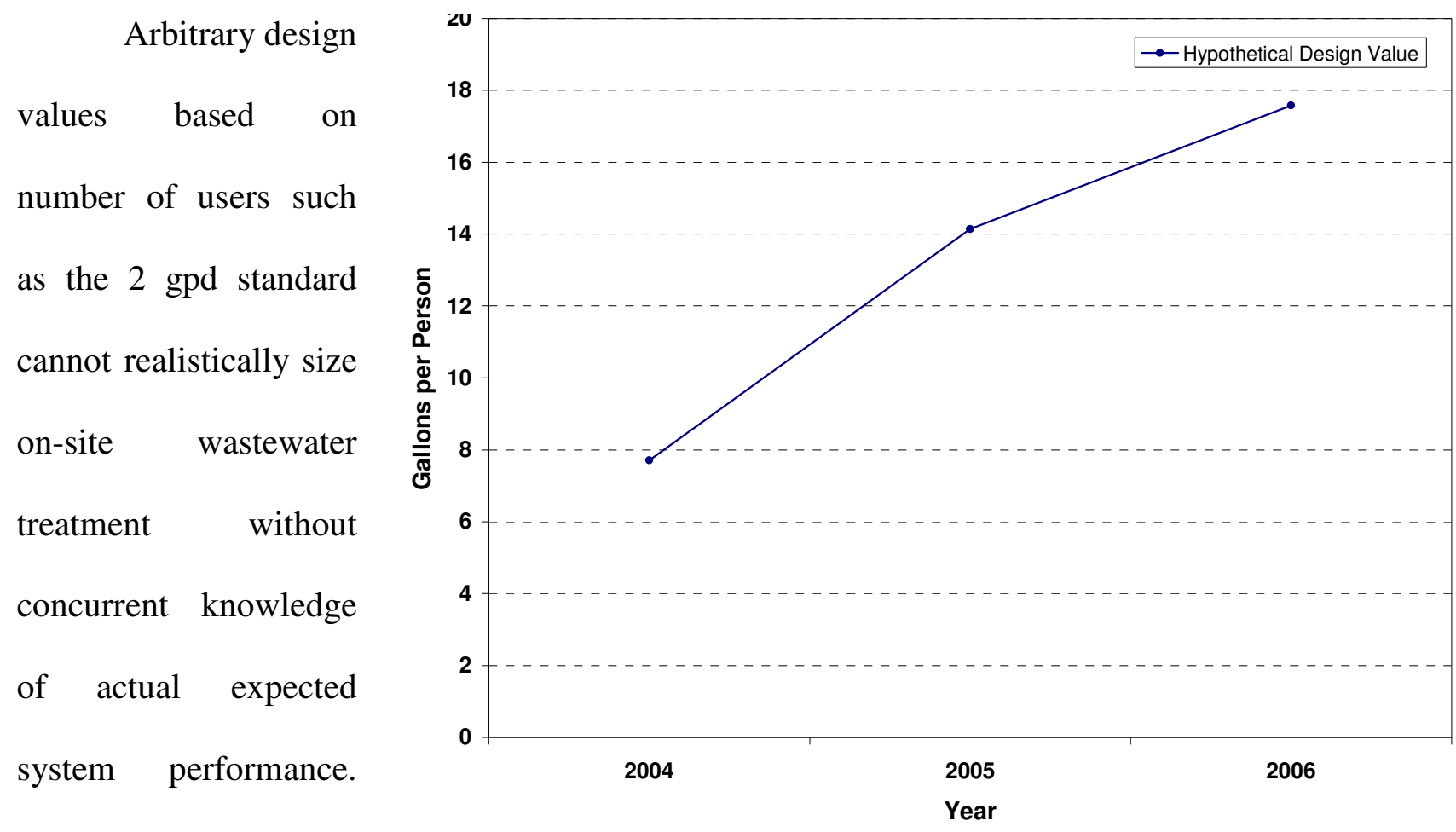

From our data we calculated

Figure 17: Calculated hypothetical design values 
the total number of users on Sundays on an annual basis and also sum the total water usage on Sundays for each year. The water usage divided by the number of users yielded a hypothetical design value indicating the number of gallons per person required for peak loading of the wastewater system (Figure 17). The hypothetical values were 7.71, 14.14 and 17.58 during 2004, 2005 and 2006 respectively and were significantly higher than the original design value. Despite this difference, the wetland system functioned normally and provided effective wastewater treatment throughout the study period This analysis indicates no correlation between the actual water use, total number of persons or seats used to design the system, and system performance.

\subsection{Conclusion}

Wastewater flows are expressed in a variety of ways for nonresidential establishments. Typically, a unit that reflects a physical characteristic of the establishment (e.g., per seat, per meat served, per car stall, or per square foot) is often used, although per person units may also be used.

Water use data analyzed in this study using both conventional and remote methodology indicates that the peak loading for this commercial facility was below the design value even with a five-fold increase in usage. There is no good correlation between the number of users or seats in the facility to the actual wastewater generated (actual water consumption). Using the three types of comparative analysis executed, it can be stated the design standards currently used by most states size a system for a Church may be more prescriptive than performance based.

There is clear evidence that a commercial facility with transient population has an incredible variation in the amount of wastewater generated. A major aspect that needs 
consideration for design is the variation or trends in use, both present and future, due to growth or expansion. This situation presents a difficult dilemma to those that are involved in establishing standards or designing a system based on the occupancy of a facility.

Alternatively, a system may be designed based on an estimated per capita use for the various wastewater generating sources or activities in a given day. Peak loading conditions may be determined by taking into account the day(s) of maximum occupancy and sizing a system accordingly. A matrix of projected water use profile based on all fixtures and/or wastewater generating components will have to be developed by each commercial facility prior to design. Consequently systems designed and installed based on this profile may be able to perform much better than those based on either arbitrary values or prescriptive standards. It is also understood that it may be difficult to develop a standard on a national basis with any degree of confidence.

This project demonstrates a new direction and comprehensive approach in the developing remote monitoring techniques as a tool to establish performance-based standards. It is anticipated that system-specific data gathered from this projects such as these can be used to develop, set, and adapt protocols, practices and procedures. Also, the information collected could enable RME's to identify core indicators and set acceptable performance criteria and threshold levels for proper operation over its entire life cycle. 


\section{References}

U.S. Census Bureau. 1999. 1997 National data chart for Total occupied housing Units. Available at: http://www.census.gov. Accessed January 2006.

USEPA. 2000. 40 CFR Parts 141 and 142. National Primary Drinking Water Regulations: Ground Water Rule; Proposed Rules, Federal Register. U.S. Environmental Protection Agency, Washington, D.C.

USEPA, 2002. Onsite wastewater treatment systems fact sheet 5: Vegetated submerged beds and other high-specific-surface anaerobic reactors. U.S. Environmental Protection Agency, Washington, D.C.

USEPA, 2002-1. Onsite Wastewater Treatment Systems Manual. U.S. Environmental Protection Agency, Washington, D.C.

WV Bureau of Public Health, 2004. Sewage treatment and collection system design standards 64 CSR 47. Charleston, WV.

Friedland, J. 2004. Effectiveness of treatment and diversity of microbial populations within a constructed wetland treating wastewater. Masters Degree Thesis. Department of Plant Pathology and Environmental Microbiology, West Virginia University, Morgantown, WV.

Solomon, C., Kamalesh, and L. S. Lin. 2006. A remote monitoring architecture enabling centralized management of decentralized wastewater systems. ASABE Annual International Meeting, Portland, OR. 


\section{CHAPTER 5}

\section{CHARACTERIZATION OF PH VARIATIONS AND TRENDS IN SEPTIC TANKS USING REMOTE MONITORED DATA ${ }^{4}$}

\subsection{Introduction}

Approximately 23 percent of the estimated 115 million occupied homes in the United States are served by onsite systems, a proportion that has changed little since 1970 (U.S. Census Bureau, 2005). State and tribal agencies report that onsite systems currently constitute the third most common source of ground water contamination due to failing systems and that these systems have failed because of inappropriate siting or design or inadequate long-term maintenance (USEPA, 2002). It has been determined that due to geological and hydrological conditions, two-thirds of the U.S. is unsuitable for septic systems (USEPA, 2002). Expensive system failures and the release of pollutants may result if a septic system is improperly sited. Fortunately, many alternative technologies have been developed for situations where conventional systems are not appropriate.

The purpose of an onsite wastewater treatment system is to adequately treat wastewater before it is discharged to the receiving environment. A conventional onsite system (septic system) refers to a septic tank followed by a drainfield or soil absorption trenches. An alternative onsite system refers to a septic tank followed by some form of secondary (also referred to as pretreatment or advanced) treatment and a soil absorption system. Figure 18 shows a crosssectional view of a septic tank. To design any wastewater system, some of the factors to be

\footnotetext{
${ }^{4}$ Solomon, C., Kamalesh, and L.S. Lin. Characterization of pH Variations and Trends in Septic Tanks using Remote Monitored Data, NOWRA 17th Annual Technical Education Conference \& Exposition, Memphis, Tennessee, April 2008 (Paper V-Perf 0820). Reprinted with permission from the National Onsite Wastewater Recycling Association (NOWRA). Note: Minor formatting changes were made to meet the electronic thesis and dissertation submission requirements of West Virginia University.
} 
considered are the type and quantity of pollutants in the water, the amount of wastewater generated, site/soil conditions, soil hydraulics and other limiting factors such as water table, soil texture, etc. (Kalb et al., 1977).

The qualitative characteristics of wastewaters generated by residential dwellings and nonresidential establishments can be distinguished by their physical, chemical, and biological composition. Because individual water-using events occur intermittently and contribute varying quantities of pollutants, the strength of residential wastewater fluctuates throughout the day (USEPA, 2002). For typical residential sources, peak flows and peak pollutant loading rates do not occur at the same time (US EPA, 2002). Wastewater flow and pollutant concentrations help define system design and process control requirements. Septic tanks are a major component of an onsite wastewater system. They have been used as early as the late 1800 s, becoming a more common practice for primary treatment during the middle of the 20th century (USEPA, 2002).

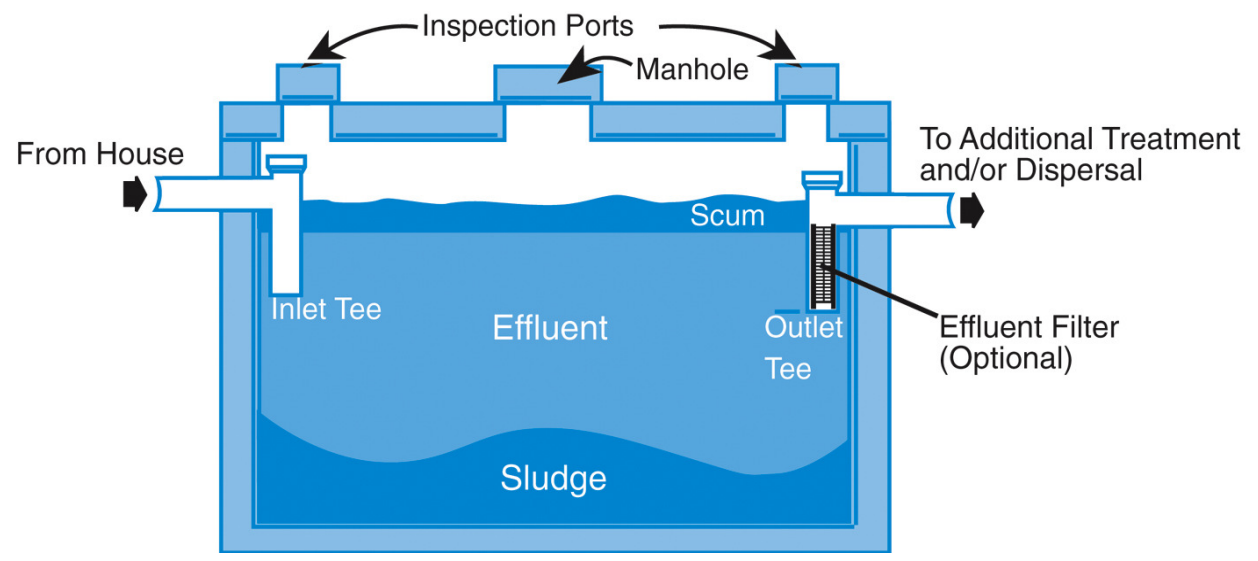

Figure 18: Cross-sectional view of a septic tank

In general, a septic tank separates stores and partially digests settled and floating organic solids in sludge and scum layers with a clarified effluent layer in the middle. The solids removed are stored in sludge and scum layers, where they undergo liquefaction. During liquefaction, the first step in the digestion process, acid-forming bacteria partially digest the solids by hydrolyzing 
the proteins and converting them to volatile fatty acids, most of which are dissolved in the water phase. The volatile fatty acids still exert much of the biochemical oxygen demand that was originally in the organic suspended solids. Because these acids are in the dissolved form, they are able to pass from the tank into the effluent stream, reducing the BOD removal efficiency of septic tanks compared to primary sedimentation. The treatment process in the septic tank is anaerobic since biological degradation is typically carried out by anaerobic bacteria. Typical septic tank BOD and TSS removal efficiencies are 30 to 50 percent (USEPA, 2002).

As in all biochemical operations, $\mathrm{pH}$ has a significant impact on anaerobic processes, with activity decreasing as the $\mathrm{pH}$ deviates from an optimum value (Grady, 1999). $\mathrm{pH}$ values ranging between 6.5 and 8.5 are considered optimum for effective microbial activity (Tchobanoglous et al., 2003). A research study conducted by Bounds (1997) found septic tank influent $\mathrm{pH}$ ranged from 6.9 to 8 across 12 systems. In studies using laboratory or field measurements, Kathleen et al. (2007) reported a typical septic tank pH range of 6.5 to 7.5 (30 systems), while Patterson (2003) reported $\mathrm{pH}$ in the septic tank effluent averaged between 6.7 to 7.2 (four systems).

It should be noted that previous research studies conducted on $\mathrm{pH}$ used conventional data collection methods and sampled systems only on a weekly or monthly basis. As mentioned earlier, wastewater characteristics entering a septic tank fluctuates considerably during the day in both a residential and commercial setting. A considerable knowledge gap still exists on $\mathrm{pH}$ variations at the influent end of the septic tank with very little continuous real-time data available on a daily basis. This paper presents a long-term study on $\mathrm{pH}$ variations in a given day under different operating conditions in a septic tank, using remote monitoring technology. 


\subsection{Objectives and Scope}

Funded by the USEPA, the overall objective of the National Onsite Demonstration Project (NODP) was to evaluate the characteristics of seven to eight parameters, and their relationships with regard to the optimal performance of onsite systems. In order to study the performance of these onsite systems, operational data that characterize these systems was collected using remote monitoring technology. Glass electrode sensors were used to collect $\mathrm{pH}$ data at the influent end of the five septic tanks (near the inlet-tee) on a real-time basis (3-minute intervals) during 2003 - 2007. The real-time data were analyzed to observe variations and trends among the monitored parameters.

Table 9: Overview of the Systems Monitored

\begin{tabular}{|l|l|l|l|}
\hline Site ID & System Description & Design Flow (gpd) & No. of Occupants \\
\hline 1 & Up-flow filters & 450 & 2 \\
\hline 2 & Recirculating Media filters & 450 & 5 \\
\hline 3 & Constructed wetland & 700 & $350^{*}$ \\
\hline 4 & ATU** & 300 & Variable \\
\hline 5 & ATU*** & 3 \\
\hline 6 & ATU** & 450 & 4 \\
\hline
\end{tabular}

Note: Sites 1,2, 5 and 6 are designed as residential systems with year-round occupancy

* Site 3 is a church (no kitchen) with varied occupancy rate

** Aerobic treatment unit

*** This residential system serves a recreational cabin with varied occupancy rate.

Results from Site 2 are not included in this paper since the $\mathrm{pH}$ was measured in the media tank influent rather than in the septic tank. Although not reported in this paper, several 
parameters relevant to system performance such as wastewater and air temperature, pump run times, trench ponding, dissolved oxygen and water use were monitored in six onsite systems. The data collected for all these parameters are being more extensively analyzed using various statistical packages. An analysis of variations in the $\mathrm{pH}$, Air Temperature (AT), Water Temperature (WT), and water use at sites 1, 2 and 3 were published in Solomon et al (2006).

All septic tanks monitored were followed by secondary treatment and types of the secondary treatment varied due to existing site and soil limitations. They included an anaerobic up-flow filter, a recirculating media filter, a constructed wetland and an aerobic treatment unit with UV disinfection. Table 9 presents a brief overview of the specifications of the systems studied. It should also be noted that the results in this research and this paper were not an influence of the secondary treatment as all data collection points were prior to the secondary treatment units.

The location of the $\mathrm{pH}$ probes inside the septic tank was generally near the influent end. Other probe and sensor locations were:

1. Ambient air temperature: usually within 50 to 150 feet of the system

2. Wastewater temperature: septic tank (sites 1,2, 4, 5 and 6) and wetland (site 3)

3. Water meter: main water supply entering the building

4. Float switch: drainfield/trenching pond

5. Pump run time/UV unit power 
Table 10: Data Points and Period of Study

\begin{tabular}{|l|l|l|l|l|}
\hline \multirow{2}{*}{ Site ID } & \multicolumn{2}{|l|}{ Data Points } & \multirow{2}{*}{ Monitoring Period } \\
\cline { 2 - 4 } & Observed & Analyzed & $\%$ Analyzed & \\
\hline 1 & 432,000 & 300,551 & 70 & January 2004 to September 2007 \\
\hline 3 & 460,800 & 359,141 & 78 & January 2004 to December 2006 \\
\hline 4 & 360,000 & 277,411 & 77 & August 2004 to September 2007 \\
\hline 5 & 288,000 & 259,830 & 90 & January 2006 to September 2007 \\
\hline 6 & 374,400 & 300,485 & 80 & January 2006 to September 2007 \\
\hline
\end{tabular}

The primary focus of this paper is to present the results of the $\mathrm{pH}$ monitoring using a frequency distribution analysis of $\mathrm{pH}$ trends in the septic tank influent of five onsite systems. Each system produced a large volume of data that was collected and analyzed. Table 10 shows the number of data points used in this analysis and the period of the study.

\subsection{Materials and Methods}

The main focus of this research study was to use remote monitoring for continuous data logging. Data were collected using a Quantum glass electrode $\mathrm{pH}$ sensor that transmitted data to a panel located near the septic tank. These glass electrode $\mathrm{pH}$ sensors are simple electrochemical sensors which work on the principle of potentiometric measurement where the relationship between the potential produced by the measuring electrode is related to the analyte by the logarithm of the analyte concentration. A typical configuration consists of a reference electrode and indicator electrode (Girard, 2005). The voltage produced is a function of the $\left[\mathrm{H}^{+}\right]$, and the voltage of ideal $\mathrm{pH}$ electrode changes $59 \mathrm{mV}$ for every $\mathrm{pH}$-unit change of $\left[\mathrm{H}^{+}\right]$.The Quantum $\mathrm{pH}$ 
sensor operates on a measuring range of $0-14 \mathrm{pH}$ and with a sensitivity of $0.002 \mathrm{pH}$. The sensor functions within $-5^{\circ} \mathrm{C}$ and $+95^{\circ} \mathrm{C}\left(23^{\circ} \mathrm{F}\right.$ to $\left.203^{\circ} \mathrm{F}\right)$ temperature range and a pressure range of 1 to $100 \mathrm{psig}$. The data from these sensors was then downloaded using a Sensaphone 2000 Manager® and stored on a regular basis. The $\mathrm{pH}$ readings were polled in each septic tank at three minute intervals to monitor transient variations due to pulse loadings of water flow and chemicals. This resulted in a total of 480 data points recorded during a 24-hour period. Details on the architecture of the data acquisition system can be found in Solomon et al. (2006).

The raw data were first checked for erroneous data points that were caused by power failure, probe malfunction, calibration, fouling of membranes, and other factors. Since the raw data has time stamps, these erroneous data points were easy to identify and remove in order to obtain a consistent data set for analysis. It can be seen from Table 10 that data from each site had erroneous data points that were recorded by the sensors and hence a small portion of the data was not included for analysis.

A customized tool, Water Data Analysis (WAD) ${ }^{\odot}$ was developed to process data for further analysis. WAD was designed to read large volumes of raw data, which were stored as comma separated values (Kamalesh, 2007). These data were processed and stored in a Microsoft Excel database from which minimum, maximum and variance values were calculated. The database was also versatile in executing user-defined queries to further refine the data set for more detailed analysis. 


\subsection{Results and Discussion}

The results of this study are presented in two parts:

1. $\mathrm{pH}$ variations showing the minimum, maximum, and variance for the entire study period.

2. Frequency distribution of observed data points for each individual site.

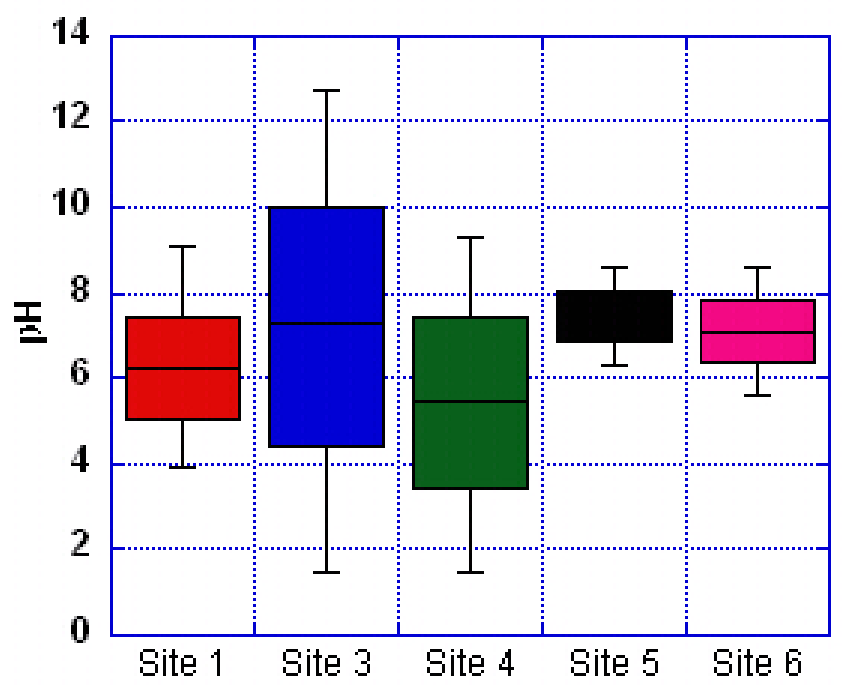

Figure 19: Box plots of pH

\subsection{1 pH variations}

Three different trends in $\mathrm{pH}$ variation were observed. As shown in Figure 19, sites 1, 5, and 6 had a low variation; site 4 had a moderate variation; and, site 3 had the highest variation in $\mathrm{pH}$. It should be noted that sites 1,5 , and 6 are residential systems (year-round occupancy); site 4 is a residential system (seasonal occupancy); and, site 3 is a commercial system (weekend use). Table 11: Minimum and Maximum pH values Recorded in the Septic Tank

\begin{tabular}{|l|c|c|c|c|c|}
\hline & Site 1 & Site 3 & \multicolumn{1}{l|}{ Site 4 } & Site 5 & Site 6 \\
\hline Minimum & 3.9 & 4.3 & 1.5 & 6.3 & 5.6 \\
\hline Maximum & 9.1 & 12.7 & 9.3 & 8.6 & 8.6 \\
\hline Variance, $\mathbf{s}^{2}$ & 1.97 & 8.19 & 5.20 & 0.48 & 0.72 \\
\hline
\end{tabular}

Table 11 shows the minimum, maximum and variance of $\mathrm{pH}$ values observed at each site. It can be seen from the variance values in Table 11 that sites 1,5 and 6 which have a year-round 
occupancy have very low variance in comparison to sites 3 and 4 which were not occupied continuously.

It was observed that during certain periods of operation, the $\mathrm{pH}$ values dropped or rose above the typical range reported in other literature. This could be due to a number of factors, such as household chemical use, laundry, and other substances that enter the system affecting the $\mathrm{pH}$.

\subsubsection{Frequency Distribution}

Figure 20 shows the frequency distribution of $\mathrm{pH}$ values that were recorded in the five septic tanks over the entire period of study (Table 10). It was observed that the $\mathrm{pH}$ value dropped to a low of 1.5 in site 4 and high of 12.7 in site 3.

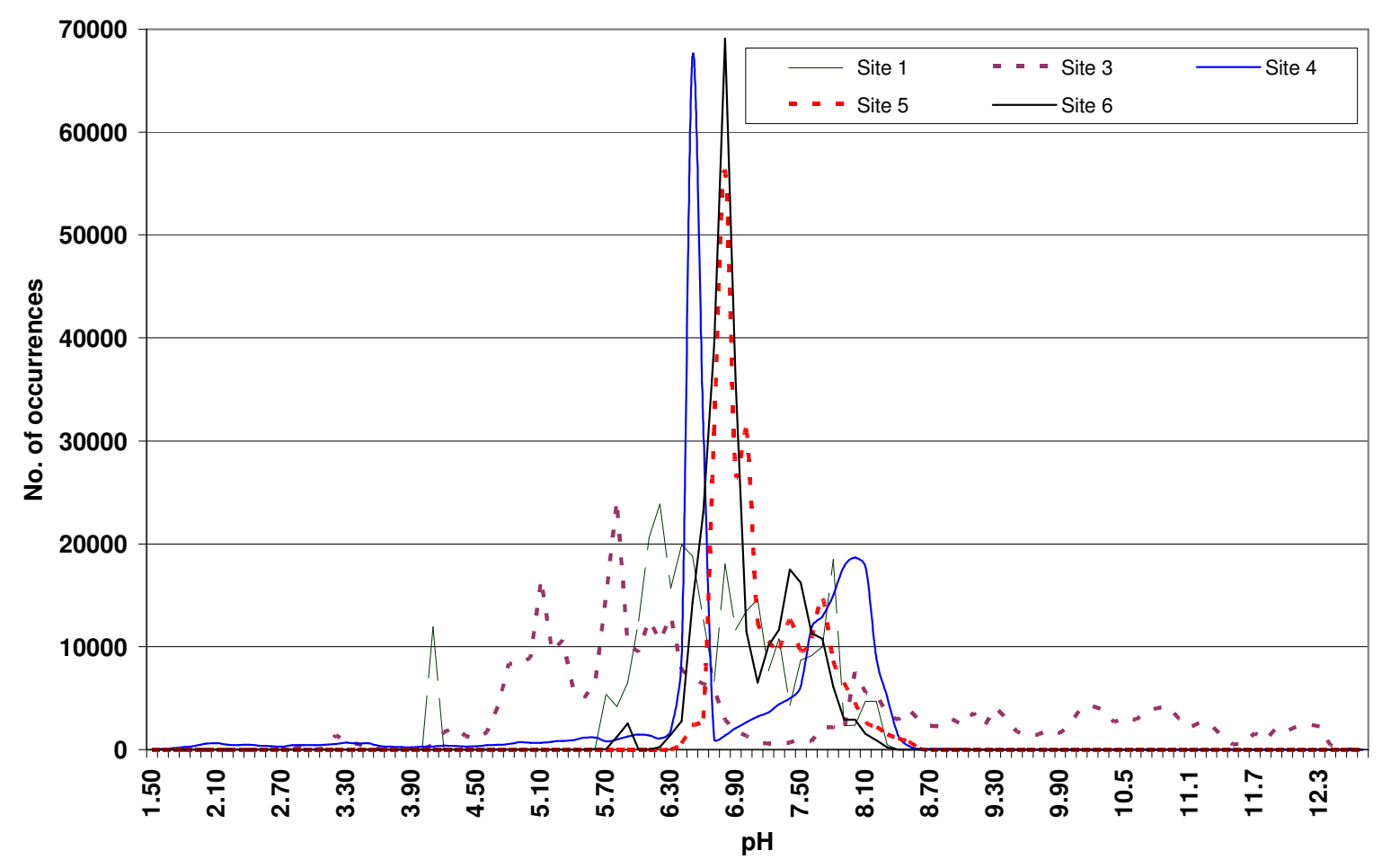

Figure 20: Frequency Distribution of pH values 
The $\mathrm{pH}$ remained with in the typical range at site 1, 4, 5 and 6 about $60 \%, 86 \%, 99.7 \%$ and $98.1 \%$ respectively. All four sites $(1,4,5$, and 6) received wastewater similar to that generated in any single family dwelling (residential). However, at site 3 which is a commercial facility it was observed that the $\mathrm{pH}$ was only about $18 \%$ within the typical range. This might be due to the fact that the site was a commercial facility with no kitchen, shower, and laundry facilities.

Table 12: Wastewater pH in the Acidic, Neutral and Alkaline Range

\begin{tabular}{|l|l|l|l|}
\hline Site ID & Acidic: 0-7 (\%) & Neutral: 7 (\%) & Alkaline: 7-14 (\%) \\
\hline 1 & 32.7 & 4.5 & 62.8 \\
\hline 3 & 37.7 & 0.4 & 61.9 \\
\hline 4 & 47.8 & 1 & 51.2 \\
\hline 5 & 41.9 & 12 & 46.2 \\
\hline 6 & 36.7 & 12 & 51.3 \\
\hline
\end{tabular}

Table 12 presents the percentage of $\mathrm{pH}$ variations under three conditions: acidic, neutral and basic. Overall, the wastewater remained in the alkaline range for more than 50 percent of the time. Wastewater in sites 1 and 3 remained alkaline for more than 60 percent of the time while in sites 4, 5 and 6 the $\mathrm{pH}$ values were closer to the neutral range.

\subsection{Conclusion}

In general, considerable variations in $\mathrm{pH}$ were observed in the wastewater entering the septic tanks. However, the $\mathrm{pH}$ remained within the typical range of 6.5 to 8.5 for the most part in septic tanks receiving residential type wastewater. The variations from the typical range may be 
due to various household products used in a typical residential setting. However, a greater variation in $\mathrm{pH}$ was observed in the case of the commercial system. It should be noted that the commercial system was not loaded on a regular basis and occupied only during weekends. The factors contributing to such variations may be a combination of certain types of wastewater constituents especially from the kitchen, shower and laundry not present, longer periods of no or minimal use of the facility (occupancy rate) and water use characteristics. Although not analyzed as part of this study, a septic tank may possess greater $\mathrm{pH}$ equalization capabilities than originally thought. However, it is recommended that more data needs to be collected at both ends of the septic tank to verify this performance capability.

\section{Acknowledgements}

The authors would like to thank the USEPA for supporting and funding this project. Special thanks to the homeowners who were early adopters of this concept for their willingness to participate in this project. Our thanks to Michael Aiton, Eric Menear, David Collins, and Mike Fogel for their contribution to this project. Special thanks to Margaret Caigan McKenzie, Marilyn Noah and John Fekete for their editorial/graphics support. 


\section{Reference:}

Bounds, T.R., Bedinger, M.S., Johnson, A.I., and Fleming J.S. 1997. Design and Performance of Septic Tanks, Site Characterization and Design of Onsite Septic Systems In Proceedings of ASTM STP 901, American Society for Testing Materials, Philadelphia, USA.

Girard, James. 2005. Principles of Environmental Chemistry. Jones \& Bartlett Publishers. ISBN 0763724718

Kalb, K.R.,Bernardin, F.E.; Coviello, A.J. 1977. Effects of toilet usage patterns on onsite treatment systems. In. Proceedings of the Fourth National Conference; National Sanitation Foundation.

Kamalesh, J. and Solomon, C. 2007. Water Data Analysis: A data management and analysis tool for wastewater engineering. Abstract submitted to Journal of Water Environment Research

Kathleen, E.C., Robert, L.S., Larry B.B. and Gregory K.B. 2007. Organic contaminants in onsite wastewater treatment systems. In. Eleventh Individual and Small Community Sewage Systems Conference. Warwick, Rhode Island, USA.

Patterson, R.A. 2003. Temporal Variability of Septic Tank Effluent. In. Future

In Directions for On-site Systems: Best Management Practice. Proceedings of On-site 2003. Armidale NSW, Australia.

Sensaphone, Inc. 2003. Sensaphone 2000 Manager. Version 3.4.

Solomon, C., Kamalesh, J., and L. S. Lin. 2006. A remote monitoring architecture enabling centralized management of decentralized wastewater systems. In Proceedings of the ASABE Annual International Meeting, Portland, OR, USA. 
Synergy Software. 2005. KaleidaGraph 2005: Tools for Discovery Version 4.

U.S. Census Bureau 2005. American Housing Survey for the United States in 2005. Series H-150 http://www.census.gov/hhes/www/housing/ahs/nationaldata.html.,Last accessed January 2008

USEPA. 2002. Onsite Wastewater Treatment Systems Manual. EPA/625/R-00/008. U.S. Environmental Protection Agency, Washington, D.C., USA.

Tchobanoglous, G., Burton, F. and Stensel, H. 2003. Wastewater Engineering: Treatment and Resuse. McGraw- Hill, New York, NY, USA. 


\section{CHAPTER 6}

\section{SUMMARY OF RESULTS AND CONCLUSIONS}

\subsection{Summary of Results}

This section presents a summary of results for each essay presented in chapter two through five. The discussion under this section is organized by chapter (essay) and covers key findings of the research.

\subsubsection{Remote Monitoring Architecture Enabling Centralized Management of Decentralized Wastewater Systems (Chapter 2)}

Federal, state, and local agencies need comprehensive information on environmental conditions and changes. This research initiated a new direction and comprehensive approach through the development of a monitoring strategy that reflects a full range of water quality management objectives. The real-time information collection instrumentation and methodology presented can help set levels of protection in water quality standards and identify problem areas that are emerging or that need additional regulatory and non-regulatory actions.

This research clearly shows the applicability and need for a "centralized management of decentralized" paradigm in the context of managing onsite systems distributed and located at different sites. The overall architecture paves a new path in the monitoring and management of decentralized systems. Real-time automation can improve the quality of any management system by complementing the various elements of decentralized wastewater management, including education and training, planning, performance, site evaluation, design, construction, operation and maintenance, residuals management, and corrective actions. 
A centralized management of decentralized systems approach can serve as a useful tool for RME's that covers a large geographical area. The element of distance is greatly marginalized by this approach. System-specific data gathered through this project can be used to develop, set, and adapt management protocols, practices and procedures. The information collected enables RME's to identify core indicators and set acceptable performance criteria and threshold levels.

\subsubsection{Real-Time Monitoring of Operational Characteristics in Septic Tanks (Chapter 3)}

The real-time monitoring of septic tanks provides greater insight and valuable operational information never before available with this level of detail. This section summarizes the results

presented in chapter 3 , an analysis of variations in the water use, water and air temperature and $\mathrm{pH}$ for the three systems.

\subsubsection{Water Use}

Water use patterns in all three sites were different and varied according to the number of occupants, type of indoor and outdoor uses, and, to some extent, the weather and climatic conditions. All three sites had some form of outdoor water use, such as watering plants, washing driveways, filling swimming pool, and using sprinklers. However, the onsite systems received wastewater only from indoor applications (bathroom, kitchen, and laundry room). Using the winter water use average as a baseline, water use was calculated.

An analysis using two different design criteria based on the number of bedrooms and number of occupants was executed. The number of bedroom criteria used a typical design value of 150 gallons per bedroom per day. Thus, sites 1 and 2 (both residential) with three bedrooms were designed for a total design flow of $450 \mathrm{gpd}$ each. The actual water use in site 1 did not 
exceed the design flow. The average and maximum daily water use was a low $25 \%$ and a high $74 \%$ of the total design flow, respectively. However, in site 2 the actual water use exceeded the design value (450 gpd). The average and maximum daily water use was around 52\% and 200\% of the design value, respectively.

The number of occupant's criteria used design values typical of conserving and nonconserving residential dwellings. The design flow was calculated using typical design values of 50 gallons per capita per day (gpcd) with conservation, and 70 gpcd without conservation (Vickers, 2002). Site 1 had two occupants, with a design flow of $100 \mathrm{gpd}$ (with conservation) and 140 (without conservation) based on occupancy. The average and maximum daily water use based on this criterion exceeded the design flow with conservation by $11 \%$ and $234 \%$, respectively. However, when calculated without conservation, the average water use was lower by $19 \%$, while the maximum water use was higher by $139 \%$ than the design flow.

Site 2 had five occupants, with a design flow of 250 gpd (with conservation) and 350 (without conservation). The average water use was lower by $7 \%$, while the maximum water use exceeded the design flow with conservation by $258 \%$. When designed without conservation, the average water use was lower by $34 \%$, while the maximum water use was $156 \%$ higher than the design flow.

Since site 3 a non-residential system (commercial facility), it was designed based on 2 gpcd for 350 persons. The total design value was 700 gpd. The average water use was lower by $71 \%$, while the maximum water use exceeded the design flow by $158 \%$. It should be noted that site 3 was heavily used during the weekends, with minimal use during weekdays. 


\subsubsection{Ambient Temperature}

The ambient air temperature seemed to have a significant relationship with the wastewater temperature having a direct effect on the biological activity in the system (Kamalesh 2008). The median ambient temperature at site 3 was lower than those measured at the other two sites. This can be attributed primarily to the geographical location of the system, which is at a higher elevation than the other two systems.

\subsubsection{Wastewater Temperature}

The wastewater temperature at all three sites was consistently within or close to the range of ambient temperature recorded, indicating the insulation effect of the confining structures (concrete and soil/liner). In general, wastewater temperature in the wetland system had a lower median temperature and a larger variability $\left(27.2\right.$ to $\left.81.9^{\circ} \mathrm{F}\right)$ than the other two sites. This can be attributed to the overall lower site temperature and less insulation, unlike the concrete structures for the other systems. Wastewater temperature in the two septic tanks ranged from low 50s to around $80^{\circ} \mathrm{F}$. They were also located in much warmer climates.

\subsubsection{4 $\mathrm{pH}$}

The $\mathrm{pH}$ values at site 1 were mostly acidic except for a small period of time, when they were above neutral $\mathrm{pH}$ (4.1 to 8.3). At site 2 , all $\mathrm{pH}$ values were below 7 (2.2 to 6.6). The $\mathrm{pH}$ in the wetland system showed a wider range, covering both acidic and alkaline conditions (3.2 to 10.8). During certain periods of operation, conditions existed in all three systems where the $\mathrm{pH}$ values dropped or rose above the typical range, indicating a possible reduction in biological activity in the system. This could be due to a number of factors, such as household chemical use, 
laundry, and other substances that enter the system affecting the $\mathrm{pH}$. In summary, all systems monitored seem to operate within design limits when average actual water use is considered, but when comparing the maximum water use (peak flows) to design flows, the systems exceeded the design values.

This may result in decreased retention times, inadequate treatment, and hydraulic overloading (affecting dispersal area performance). Preliminary analysis of the relationship between air and wastewater temperatures shows a good correlation between them. Although variations in $\mathrm{pH}$ were large, it seems that the septic tank may be equalizing flow and maintaining the biological stability in the tank.

\subsubsection{Analysis of Remote Monitored Water Use Trends and Patterns in a Commercial Facility (Chapter 4)}

Wastewater flows are expressed in a variety of ways for nonresidential establishments. Typically, a unit that reflects a physical characteristic of the establishment (e.g., per seat, per meal served, per car stall, or per square foot) is often used, although per person units may also be used. Results from the analysis of water use in the commercial facility and its relationship to the original design values using two metering modes are presented for the two types of data recorded. A comparative analysis of the number of users and total water use on an annual basis was performed to calculate a hypothetical design value per user.

The first part of the analysis is a discussion on water use recorded using a conventional water meter between January 2000 to October 2006. This data was compiled using actual water bills as recorded by the local water utility. The second part of the analysis is based on water use data collected using remote monitoring water meter that spanned from May 2004 to October 
2006. Also, in this analysis a hypothetical estimate based on the observed values of actual water use and the number of persons using this facility is included.

\subsubsection{Conventional Metered Water Use}

When comparing the average daily water use to the maximum daily loading (700 gpd), wastewater generated did not exceed the original design specifications. Data recorded from 2000 to 2006 showed that the average daily wastewater generated ranged from 88 to 408 gpd. It was observed that there is very little correlation between the water use and number of users or the total number of seats in the facility. Daily average water use underestimates maximum daily system loading, which occurs mainly on Saturday's and Sunday's, rather than a seven-day period.

\subsubsection{Remote Monitored Data and Actual Flow}

As mentioned earlier, peak hydraulic loading generally occurred once a week on Sundays which has the maximum facility use. In general, water use on Saturdays exceeded the weekday consumption limits at all times due to a slightly increased facility use. However, the water use on Saturdays stayed well within design standard of 700 gpd. It was usually in the range between 100 and 200 gpd with a few peaks. Some of variations were observed and could have been due cleaning or a seasonal activity in the facility. It is clear that these recorded water use was only about a third of the original design loading rate.

Four types of water usage patterns (Saturdays, Sunday, weekends, and weekdays) were

analyzed in this study. It was observed that the lowest water usage occurred from Monday through Friday (weekdays), followed by an increase on Saturday, and maximum usage on 
Sunday. Increased variability in mean estimates was observed with increasing water usage. Average water flow was always within the design standard regardless of weekly interval; however, individual daily observations sometimes exceeded the design criterion.

Individual daily maximum flow exceeded 700 gpd on Saturday and Sundays by a factor of up to 1.5, but weekday determinations never exceeded the design standard. Excess loading on Saturdays was infrequent, occurring in only $3 \%$ of the total observations, while the excess loading on Sundays was more common, occurring in about $25 \%$ of the total observations. Although originally designed for significantly fewer users (350 persons), peak Sunday water use was within the 700 gpd standard $75 \%$ of the time even though the number of users had increased 5-fold by the year 2006. It is also interesting to note that the Sunday with highest water did not necessarily correspond with the highest number of users of the facility.

For example, when the facility recorded its highest water use of 1,806 gpd, the corresponding actual number of users was 1,399 . On the contrary, when the facility had the highest number of users of 1,774, the water use was only around 1,300 gpd. This indicates that there is no direct correlation between the number of users or total number of seats and the water use. If the system were to be designed and installed today, based on 2 gallons of wastewater per person per day as the regulation, the wetland would have to be sized to receive an average of 3,500 gpd (based on number of attendees).

\subsubsection{Hypothetical Wetland Design (based on number of users)}

To further illustrate the prescriptive system sizing criteria based on the number of seats in a commercial facility, a hypothetical calculation is presented. Hypothetical design values based on the number of users was calculated by taking the total water usage divided by the total 
number of Sunday users for an entire year. The hypothetical design values were 7.71, 14.14 and 17.58 during 2004, 2005 and 2006 respectively, which is significantly higher than the original design value based on the number of seats. Despite this difference, the wetland system functioned normally and provided effective wastewater treatment throughout the study period.

There is clear evidence that a commercial facility with transient population has an incredible variation in the amount of wastewater generated. A major aspect that needs consideration for design is the variation or trends in use, both present and future, due to growth or expansion. This situation presents a difficult dilemma to those that are involved in establishing standards or designing a system based on the occupancy of a facility.

\subsubsection{Characterization of $\mathrm{pH}$ Variations and Trends in Septic Tanks using Remote Monitored Data (Chapter 5)}

In this section, the results of $\mathrm{pH}$ variations in the septic tanks at five sites are presented in two parts: $\mathrm{pH}$ variations showing the minimum, maximum, and variance for the entire study period; and frequency distribution of observed data points for each individual site.

\subsubsection{1 pH Variations}

Three different trends in $\mathrm{pH}$ variation were observed. Sites 1, 5, and 6 had a low variation; site 4 had a moderate variation; and site 3 had the highest variation in $\mathrm{pH}$. It should be noted that sites 1, 5, and 6 are residential systems (year-round occupancy); site 4 is a residential system (seasonal occupancy); and site 3 is a commercial system (weekend use). Minimum, maximum and variance of $\mathrm{pH}$ values was calculated for each site. The variance values in for sites 1, 5 and 6 which have a year-round occupancy were very low variance in comparison to sites 3 
and 4 which were not occupied continuously. It was observed that during certain periods of operation, the $\mathrm{pH}$ values dropped or rose above the typical range reported in other literature. This could be due to a number of factors, such as household chemical use, laundry, and other substances that enter the system affecting the $\mathrm{pH}$.

\subsubsection{2 pH Frequency Distribution}

It was observed that the $\mathrm{pH}$ value dropped to a low of 1.5 in site 4 and high of 12.7 in site 3. The $\mathrm{pH}$ remained within the typical range at sites $1,4,5$ and 6 about $60 \%, 86 \%, 99.7 \%$ and $98.1 \%$ respectively. All four sites $(1,4,5$, and 6$)$ received wastewater similar to that generated in any single-family dwelling (residential). However, at site 3 , which is a commercial facility, it was observed that the $\mathrm{pH}$ was only about $18 \%$ within the typical range. This might be due to the fact that the site was a commercial facility with no kitchen, shower, and laundry facilities. Overall, the wastewater remained in the alkaline range for more than 50 percent of the time. Wastewater in sites 1 and 3 remained alkaline for more than 60 percent of the time while in sites 4, 5 and 6 , the $\mathrm{pH}$ values were closer to the neutral range.

\subsection{Conclusions}

This section presents a summary of five key conclusions that directly relate to the two core objectives (application of a centralized management paradigm and remote monitoring as a viable monitoring tool for developing performance-based standards and monitoring) of this research. A discussion under each theme serves to further elaborate and support the abovementioned objectives and results presented in the previous section. They link the application of 
remote monitoring to various aspects of system design, performance, and management as well as policy and regulatory issues essays in chapters $2,3,4$, and 5 .

The intent of this research is not necessarily to criticize any party, organization, or agency, but to draw attention to a technology-based, science-driven path. It presents a unique opportunity to tackle this issue as a society to develop a set of policies and standards for a sustainable decentralized infrastructure in communities across the country. Although many questions remain, this study brings to the forefront a philosophical debate and highlights what many small communities are facing across America today. It paves the way to modify the current policy path that lacks a consistent and coherent long-term strategy.

This research directly captures and presents a snapshot of this major policy issue in the context of using the right blend of man and machine. One of the key challenges is that DWS management issues cut across so many federal, state, and local agencies that a concerted policy framework has not yet been established.

It is believed that this research initiates a new paradigm that can assist key decisionmakers in developing sound practices, protocols and procedures to sustain both the financial and environmental resources of many cash-strapped small communities. It outlines a new way of thinking where decisions are not driven just by first costs. It integrates economic and environmental optimization principles that involve minimizing costs as well as maximizing value for both the direct and indirect user over the lifecycle of a system.

\subsubsection{Decentralized Wastewater Management - The Key}

As communities grow, many urban and suburban residents move to unsewered areas unaware of their system location and the need for periodic maintenance. In this "unmanaged" 
condition, DWS do not perform adequately, and many will develop problems that ultimately result in system failure. According to the USEPA, the key to achieving effective performance of these systems-from the simplest "box and rocks" septic tank and drainfield system to the most complex treatment and dispersal unit-is an effective management strategy.

With the explosive growth in advanced treatment technologies and a growing recognition of the environmental damage wrought by existing, improperly maintained septic systems (which have been ignored for many years), the need for RME's is paramount. This research demonstrates and fully supports the concept of using RME's to provide wastewater management for residential dwellings (both individual and clusters of homes) as well as commercial facilities. To further extend this discussion, it is suggested that RME's should be mandated and required, if we are serious about protecting public health and the environment.

As suggested by the USEPA, an responsible management entity that has the proper institutional structure and technical capabilities may be the answer to reducing the risk posed to public health and the environment by improperly managed DWS. Functioning much like centralized sewer districts, decentralized RME's have access to the technical expertise to choose appropriate treatment technologies, oversee installation, and ensure ongoing operation and maintenance. The five models proposed by the USEPA do serve as guideposts to those communities, cities, towns or counties seeking to design, install and manage their decentralized wastewater infrastructure.

\subsubsection{Centralized Management of DWS - The Paradigm}

The sheer magnitude of the number of systems that are geographically dispersed calls for implementing the "centralized management" paradigm. As population growth and homeowner 
preferences shift to areas with no conventional sewers, the status quo becomes an economically and environmentally untenable proposition. At best, it is a short-sighted approach with no consideration given to life-cycle and long-term costs. This study documents the applicability and need for this "centralized management" paradigm in the context of managing onsite systems distributed and located at different sites. This research initiates a new direction and comprehensive approach to management strategies that support a full range of water quality management objectives including, but not limited to, the Clean Water Act goals.

Based on this paradigm (centralized management of DWS), it is clear that the monitoring of multiple systems from a central location is viable. The design and instrumentation as well as the implementation framework and architecture can be tailored to meet specific needs. The right synergy between man and machine can be achieved to optimize capabilities subject to limitations; harness efficient and effective process control; and develop appropriate response strategies. Other overarching conclusions from this paradigm shift to centralized monitoring/management of decentralized systems (wherever appropriate) and the use of remote monitoring methodologies are outlined below. The centralized monitoring/management of decentralized paradigm:

- Fits well and complements with current USEPA policy (13 elements of management).

- Meets the growing need for qualitative data (objective and numerical).

- Leads to time efficiencies as real-time events are sampled and translated into machine-readable signals in a short period of time.

- Provides a cost-saving rapid response to system recovery and operation.

- Enhances labor and other economic efficiencies through targeted responses strategies.

- Improves the quality and operational costs of any management program. 


\subsubsection{Remote Monitoring - A Viable Tool}

Federal, state, and local agencies need comprehensive information on environmental conditions and changes. As technological innovations continue to occur at a fast pace, the complexity of systems increases, resulting in a greater need for automated monitoring and control systems. There is a need for a greater understanding of design specifications, construction materials, installation, operation and maintenance, and performance of DWS. This problem is further compounded by the variation in prescriptive procedures and practices used by different states and local agencies.

Real-time information collected using the remote monitoring technologies can be used to set levels of protection for water quality standards and helps in identifying problem areas that are emerging or that need additional regulatory and/or non-regulatory actions. They provide a sound technological and science-based opportunity to rethink current policy and standards, to produce gains in environmental and economic efficiencies, develop consistent protocols, practices and procedures, etc. Real-time information does serve as a tool to evaluate system performance and economics. Specifically, essays presented in this dissertation also present an innovative way to evaluate wastewater trends and characteristics (operational thresholds).

The centralized monitoring and management architecture of this research directly supports regulators and policy makers with water quality and resource management decisions such as determining TMDL, issues surrounding NPDES permits, enforcement, and non-point source pollution management. Instrumentation to meet specific water quality and ecosystem protection goals may vary but can be accomplished through remote monitoring.

The paucity of published data to describe the operational characteristics of DWS and the factors that affect their performance has been clearly documented in many studies. Most 
monitoring schemes revolve around unit processes, with little attention given to establishing the necessary baseline characteristics of individual systems under field operating conditions. Reliance on traditional data-collection methods that involve grab or less commonly, composite sampling procedures are now proving to be an incomplete monitoring and data-collection methodology for performance standards development.

System-specific data gathered from this project can be used to develop, set, and adapt management protocols, practices and procedures. The information collected will enable RME's to identify core indicators and set acceptable performance criteria and threshold levels (both low and high). As this methodology gains acceptance with more choices available, the costs are likely to go down due to economies of scale and size.

Although adding the remote monitoring equipment adds to initial costs, it will eventually prove to be a viable tool to understand operational characteristics of DWS for effective and efficient performance of secondary treatment devices in achieving high effluent quality goals to protect water quality and protect public health. This research identified remote monitoring as a key element and stable component for process and overall system management during this research.

As with many small and rural community services, a combination of federal, state, and local funding is needed to meet the growing wastewater infrastructure needs, especially in small, low-income communities. Although remote monitoring requires some upfront investment in capital costs, standardizing it as a design and installation requirement may however prove to be a creative and new way to manage DWS effectively and efficiently over its life-cycle. 


\subsubsection{Design Standard Variations - The Inconsistency}

The availability of, and access to, information and the analytical tools to process and understand it are essential in assessing environmental and human health risks, as are designing appropriate and cost-effective policies and response strategies and measuring environmental improvements. Without this information, it is difficult to set priorities, evaluate the success of programs and activities, and report on accomplishments in a credible and informed way.

Although the scope of this study was limited to six systems, the information collected can be useful for decision makers, regulators, designers, manufacturers, installers, and other stakeholders in extending this knowledge base to other systems. The experience gained can also be helpful in determining baselines as the frequency of data collected and system status is available on real-time basis. A discussion of key deviations from the prescribed design standards and commonly accepted parameter values are presented in the following section.

\subsubsection{Water Use}

Based on the commonly used number of bedrooms standard for sizing septic systems, the actual water use recorded ranged from a low of $25 \%$ to a high of $200 \%$ of the standard across the various sites monitored sites selected for this study. Based on conservation and no conservation standards (calculated per person in the residence), the actual water use recorded from a low of $11 \%$ to a high of $258 \%$ of the standard across the various remote monitored sites. In the case of the commercial facility, the water use stayed below the design standard for most of the time even with a 3 to 4 fold increase in users. The analysis indicated no correlation between the actual water use, total number of persons or seats used to design the system, and system performance. 
Also, design standards vary from state to state with a documented range from a low of one gallon to a high of 12 gallons per seat in the facility. This indicates a very weak relationship between the current design standards and actual system performance. A major aspect that needs consideration for design is the variation in current and anticipated trends in future use. This situation presents a difficult dilemma to a designer using occupancy to size a system for a facility.

Alternatively, a system may be designed based on an estimated per capita use for the various wastewater generating sources or activities in a given day. Peak loading conditions may be determined by taking into account the day(s) of maximum occupancy and sizing a system accordingly. A matrix of projected water use profile based on all fixtures and/or wastewater generating components should to be developed by each commercial facility prior to design. Systems designed and installed based such a profile should be able to perform much better than those based on either arbitrary values or prescriptive standards. It is also understood that it may be difficult to develop a standard on a national basis with any degree of confidence.

\subsubsection{2 $\mathrm{pH}$}

In general, considerable variations in $\mathrm{pH}$ were observed in the wastewater entering the septic tanks. It was also noted that the $\mathrm{pH}$ values ranged from 1.5 to 12 . The variations from the typical range may be due to various household products used in a typical residential setting. A greater variation in $\mathrm{pH}$ was observed in the case of the commercial system. The factors contributing to such variations may be a combination of certain types of wastewater constituents especially from the kitchen, shower and laundry, long periods of no or minimal use of the facility (occupancy rate) and water use characteristics. 
In summary, with regard to the systems that were remotely monitored during this research, data indicated considerable variation in the actual values recorded and standards values recorded using conventional sampling methods. Current prescriptive standards do not seem to address the dynamic nature of how these systems perform and all the variations it is subjected to. Process variations during normal operating conditions are far more complex and depend heavily on the configuration of a given system.

Specific technical recommendations for both water use and $\mathrm{pH}$ are discussed in detail in chapters 3, 4, and 5. The recommendations call for the use of performance-based standards to design and install appropriate, economically viable systems that are able to meet the water quality and public health goals. The difficulty of developing a uniform standard on a national basis with any degree of confidence is also understood.

A common thread connecting all systems monitored revealed that the design standards and actual values did not correlate well nor establish a substantial link to the quantitative regulatory requirements and/or commonly reported values. Several questions remain unanswered, even though there were no visible failures.

- Are current standards more prescriptive than performance-based?

- What constitutes a failure or malfunction?

- Is this deviation an allowable risk?

- What strategies do we have in place to incorporate timely process control of a system that is buried (inaccessible in many cases)?

- How can economic priorities and technical requirements be balanced and optimized? Even though many questions remain at the conclusion of the research, it is believed that remote monitoring combined with contextually tailored regulations with rich information 
feedback and continuous adjustment of ends and means in light of new learning leads to improved performance-based standards development.

\subsubsection{Policy and Cost Efficiency Analysis}

DWS are a permanent part of our infrastructure and remain a reality for a large percentage of the U.S. population. The current inconsistencies can not be ignored as they pose a significant threat to our water resources, local economies and public health. Complicated state and local bureaucracies coupled with property rights issues may be a challenge, but it is imperative that a framework for action be developed. This research aids policy development that supports this paradigm shift by putting data into a meaningful context and increasing the knowledge base.

A critical aspect often ignored is the lack of consistent enforcement of policy and standards at the local level. This research serves as a guide to a more consistent enforcement of existing regulations based on science rather than the conventional regulatory practice of trying to fit a square peg in a round hole. Also, as this approach uses science-based rules, it gives regulators an opportunity to make exceptions or variance to existing regulations under difficult site conditions and other extenuating circumstances. Engineers and designers now have a unique opportunity to innovate and present solutions that go beyond traditional design choices.

Public health and environmental protection officials need to move toward a consistent and comprehensive sustainable decentralized wastewater policy that considers both the qualitative and quantitative aspects of water quality and public health protection. It can be done through baseline standards and guidance at the federal level with states setting specific protocols, 
practices and procedures adapted to local conditions. Standardizing policies, practices and procedures based on performance greatly enhances the chance of achieving water quality goals.

The industry as a whole must come together to develop and abide by standards that are similar to other regulated industries that follow performance-based approaches. This would help manufacturers reduce the design and monitoring requirements and consequently, costs, to sell standardized products in all markets. Adjustments can be made by comparing economic efficiencies in the different regional markets or by performing economic engineering studies to calculate the cost and efficiency of each type of system.

This would directly benefit homeowners and allow cash-strapped communities to apply an integrated strategy of minimizing cost and maximizing value. It paves the way to improving the cost-effectiveness of investment decisions. From an economic perspective, reducing the number of trips to the site or system downtime by performing maintenance only when it is needed is quite promising as a cost-saving policy. It makes economic sense to have a targeted response strategy that considers an acceptable factor of safety for preventive maintenance or system repair. It should be driven by not what a certain entity or homeowner prefers but by what the DWS would need to perform effectively over its entire lifecycle.

The guiding framework presented in this research supports the development of standards that are based on science that can substitute for the existing regulatory patchwork. The framework integrates a management and monitoring program that supports sound decision making. As this transition continues the cost-effectiveness of this approach and the potential cost-benefit ratio of adoption is enormous. This approach presents a great market opportunity for innovators and early adopters. 


\subsection{Recommendations for the Future}

This dissertation outlines a new course and trajectory for the application of remote monitoring techniques as a viable tool in developing and establishing performance-based standards. It is recommended that more research of this nature be conducted to extend this approach into standard practice for establishing DWS performance guidelines or baselines. Efforts should be directed to develop performance-based (end-of-pipe) national technical guidelines that are qualitative in nature with numerical values assigned, as done with other types of pollutants. It is recommended that system-specific data be gathered from projects to develop, set, and adapt protocols, practices and procedures to varying site conditions.

Also, additional studies of different types of systems and their performance capabilities to set low and high thresholds are needed. By conducting such research projects researchers could assist regulators in performance-based standards development with science-based data driven recommendations. It is also recommended that additional studies be conducted to identify appropriate probes and sensors that match the specific performance characteristics of the DWS. A centralized information repository of such research project should be developed to add to the knowledge base of this new trend and innovative approach.

Remote monitoring equipment manufacturers are urged to seize this market potential in the decentralized wastewater industry. It is recommended that they forge collaborations with the researchers in educational institutions, regulators, RME's, funding agencies, and other stakeholders to test and evaluate remote monitoring equipment and accessories (probes, sensors, and data acquisition systems). Efforts should be directed to develop new products that can be delivered as part of a DWS package to the customer. RME's of all sizes should explore the use of remote monitoring for performance monitoring as a standard practice as well. Depending on 
the type of system they could identify core indicators and set acceptable performance criteria for proper operation of the system over its entire life cycle.

From a policy perspective, federal and state agencies should be enabled to make funds or subsidized loans available to RME's and other eligible organizations to evaluate a wide range of innovative and cost-effective options. Another proven practice has been through demonstration projects that integrate technological and managerial solutions at a low risk. An economic analysis comparing efficiency improvements in relying entirely on human labor versus a combination of human labor and technology (man-machine interface) should be explored. It is anticipated that a significant reduction in labor costs can be achieved by using a targeted response approach. 


\section{APPENDIX 1}

\section{BIBLIOGRAPHY}

Bounds, T.R., Bedinger, M.S., Johnson, A.I., and Fleming J.S. 1997. Design and Performance of Septic Tanks, Site Characterization and Design of Onsite Septic Systems In Proceedings of ASTM STP 901, American Society for Testing Materials, Philadelphia, USA.

Friedland, J. 2004. Effectiveness of treatment and diversity of microbial populations within a constructed wetland treating wastewater. Masters Degree Thesis. Department of Plant Pathology and Environmental Microbiology, West Virginia University, Morgantown, WV.

Gene, M.Y. 1991. Environmental Data Bases: Design, Implementation and Maintenance. Lewis Publishers, Inc. ISBN, 0-87371-422-9.

General Accounting Office. 2000. Water Quality-Key EPA Limited by Inconsistent and Incomplete Data. GAO/RCED-00-54. Washington, D.C.

Girard, James. 2005. Principles of Environmental Chemistry. Jones \& Bartlett Publishers. ISBN 0763724718

Horton, D., and M. Cross. 1995. Combined Maintenance, Management Cuts Labor Costs. Water Environment and Technology. 7(8): 28-30.

Kalb, K.R.,Bernardin, F.E.; Coviello, A.J. 1977. Effects of toilet usage patterns on onsite treatment systems. In. Proceedings of the Fourth National Conference; National Sanitation Foundation. 
Kamalesh, J. and Solomon, C. 2007. Water Data Analysis: A data management and analysis tool for wastewater engineering. Abstract submitted to Journal of Water Environment Research.

Kathleen, E.C., Robert, L.S., Larry B.B. and Gregory K.B. 2007. Organic contaminants in onsite wastewater treatment systems. Eleventh Individual and Small Community Sewage Systems Conference. Warwick, Rhode Island, USA.

Kottegoda, T., and R. Renzo. 1997. Statistics, Probability, and Reliability for Civil and Environmental Engineers. McGraw-Hill Companies, Inc. ISBN. 0-07-035965-2.

Leverenz, H., G. Tchobanoglous, and J. Darby. 2002. Review of Technologies for Onsite Treatment of Wastewater in California. Center for Environmental and Water Resources Engineering, Department of Civil and Environmental Engineering, University of California, Davis. Davis, California.

Microsoft. 2002. Microsoft Excel 2002: Data Analysis Toolpak.

Nawathe, Dilip. 2000. Using Smart Controllers with Remote Monitoring Capability to Meet the New Market Needs. Conf Proc. of National Onsite Wastewater Recycling Association (NOWRA).

Nelson, V.I., S.P. Dix, and F. Shephard. 1998. Advanced Onsite Wastewater Treatment and Management Scoping Study- Assessment of Short-Term Opportunities and Long-Run Potential, Conf Proc. of National Onsite Wastewater Recycling Association (NOWRA). 
Patterson, R.A. 2003. Temporal Variability of Septic Tank Effluent. In. Future in Directions for On-site Systems: Best Management Practice. Proceedings of On-site 2003. Armidale NSW, Australia.

Parten, S.A. 2008. Analysis of Existing Community-Sized Decentralized Wastewater Treatment Systems, Co-published by IWA, London, U.K. and Water Environment Research Foundation, Alexandria, VA.

Pearl, H. W., July 1997. Coastal Eutrophication and harmful algal blooms: Importance of atmospheric deposition and groundwater as "new" nitrogen and other nutrient sources. Limnology and Oceanography, Vol., 42, Issue 5, Part 2: The ecology and oceanography of harmful algal blooms, 1154-1165.

Ryan, G., and G. Schillinger, 1997. Illinois Facility Upgrade Monitoring Ability with Spread Spectrum Radio for SCADA Systems. Water Environment and Technology. 6(2): 59-62.

Sarasota Bay (FL) National Estuary Program, 1992. Sarasota Bay: Reclaiming Paradise -A Vision for Sarasota Bay (State of the Bay, http://www.sarasotabay.org.

Sensaphone, Inc. 2003. Sensaphone 2000 Manager. Version 3.4.

Small Communities - Development of Voluntary Management Standards. Sixth EPA Technology Transfer Workshop, Kansas City, MO.

Solomon, C., Kamalesh, and L. S. Lin. 2006. A remote monitoring architecture enabling centralized management of decentralized wastewater systems. ASABE Annual International Meeting, Portland, OR. 
Solomon, C., J. Kamalesh, and L. S. Lin. 2006. Real-time Monitoring of Operational Characteristics in Septic Tanks, ASABE Annual International Meeting, Portland, OR.

Synergy Software. 2005. KaleidaGraph 2005: Tools for Discovery Version 4.0.

Tchobanoglous, G. 1998. Decentralized Wastewater Management. Trans ASCE - Water Resources and the Urban Environment, 559-564. Chicago, IL.

Tchobanoglous, G., and R. Crites. 1998. Small and Decentralized Wastewater Management Systems. McGraw-Hill Companies, Inc. ISBN 0-07-289087-8.

Tchobanoglous, G., Burton, F. and Stensel, H. 2003. Wastewater Engineering: Treatment and Resuse. McGraw- Hill, New York, NY, USA.

U.S. Census Bureau. 1999. 1997 National Data Chart for Total Occupied Housing Units. U.S. Census Bureau, Available at: http://www.census.gov. Last accessed January 2006.

U.S. Census Bureau 2005. American Housing Survey for the United States in 2005. Series H-150 http://www.census.gov/hhes/www/housing/ahs/nationaldata.html. Last accessed January 2008.

U.S. Congress, 1972. Federal Water Pollution Control Amendments of 1972, 33 USC § 1251, PL 92-500.

U.S. Department of Commerce. May 1992. NOAA Economic Statistics. National Oceanic and Atmospheric Administration, Office of Policy and Strategic Planning.

U.S. Department of Commerce. 1997. American Housing Survey for the United States -1995. U.S. Census Bureau, Washington, D.C. 
U.S. Department of Commerce, 1995. National Shellfish Register, National Oceanic and Atmospheric Administration.

U.S. Department of Commerce 1990. Historical Census of Housing Tables: Sewage Disposal. U.S. Census Bureau, Washington, D.C.

USEPA 2003. Clean Watersheds Needs Survey - Report to Congress. EPA 832-R-03-001. U.S. Environmental Protection Agency, Washington, D.C.

USEPA. 1996. Clean Water Needs Survey Report to Congress. U.S. Environmental Protection Agency, Available at: http://www.epa.gov/owm. Last accessed January 2006.

USEPA 2005. Decentralized Wastewater Treatment Systems: A Program Strategy. EPA 832-R05-002. Office of Water, U.S. Environmental Protection Agency, Washington, D.C.

USEPA. 2000. 40 CFR Parts 141 and 142. National Primary Drinking Water Regulations: Ground Water Rule; Proposed Rules, Federal Register. U.S. Environmental Protection Agency, Washington, D.C.

USEPA 2002. Guidelines for Ensuring and Maximizing the Quality, Objectivity, Utility, and Integrity of Information Disseminated by the Environmental Protection Agency. EPA 260R-02-008. U.S. Environmental Protection Agency, Office of Environmental Information, Washington, D.C.

USEPA 2005. Handbook for Managing Onsite and Clustered (Decentralized) Wastewater Treatment systems - An Introduction to Management Tools and Information for 
Implementing EPA's Management Guidelines. EPA 832-B-05-001. Office of Water, U.S. Environmental Protection Agency, Washington, D.C.

USEPA. 1996. National Water Quality Inventory Report to Congress [305b Report]. EPA 841 R-97-008. U.S. Environmental Protection Agency, Washington, D.C.

USEPA. 2002. Onsite Wastewater Treatment Systems Manual. EPA. 625-R-00-008. U.S. Environmental Protection Agency, Washington, D.C.

USEPA, 1998. National Water Quality Inventory: 1996 Report to Congress, EPA 841-R-97-008. U.S. Environmental Protection Agency, Washington, D.C.

USEPA 1997. Response to Congress on Use of Decentralized Wastewater Treatment Systems. EPA 832-R-97-001b. U.S. Environmental Protection Agency, Washington, DC.

USEPA, 2002. Onsite wastewater treatment systems fact sheet 5: Vegetated submerged beds and other high-specific-surface anaerobic reactors. U.S. Environmental Protection Agency, Washington, D.C.

USEPA 2003. Voluntary National Guidelines for Management of Onsite and Clustered (Decentralized) Wastewater Treatment Systems. EPA 832-B-03-001. U.S. Environmental Protection Agency, Washington, D.C.

Vickers A. 2002. Handbook of Water Use and Conservation. Waterplow Press. ISBN 19311579-07-5.

WV Bureau of Public Health, 2004. Sewage treatment and collection system design standards 64 CSR 47. Charleston, WV. 


\section{APPENDIX 2}

\section{CO-AUTHOR BIOGRAPHY}

\section{AUTHOR 1: LIANSHIN LIN}

\section{Professional Preparation}

$\begin{array}{lll}\text { Postdoctoral Researcher } & \text { Purdue University, West Lafayette, IN. } & 1999-2000 \\ \text { Ph.D., Environmental Eng. } & \text { Purdue University, West Lafayette, IN. } & 1997 \\ \text { M.S., Nuclear Eng. } & \text { National Tsing-Hua University, Taiwan. } & 1988-1990 \\ \text { B.S., Nuclear Eng. } & \text { National Tsing-Hua University, Taiwan. } & \text { 1984-1988 }\end{array}$

\section{Appointments}

Assistant Professor
Associate Research Scientist
Water Quality Control
Engineer
Lecturer

\section{Synergistic Activities}

2004-present

$2002-2004$

Champaign, IL.

Santa Ana Regional Water Quality Control 2000 - 2002 Board, Riverside, CA.

California Polytechnic State University 1997 - 1998

San Luis Obispo, CA.

Research: Dr. Lin's research focuses on water quality related issues in surface and groundwater, including development of treatment methods for pollution control, water quality modeling, and pollutant environmental fate and transport. Specific pollutants of interests include nutrients, metals/metalloids (e.g., mercury, selenium, aluminum, arsenic), sediments, emerging contaminants (e.g., active ingredients in personal care products, antibiotics, engineered nanomaterials). Dr. Lin also conducts research on how anthropogenic stressors (e.g., highway construction) affect the health of aquatic ecosystems and development of innovative carbon materials to reduce mercury emission from coal power plants. Prior to joining WVU, Dr. Lin worked from the Santa Ana Regional Water Quality Control Board (Riverside, CA) where he developed a selenium TMDL as part of a Toxics TMDL for Newport Bay/San Diego River watershed. He also implemented a nutrient TMDL and sediment TMDL for the same watershed. In Illinois, he worked for the Illinois State Water Survey, conducting water quality research and assisted Illinois EPA and USEPA Region 5 in developing nutrient criteria for streams and rivers in Illinois.

Teaching: Dr. Lin teaches Introduction to Environmental Engineering, Physicochemical Treatment, Environmental Biotechnology, and Water Quality Modeling in the Department of Civil and Environmental Engineering at WVU. 


\section{AUTHOR 2: JOSEPH KAMALESH}

\section{Education}

MS Civil and Environmental Engineering

August 2008

West Virginia University, Morgantown, WV.

MS Electrical Engineering

December 2006

West Virginia University, Morgantown, WV.

BS Electronics and Communication

University of Madras, India.

May 2003

\section{Professional Experience}

Environmental Engineer

Stantec Consulting Ltd., Cincinnati, $\mathrm{OH}$.

\section{Research Intern}

Water Research Institute, West Virginia University.

\section{Research Assistant}

NRCCE, West Virginia University, Morgantown, WV.
September 2008 - Present

July 2007 - January 2008

August 2006 - May 2008

\section{Projects:}

- USPEA funded - National Onsite Demonstration Project Phase V and VI, Performance

- Evaluation of Advanced Onsite Wastewater Treatment Options (Chesapeake Bay Watershed)

- Watershed Bacterial Study and Decentralized Wastewater Demonstration.

\section{Publications}

1. Solomon, C., J. Kamalesh, and L. S. Lin. 2006. Real-time Monitoring of Operational Characteristics in Septic Tanks, ASABE Annual International Meeting, Portland, OR.

2. Solomon, C., J. Kamalesh, and L. S. Lin. 2006. A Remote Monitoring Architecture Enabling Centralized Management of Decentralized Wastewater Systems. ASABE Annual International Meeting, Portland, OR.

3. Solomon, C., J. Kamalesh, and A. Sexstone. 2007. Analysis of remote monitored water use trends and patterns in a commercial facility. Accepted at NOWRA Annual Technical Education Conference and Exposition

4. Solomon, C., J. Kamalesh, and L. S. Lin. 2007. Cost analysis of water efficiency measured using low-flow fixtures in residential applications. Accepted at AWWA Annual Conference and Exposition. 